\title{
Investigation into the use of a tapered element oscillating microbalance for real-time particulate measurement
}

Marcus Gilbert

West Virginia University

Follow this and additional works at: https://researchrepository.wvu.edu/etd

\section{Recommended Citation}

Gilbert, Marcus, "Investigation into the use of a tapered element oscillating microbalance for real-time particulate measurement" (2003). Graduate Theses, Dissertations, and Problem Reports. 1317. https://researchrepository.wvu.edu/etd/1317

This Thesis is protected by copyright and/or related rights. It has been brought to you by the The Research Repository @ WVU with permission from the rights-holder(s). You are free to use this Thesis in any way that is permitted by the copyright and related rights legislation that applies to your use. For other uses you must obtain permission from the rights-holder(s) directly, unless additional rights are indicated by a Creative Commons license in the record and/ or on the work itself. This Thesis has been accepted for inclusion in WVU Graduate Theses, Dissertations, and Problem Reports collection by an authorized administrator of The Research Repository @ WVU. For more information, please contact researchrepository@mail.wvu.edu. 


\title{
Investigation into the Use of a Tapered Element O scillating Microbalance for Real-Time Particulate Measurement
}

\author{
by \\ Marcus Gilbert \\ THESIS \\ Submitted to the College of Engineering and Mineral Resources \\ at \\ West Virginia University
}

in partial fulfillment of the requirements for the degree of

\author{
Master of Science \\ in \\ Mechanical Engineering \\ Nigel N. Clark, Ph.D., Chair \\ Christopher M. Atkinson, Sc.D . \\ Gregory Thompson, Ph.D. \\ Ralph D. Nine, MSME \\ D epartment of Mechanical and Aerospace Engineering \\ Morgantown, West Virginia \\ 2002
}




\section{Abstract \\ Investigation into the Use of a Tapered Element Oscillating Microbalance for Real- Time Particulate Measurement}

\section{Marcus S. Gilbert}

Characterizing particulate matter (PM) in diesel exhaust emissions during transient test cycles has been a challenge for researchers. Acquisition of real-time PM data was proposed by the use of a Rupprecht and Patashnick Co., Inc. Series 1105 Diesel Particulate Monitor Tapered Element O scillating Microbalance (TEOM) mass measuring device. The objectives of testing with a TEOM diesel particulate analyzer were to validate its collection capability and evaluate its real-time characteristics on transient test cycles. Conventional PM filtration was used as the base line for evaluating the TEOM collection capability. To evaluate real-time TEOM characteristics, the real-time mass rate data were separated into positive and negative values, then integrated over the duration of the test. The integrated positive mass was divided by the integrated negative mass to create a positive-tonegative mass ratio. This ratio was indicative of real PM collected versus moisture released from the filter. TEOM sample tube temperatures at $35^{\circ} \mathrm{C}$ yielded the best TEOM to conventional PM filtration ratio. However, a compromise between conventional filter data and real-time data was made in selecting the temperature set point of $40^{\circ} \mathrm{C}$ as the most desirable sampling temperature. Sample flow rate was varied from one to four liters per minute (lpm). The $1 \mathrm{lpm}$ set point provided the best TEOM to conventional filtration ratio. The flow rate of $3 \mathrm{lpm}$ was chosen to be a compromise between TEOM to conventional filtration ratio and real-time results. The best TEOM to conventional filtration ratio measured was 0.97 . The filter collection efficiency of a new filter was found to be a significant source of variability. When the initial test with a new filter was disregarded, the $99 \%$ confidence interval in TEOM results was $\pm 4.3 \%$. In comparison, the $99 \%$ confidence interval in conventional PM results was $\pm 1.7 \%$. 


\section{Acknowledgements}

The author thanks Nigel Clark, Chris Atkinson, Greg Thompson (for the advice and direction I should have listened to), and Ralph Nine for their support, guidance, and motivation. All of this has played an important role in helping understand the depth and diversity of the words "research" and teamwork. I would also like to thank Richard Atkinson, Mike Traver, Wayne Hildebrand, Tom Spencer, and Tom McDaniel for always helping me without complaint. I would still be lost if it were not for their expertise. I would like to thank Matt Hawkins and Steph Paree (now Hawkins): their garage provided a perfect haven for a "gear head" like me, and the friendship that provided the brotherhood that everyone deserves. I would like to thank Steve Hamm, Jim Daley, and Bill Marty for being good friends to keep. Jim even more for being the Jim D aley more people should know, himself. Life becomes simpler after you meet him, an important thing to embrace. I hope he remembers. I would like to thank Jen Hoppie for talking me into graduate school and helping me find the path in life I knew was right, but was not aware of. A special thank you to Georgian Steinhardt, I deeply appreciate the sacrifices you have made to help me through this. I know having a "little boy" around the house was difficult. I want to thank my loving parents, Steve and Charlotte. I love the both of you with all my heart. I would not have made it very far in life if it were not for your love and support. I owe all I have to you. Alison, only you could even begin to understand my thanks, because you are the only one that ever could. Thank you for taking care of me throughout the writing of this. You have enlightened my life by giving it cause and meaning. Most importantly, you make me feel good about myself. I hope I can return those favors some where down our road together. 


\section{Table of Contents}

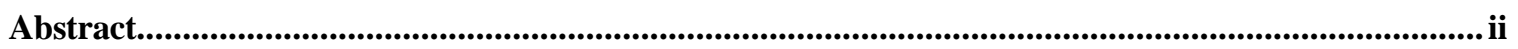

Acknowledgements........................................................................................................................... iii

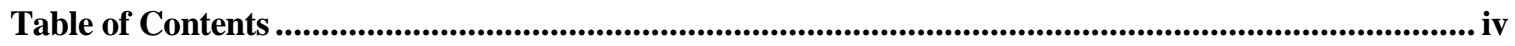

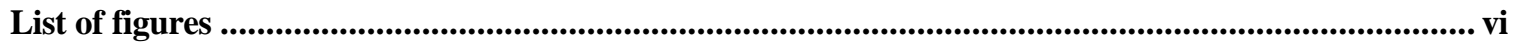

List of Tables........................................................................................................................

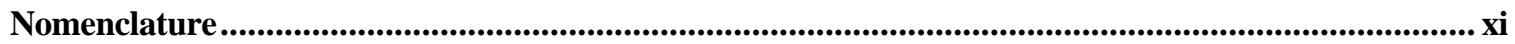

1 Introduction and Objective ............................................................................................... 1

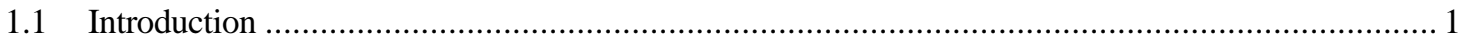

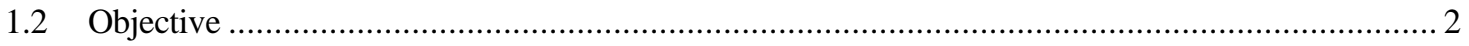

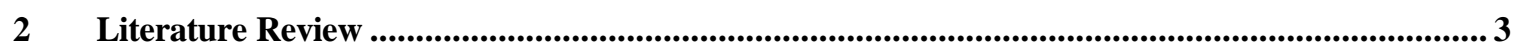

2.1 Particulate Matter Emissions ................................................................................. 3

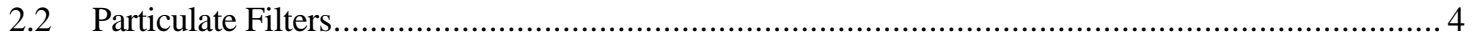

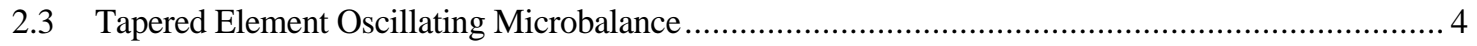

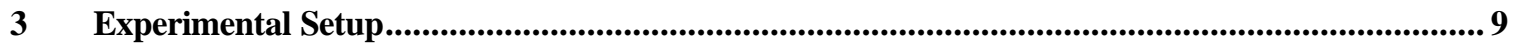

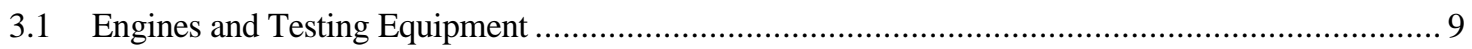

3.1.1 Engine and Emissions Research Laboratory ......................................................... 9

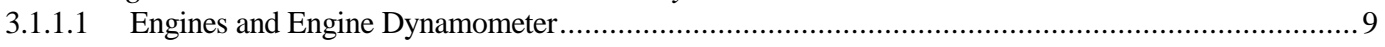

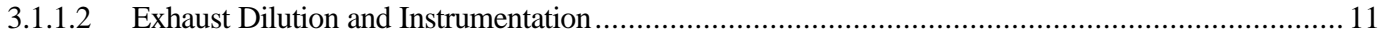

3.1.2 Transportable Heavy Duty Vehicle and Emissions Laboratory...................................... 16

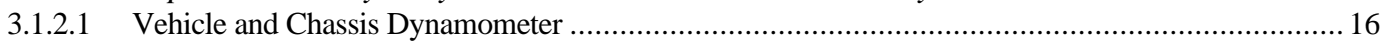

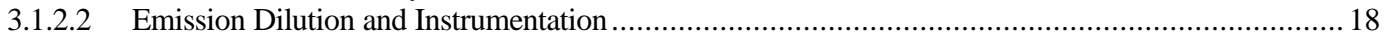

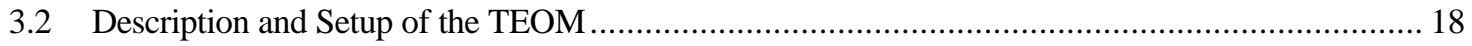

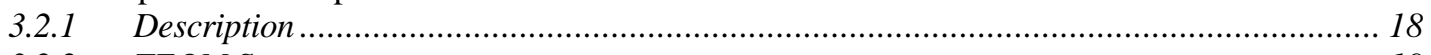

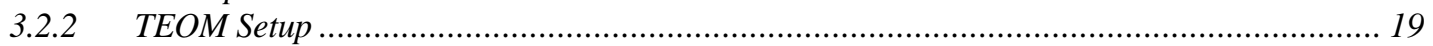

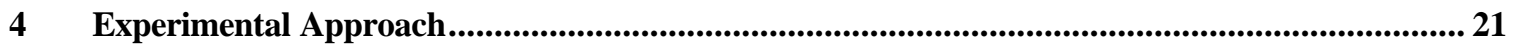

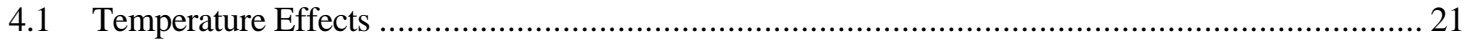

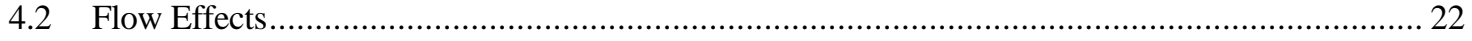

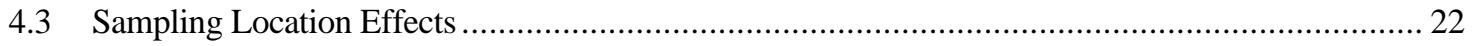

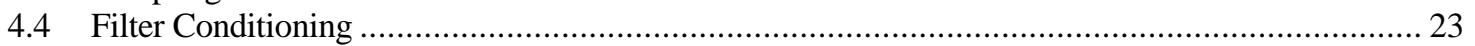

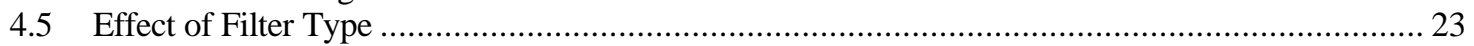

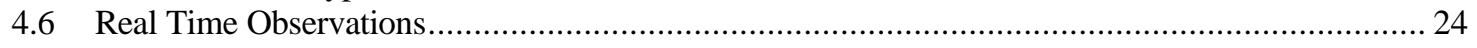

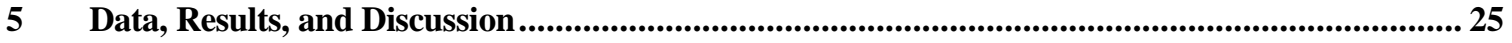

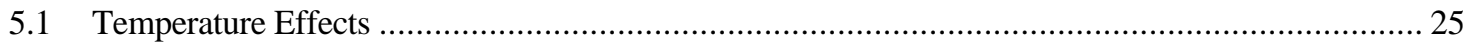

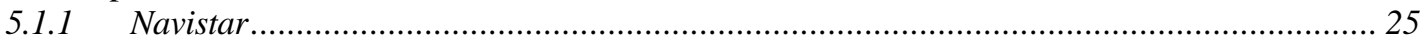

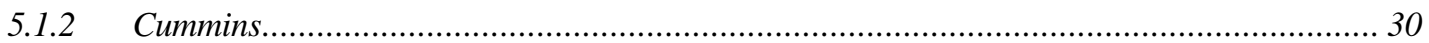

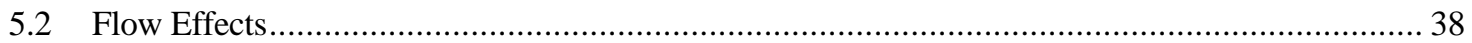

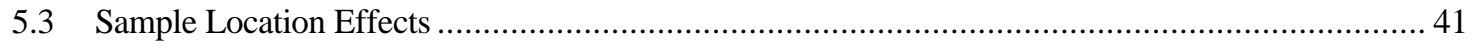

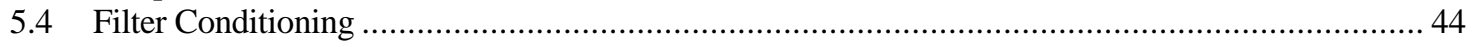

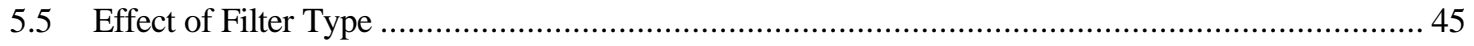


6 Real-time Observations .................................................................................................................... 47

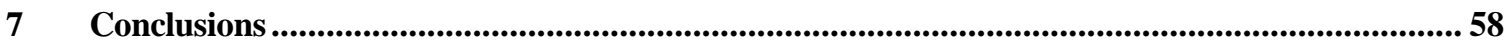

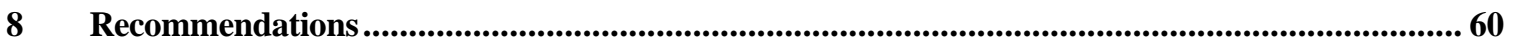

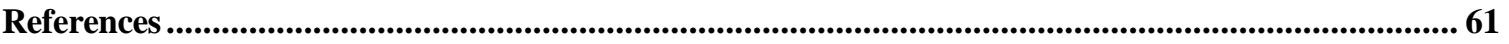

Appendix A: TEOM configuration files and I/O port pin out ................................................................... 63

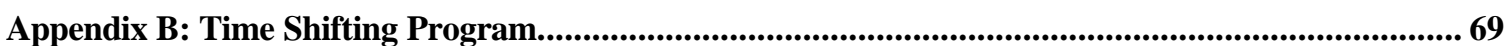

Appendix C: Verification of the Time Shifting Program................................................................... 72 


\section{List of figures}

Number

Figure 1: A cut away illustration of the TEOM filter and its mounting on the TE

Figure 2: Engine speed and load for a 10.8 liter Cummins during a FTP test cycle.

Figure 3: Engine speed and load for a 7.3 liter Navistar for a WVU FTP 75 test cycle.

Figure 4: The $70 \mathrm{~mm}$ diameter PM filter cartridge disassembled. This filter module was used for the conventional, EPA-style, PM collection............................................................ 12

Figure 5: The PM filter cartridge assembled.

Figure 6: Typical used secondary (left) and primary (right) PM filters. This photo shows the inefficiency of the T60A20 filter by the amount of PM collected on the secondary filter.

Figure 7: The microbalance used weigh conventional PM filters before and after each test.....13

Figure 8: The particulate sampling system with the TEOM sampling from the primary dilution tunnel

Figure 9: The TEOM sampling location on the primary dilution tunnel.

Figure 10: The particulate sampling system with the TEOM sampling from the secondary dilution tunnel.

Figure 11: The TEOM sampling location on the secondary dilution tunnel.

Figure 12: Measured vehicle speed for a Collins transit bus driving the CBD cycle on the transportable laboratory.

Figure 13: Although this illustration does not show the transit busses used, illustrated here is a typical vehicle operation on the portable heavy-duty chassis dynamometer.

Figure 14: Typical routing of vehicle exhaust into the emissions trailer of the mobile laboratory.

Figure 15: Internal view of the TEOM showing the mass flow controller, amplification boards, TE housing, and the internal sample line.

Figure 16: The front panel of the TEOM. Although the results were not verified, the foam that the TEOM was resting upon was to help eliminate external vibration.....................20

Figure 17: TEOM/ conventional PM ratio for the $35^{\circ} \mathrm{C}$ TEOM set point on a Navistar 7.3 liter diesel. The improvement in filter efficiency was evident as the test sequence proceeds due to PM loading.

Figure 18: TEOM/ conventional PM ratio for the $40^{\circ} \mathrm{C}$ TEOM set point on a Navistar 7.3 liter diesel. The improvement in filter efficiency was repeats as the test sequence proceeded due to PM loading.

Figure 19: TEOM/ conventional PM ratio for the $50^{\circ} \mathrm{C}$ TEOM set point on a Navistar 7.3 liter diesel. The TEOM continues to deviate from conventional PM filters as temperature increased.

Figure 20: TEOM/ conventional PM ratio for the $60^{\circ} \mathrm{C}$ TEOM set point on a Navistar 7.3 liter diesel.

Figure 21: New filter collection error increased as TEOM air temperature increased with an apparent expontial relationship. 
Figure 22: TEOM/ conventional PM ratio for the $30^{\circ} \mathrm{C}$ TEOM set point on a Cummins 10.8 liter diesel engine. A test cycle was performed prior to test 1 shown above. This provided and increased consistency (COV\% of 1.28\%) during this test series.............. 31

Figure 23: TEOM/ conventional PM ratio for the $40^{\circ} \mathrm{C}$ TEOM set point on a Cummins 10.8 liter diesel engine. This series proved to be a very consistent set of tests, $\mathrm{COV} \%$ of the ratio was $0.15 \%$.

Figure 24: TEOM/ conventional PM ratio for the $50^{\circ} \mathrm{C}$ TEOM set point on a Cummins 10.8 liter diesel engine. As with the temperature test on the Navistar engine, a $50^{\circ} \mathrm{C}$ sampling temperature yielded a decrease in the TEOM/ conventional PM ratio...........33

Figure 25: Error data for varying TEOM sample tube temperatures. The greatest error occurred at $50^{\circ} \mathrm{C}$.

Figure 26: A section of the FTP illustrating that increased temperature decreased TEOM realtime data amplitude.

Figure 27: TEOM sampling temperature effects on total mass. The $50{ }^{\circ} \mathrm{C}$ set point yielded an undercollection compared to the other two set points...................................................... 36

Figure 28: A section of the FTP illustrating the repeatability of the real-time results. The deviation of the two traces could be from variation of engine output.

Figure 29: The accumulated mass as measured by the TEOM, illustrating test to test repeatability.

Figure 30: TEOM/ conventional PM ratio as TEOM sample flow rate was varied on the Cummins engine. The hollow data points represent tests that required a new TEOM filter, solid data points represent test taken with a used TEO M filter.

Figure 31: A section of the FTP illustrating increased flow decreased TEO M real-time data amplitude.

Figure 32: A section of the FTP illustrating sample location effects on real-time TEOM data.42

Figure 33: Mass concentration response due to different filter conditioning. 44

Figure 34: Error showing the initial collection efficiency of TX 40 and T60A20 filter media types..

Figure 35: Results from the cross correlation program, where peaks in data represent best estimated time shift. TEOM data were the least delayed, possibly due to the fast response of the instrument and shorter sample length. Validation of the time shifting program can be found in Appendix C.

Figure 36: Average normalized HC and TEOM real-time data for the FTP cycle. The amplitude and duration of the TEOM spikes do not correlate with the HC spikes thought the cycle.

Figure 37: Average normalized HC versus TEO M real-time data for the FTP cycle. There was not a correlation between $\mathrm{HC}$ and real-time TEOM data.

Figure 38: Average normalized CO and TEOM real-time data for the FTP cycle. The CO data tends to follow the TEOM data with exception to the zones of high speed in combination with varying or low load conditions.

Figure 39: Average normalized CO versus TEOM real-time data for the FTP cycle. A weak linear correlation between $\mathrm{CO}$ and real-time TEOM data were shown. This does support the conclusions reached by Clark [16]. The larger loops relate to the zones of high speed in combination with low load conditions. For example, around the time of 230 seconds and from 600 to 900 seconds (see Figure 2 for the speed and load point during an FTP). 
Figure 40: Average normalized $\mathrm{CO}_{2}$ and TEOM real-time data for the FTP cycle. The amplitude and duration of the TEOM spikes do not correlate with the $\mathrm{CO}_{2}$ spikes thought the cycle.

Figure 41: Average normalized $\mathrm{CO}_{2}$ versus TEO M real-time data for the FTP cycle. This figure shows that there was a slight upward trend between $\mathrm{CO}_{2}$ and real-time TEOM data

Figure 42: Average normalized time derivative of $\mathrm{CO}_{2}$ and TEOM real time data for the FTP cycle. Additional time shifting brought about a correlation, which could correspond to turbocharger lag

Figure 43: Average normalized time derivative of $\mathrm{CO}_{2}$ versus TEO M real-time data for the FTP cycle.

Figure 44: Average normalized $\mathrm{NO}_{\mathrm{x}}$ and TEOM real-time data for the FTP cycle. The amplitude and duration of the TEOM spikes do not correlate with the $\mathrm{NO}_{\mathrm{x}}$ spikes thought the cycle.

Figure 45: Average normalized $\mathrm{NO}_{\mathrm{x}}$ versus TEO M real-time data for the FTP cycle. There was a slight upward trend between $\mathrm{NO}_{\mathrm{x}}$ and real-time TEO M data.

Figure 46: Average normalized torque and TEOM real-time data for the FTP cycle. The torque data tends to follow the TEOM data with exception to the zones of high speed in combination with low load conditions........................................................................5 54

Figure 47: Average normalized torque versus TEOM real-time data for the FTP cycle. This figure shows that there was a weak second order polynomial correlation between torque and real-time TEOM data. The areas of high speed in combination with varying or low load conditions tend to give a weaker relationship. For example, around the time of 230 seconds and from 600 to 900 seconds (see Figure 2 for the speed and load points during an FTP).

Figure 48: Average normalized CO versus TEOM real-time data for the WVU FTP 75 cycle.

This figure shows that there was a weak linear correlation between $\mathrm{CO}$ and real-time TEOM data.

Figure 49: Average normalized NOx versus TEO M real-time data for the WVU FTP 75 cycle. A weak linear correlation between NOx and real-time TEO M data were shown. It appears that two modes of operation are shown here.

Figure 50: Average normalized torque versus TEOM real-time data for the WVU FTP 75 cycle. The second order polynomial correlation found with the FTP cycle did not prove to exist with the FTP75.

Figure 51: Average normalized CO versus TEOM real-time data for the CBD cycle. A correlation between $\mathrm{CO}$ and real-time TEOM data were evident. See figure 12 for the vehicle speed during a CBD.

Figure 52: Average normalized $\mathrm{NO}_{\mathrm{x}}$ versus TEOM real-time data for the CBD cycle. A correlation seems to exist, however, the CBD cycle was a repetitive cycle. A trend is likely to repeat, looking as if there is a good correlation.

Figure 53: Average normalized axial power versus TEOM real-time data for the CBD cycle. Again, a trend will recur with this repetitive cycle.

Figure 54: A proposed TEO M filter design.

Figure 55: A section of real-time FTP data shifted per the program's recommended amount. It can be seen here that the compromise to best power correlation is an unrealistic advance of the emission data. 
Figure 56: Results from cross correlating engine power with $\mathrm{NO}_{\mathrm{x}}$ and $\mathrm{CO}_{2}$ using the coefficient of determination. The time at peak correlation using this method is equal to the time shift of the program......................................................................................... 74 


\section{List of Tables}

Number

Table 1: Information detailing the specifications of each engine used at the EERL for this testing.

Table 2: Transit bus tested on the mobile emission laboratory.

Table 3: T60A20 filter properties [15].

Table 4: TX 40 filter properties [15].

Table 5: Results from the $35^{\circ} \mathrm{C}$ TEOM set point on the Navistar.

Table 6: Results from the $40^{\circ} \mathrm{C}$ TEOM set point on a Navistar 7.3 liter diesel engine.

Table 7: Results from the $50^{\circ} \mathrm{C}$ TEOM set point on a Navistar 7.3 liter diesel engine.

Table 8: Results from the $60^{\circ} \mathrm{C}$ TEOM set point on a Navistar 7.3 liter diesel engine................28

Table 9: Results from the $30^{\circ} \mathrm{C}$ TEOM set point on a Cummins 10.8 liter diesel engine..........30

Table 10: Results from the $40^{\circ} \mathrm{C}$ TEOM set point on a Cummins 10.8 liter diesel. ....................31

Table 11: Results from the $50^{\circ} \mathrm{C}$ TEOM set point on a Cummins 10.8 liter diesel engine........33

Table 12: Real-time positive/ negative collection evaluation for varying air temperature. ...........35

Table 13: Error variation with TEO M sample flow rate. ................................................................38

Table 14: Real-time positive/ negative collection evaluation for varying flow rate. ......................40

Table 15: Results of sampling from the secondary dilution tunnel...............................................4

Table 16: Positive/ negative collection evaluation for secondary tunnel sampling....................... 42

Table 17: WVU FTP 75 comparison of sampling modification results shows a 10.6\% average

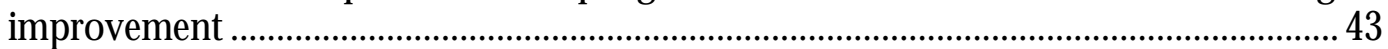

Table 18: Results from using T60A20 filters in the TEO M........................................................ 45

Table 19: The TEOM user configuration, "1105P.CO N", file mainly contains data logging information.

Table 20: The instrument configuration file, "1105.INS", containing critical instrument 21: TEO M channel assignments for the configuration files.

Table 21: TEO M channel assignments for the configuration files.

Table 22: Pin designations for the user I/ O connection for external data collection and remote activation.......................................................................................................... 68

Table 23: TTL control logic for remote collection.

Table 24: The time shifts for $\mathrm{CO}$ and $\mathrm{CO}_{2}$ emissions suggested by the correlation program exceeded the EPA recommended 20 second maximum.

Table 25: The recommended emission shifts base on the alignment of emission and power increase after an idle. Unfortunately, these time shifts also exceed the 20 second EPA guidelines 


\section{N omenclature}

\begin{tabular}{|c|c|}
\hline \multicolumn{2}{|c|}{ Abbreviations and Symbols } \\
\hline CBD & Central Business District \\
\hline CFR & Code of Federal Regulations \\
\hline $\mathrm{CO}$ & Carbon Monoxide \\
\hline $\mathrm{CO}_{2}$ & Carbon Dioxide \\
\hline $\mathrm{COV}$ & Coefficient of Variance \\
\hline DI & Direct Injection \\
\hline EERL & Engine and Emission Research Laboratory \\
\hline EPA & Environmental Protection Agency \\
\hline FTP & Federal Test Procedure \\
\hline $\mathrm{HC}$ & Hydrocarbon \\
\hline HP & Horsepower \\
\hline I/ $\mathbf{O}$ & Input and Output \\
\hline IDI & Indirect Injection \\
\hline ISF & Insoluble Fraction \\
\hline LED & Light Emitting Diode \\
\hline MC & Mass Concentration \\
\hline MHz & Megahertz \\
\hline $\mathrm{NO}_{\mathrm{X}}$ & Oxides of Nitrogen \\
\hline PC & Personal Computer \\
\hline PM & Particulate Matter \\
\hline PPM & Parts Per Million \\
\hline PTFE & Polytetrafluoroethylene \\
\hline $\mathbf{R} \& \mathbf{P}$ & Rupprecht \& Patashnick \\
\hline RH & Relative Humidity \\
\hline$\sigma_{x}$ & The standard deviation of the data set "x" \\
\hline$\sigma_{y}$ & The standard deviation of the data set " $\mathrm{y}$ " \\
\hline SOF & Soluble O rganic Fraction \\
\hline T90 & 90 percent boiling point temperature \\
\hline TE & Tapered Element \\
\hline TEOM & Tapered Element O scillating Microbalance \\
\hline TFE & Tetrafluoroethylene \\
\hline
\end{tabular}

THDVETL Transportable Heavy Duty Vehicle and Emissions Testing Laboratory 


\section{TTL Transistor to Transistor Logic \\ VOC Volatile Organic Compound \\ VW Volkswagen}

WVU FTP 75 West Virginia University engine dynamometer simulation of the Federal Test Procedure 75

$\mathbf{x}$

Data set "x"

$\overline{\mathbf{x}} \quad$ Mean of data set "x"

$\mathbf{y} \quad$ Data set "y"

$\overline{\mathbf{y}} \quad$ Mean of data set "y" 


\section{Introduction and 0 bjective}

\subsection{Introduction}

In view of increasingly stringent fuel economy standards, diesel engines appear to be attractive alternative powerplants for passenger vehicles. However, despite its inherent efficiency benefit, the diesel engine generally presents a challenging particulate matter (PM) emission control problem. PM is an Environmental Protection Agency (EPA) regulated emission that has attracted special attention due to the investigation of adverse health effects from particulate with aerodynamic diameters of $10 \mu \mathrm{m}$ $\left(\mathrm{PM}_{10}\right)$ and 2.5 $\mu \mathrm{m}\left(\mathrm{PM}_{2.5}\right)$ [1]. Knowing the effect of transient engine changes, for example fueling, injection timing, torque, and speed, on PM in real time could be the key to reduction of PM. Therefore, an instrument is needed to measure real time PM in diesel exhaust.

A Tapered Element Oscillating Microbalance (TEOM) diesel particulate analyzer infers the weight of PM deposited on a small filter in real-time. This is potentially the most feasible method to measure PM emissions in real-time. The TEOM uses a hollow, tapered, cantilever element, which is forced to oscillate at its natural frequency via magnetic field plates and a closed loop control system. The filter is mounted on the free end of the cantilevered tapered element. An internal volumetric flow controller regulates a constant sample of diluted exhaust gas pulled across the filter and through the tapered element. Simplistically, the element and filter system can be represented by a spring-mass system, where a change in mass correlates to a change in the natural frequency. As the filter weight changes due to PM accumulation, the frequency of the element's oscillation changes. This change in frequency is proportional to mass change by the equation below:

$$
\Delta M_{n}=K_{o}\left(\frac{1}{f_{n}^{2}}-\frac{1}{f_{n-1}^{2}}\right)
$$

where $\Delta M_{n}$ is the change in mass in grams, $K_{o}$ is the TEOM calibration constant, and $f_{n}$ and $f_{n-1}$ are tapered element (TE) frequency measurements. Unfortunately, the TEOM is sensitive to external vibrations, temperature and pressure variations, and TEOM filter collection efficiency. Filter efficiency changes during collection due to PM accumulation on the filter face and the consequent shrinking of effective pore size. In this research, the use of the TEOM to measure PM is investigated. 


\subsection{Objective}

The objective of this research was to evaluate the use of the TEOM by comparing test results with the conventional gravimetric method. In order to meet these objectives, the following evaluations were performed: (1) TEOM response as (a) instrument temperature, (b) flow, (c) filter media and (d) sample location were changed, (2) filter preconditioning on sampling delay when changing the TEOM filter, (3) real-time TEOM characteristics by comparing its output to real-time gaseous engine emissions. 


\section{Literature Review}

\subsection{Particulate Matter E missions}

Particulate emissions created by diesel engines are broken up into two components, the soluble organic fraction (SOF) and the insoluble fraction (ISF). The SOF, or extractable fraction, can be separated from the collected particulate with solvents such as dichloromethane or a benzene-ethanol mixture. When diluted, cooled PM passes through a sampling filter, the soot, other particles, and condensable compounds will be trapped by the filter media and particulate collected on the filter. These trapped HC and oxidation products collected on the filter are labeled the SOF after extraction from the filter [3]. The EPA has set an upper limit on the temperature of PM sampling from diluted engine exhaust of $52^{\circ} \mathrm{C}$ [2]. It is assumed that this would be the point at which an "acceptable" fraction of condensable hydrocarbon ( $\mathrm{HC}$ ) would stay in the gaseous form to be accounted for by the $\mathrm{HC}$ analyzer. The magnitude of SOF in the total particulate ranges from 10 to 90 percent mass, but generally is observed to be around 15 to 30 percent mass [4]. SOF is mainly composed of heavy hydrocarbons that have condensed and grown onto PM particles as the exhaust gas has cooled due to the dilution and mixing with the ambient air. The extractable fraction is one cause for alarm of health concerns and environmental hazards [1,4,5]. This fraction corresponds to 25 to 50 percent of gaseous HC. The exact portion of the total PM depends on operating conditions and engine due to their effect on the distribution of the boiling range of the gaseous $\mathrm{HC}$ [5]. The $90 \%$ boiling temperature (T90) of the fuel is strongly related to PM production. A high T90 relates to more high temperature boiling point hydrocarbons that tend to be SOF or particulate [3]. The EPA's temperature limit would have to account for a range of possible fuels and engines, implying a question as to its viability for modem alternative fuels. The fuel sulfur content is a strong cause of inorganic content. A linear relationship has been found between the sulfate content in PM to the sulfur content in diesel fuel. However, only 1 to 2 percent of fuel sulfur is generally found in PM [5].

PM in diesel engines is caused by incomplete combustion (oxidation) and pyrolysis of fuel and engine oil. Incomplete combustion is mainly caused in areas of rich equivalence ratios within the cylinder. The central axis of the fuel injection spray pattern is a critical area of PM formation. As the fuel is injected into the cylinder, it has to mix with the existing hot gases. Heywood [4] postulates this creates an inhomogeneous fuel-air mixture, which contains regions that are too lean or too rich to ignite. As soon as cylinder pressure and temperature are high enough, the combustible regions are first to ignite. The fuel and air continue to mix as the flame propagates throughout the cylinder. Some regions that were once too rich or lean to combust now have mixed with air and the increased pressure and temperature cause combustion to continue. Rich areas that do not mix with enough air during this 
crucially short time cause the origins of PM. The increased heat and pressure during combustion lead to pyrolysis, or non-oxidation reactions of fuel and engine oil [4]. Another source of PM is from wall quenching, or cooling of combustion gases close to the cylinder and cylinder head walls. Kato et al. [6] found that both SOF and ISF were influenced by wall quenching effects.

\subsection{Particulate Filters}

For analysis, PM is conventionally captured by sampling a diluted exhaust stream across filter media. Two popular PM filter materials, Pallflex TX40 and T60A20, are similar in material and construction. However, the filters differ in initial collection efficiency, or initial collection rate. Both filters are made from Polytetrafluoroethylene (PTFE) coated glass fibers, and are used in both conventional and TEOM PM collection. Shore [7] states that the T60A20 has a diesel PM collection efficiency of $80 \%$ until the "filter has an appreciable coating of particles" after a couple of tests. Furthermore, it is stated that the TX40 has a diesel PM collection efficiency of 98\% under all conditions. It is assumed that the diesel collection efficiency of any PM filter would be different for each engine, fuel, and test type due to ISF and SOF variations. Okrent [8] reports that at 0.3 microns, the TX 40 filter is 97\% efficient and the T60A20 filter is 95\% efficient. However, Shore's results show that the TX40 filter produced larger differences between conventional PM and TEOM measurement results than the T60A20. Okrent stated the degree of filter loading did not influence TEOM TX40 collection efficiency [8].

\subsection{Tapered Element Oscillating Microbalance}

Whitby et al. [9], in 1982, were the first to test an exciting new prototype instrument that allowed real time particulate measurement which truly measured particulate mass without using optical methods. The prototype Tapered Element Oscillating Microbalance, manufactured by Rupprecht and Patashnick Company under the commission of Cummins Engine Company, was tested at the New York State D epartment of Environmental Conservation facilities for light duty diesel testing. The heart of the instrument was similar to the current generation TEOM unit, a tapered element (TE) firmly mounted at the wide end and with a replaceable filter at the free narrow end. The TE was mounted between two field plates to induce and control oscillation. Measuring the TE frequency of oscillation was an LED and phototransistor system that outputs an AC signal. The signal was amplified and used as a feedback via a conductive path on the TE, which interrupts the field generated by the plates. The amplified signal was also used to analyze the frequency of the TE by means of a counter and then converted to a mass value via a microprocessor algorithm. A sample of diluted exhaust gas was pulled through the filter and tube system, collecting particulate on the filter face. As the mass of the filter changed, so did the frequency of the TE. 
The exhaust specimen for the prototype TEOM unit was sampled from a dilution device into an unheated, stainless steel tube, 9.5-mm outside diameter and $50 \mathrm{~cm}$ in length. The data were acquired using a Ballston Inc., type $\mathrm{CH}$ filter and flow rate of 2.5 liters per minute. The internal temperatures were set at room conditions to create an equivalent environment to the conventional particulate collection method in use. The frequency data output from the TEOM was subjected to a 15 second moving window least-squares linear regression. To compare the TEOM accumulated mass with the conventional method; the conventional filters were weighed immediately after use instead of after the recommended environmental conditioning period. The test bed was a Volkswagen Rabbit Diesel and an Oldsmobile 5.7 L Diesel. These cars ran a combined total of 29 tests cycles consisting of " 505 hot starts" (bag III) of the light duty Federal Test Procedure and the New York City Cycle. The results from their tests were an average TEOM over conventional ratio of 0.94 with a coefficient of variance of $13 \%$. It should be noted that these diesels would be considered very dirty by today's standards. The higher PM concentrations from these vehicles could have caused an increase in the collection efficiency of the TEOM filter. The authors noted a negative trend in the mass rate data that followed each positive spike of mass collection. It was proposed that the positive data represented volatile organic compounds (VOC), moisture, and particulate collecting on the filter. During light loading conditions, such as idle or no-load conditions, the VOC and moisture that had built up during heavy loading continued to evaporate from the filter. This exodus of mass from the filter displayed in the data as a negative mass change.

In 1985, Whitby et al. [10] authored another paper geared toward furthering validation of the TEOM as an accepted diesel particulate measurement system. For this testing, only Pallflex T60A20 filters were used instead of Ballston Type $\mathrm{CH}$ media. A total of 82 mass comparison tests were performed on a 1979 VW Rabbit Diesel at idle. The Rabbit was used because its emission characteristics had been proven consistent at idle. However, a very high soluble fraction could be expected at idle conditions. The exhaust emissions were diluted through an 18 inch diameter dilution tunnel and sampled through a probe adjacent to the conventional collection method probe. The new TEO M filters, as illustrated in Figure 1, are of the same construction as filters used in this research. 


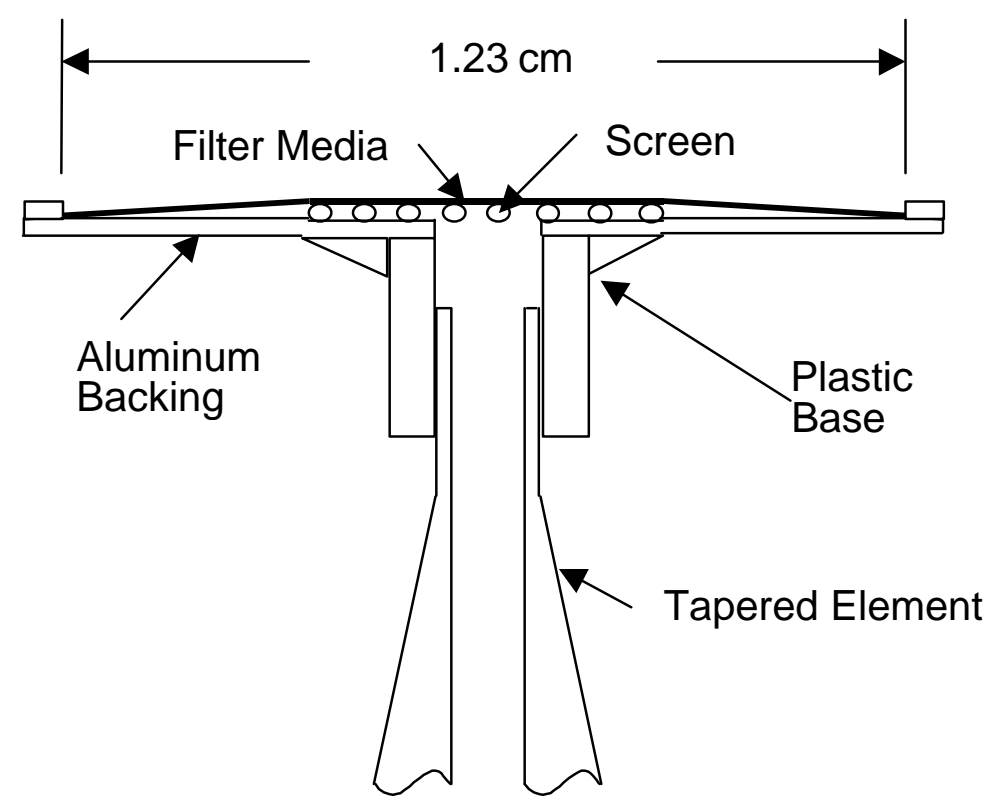

Figure 1: A cut away illustration of the TEOM filter and its mounting on the TE.

EPA guidelines for surface area specific filter flow rate are $0.792-2.638 \mathrm{l} / \mathrm{min} / \mathrm{cm}^{2}$. Filter flow rates for the TEOM operation at the low end of EPA guidelines compared to high-end operation did not significantly alter results. Samples for Whitby's research were collected at ranges from $3.2 \mathrm{lpm}$ to $1.1 \mathrm{lpm}$. To verify the TEOM as an accurate measuring device, 33 non-volatile masses were measured with the TEOM and gravimetrically. Correlation between the two measurements yielded a "virtual 1:1" ratio. Comparison between conventional style particulate collection and TEOM measurements over 27 tests with near equivalent temperatures resulted in a $23 \%$ under-collection from the TEOM. The TEOM results were suggested to be lower due to the premise that the amount of volatile species collected on the TEOM filter was lower because of relatively higher vacuum downstream of the filter. Whitby proposed that equivalent masses could be achieved by sampling the TEOM at a lower temperature than conventional filtration. TEOM filters were also tested in a conventional style collection module and gravimetrically weighed. This also resulted in an under-collection (0.85) when compared to conventional methods. Expanding on this idea, TEOM results were compared to the conventional style gravimetric collection on TEOM filters mentioned above, resulting in a ratio of 0.916 .

Shore et al. [7] used an undisclosed TEOM model applied to a light duty IDI diesel on the LA4, Japanese 10-mode and European ECE-15 Cycles, as well as a heavy-duty DI diesel on the Federal Test Procedure (FTP). The exhaust sample was drawn from the dilution tunnel adjacent to the conventional PM sample location. From the dilution tunnel, the sample was conveyed through a PTFE tube of similar length to the conventional PM collection system. The external sample tube and TE 
housing temperature were set at $50^{\circ} \mathrm{C}$. The filter medium used was Pallflex T60A20. The sample flow rate of 1.2 liters per minute was chosen. However, the authors state that flow rates between 0.8 and 3.0 liters per minute produced a proportional mass accumulation. The conclusion reached was that choice of flow rate was not critical.

Thermogravimetric analysis of the filters showed that the amount of volatile material from tests of two different vehicles was similar; however, the TEO M signal from one vehicle exhibited more negative valleys than the other. This suggests that other factors were involved in the negative mass rate trend than the amount of volatiles. The user could not alter the temperatures of the TEOM sample lines and TE housing. Tests where the conventional PM filter temperatures were close to the TEOM filter temperature yielded a better correlation. It was proposed that this phenomena was caused by a greater amount of hydrocarbons being absorbed due to the lower temperatures of the conventional PM filter. The results from the tests yielded TEOM values within $5 \%$ to $20 \%$ of conventional PM measurements.

Saito et al. [11] performed a comparison of a TEOM, a high-sensitivity light extinction opacimeter and conventional PM filters. The TEOM sampled from location adjacent to the conventional PM collection point. Filter temperature was held at $50^{\circ} \mathrm{C}$ and sample flow rate was set to 3 liters per minute during the duration of the testing. The test rig was a 3.4-liter DI diesel powered truck on a chassis dynamometer. As with Shore, Saito found that the TEOM collected mass was lower than the conventional PM method, reporting a 40\% TEOM undershoot. Higher TEOM filter temperatures were theorized to be the cause of the large difference with Saito's data: he stated that SOF and moisture was evaporating from the PM. The cooler conventional PM filter was allowing these constituents to remain condensed onto absorbed PM. Also proposed, the moisture and SOF loss caused a slow negative drifting trend in the data.

Okrent [8] investigated the use and optimization of the third generation TEOM. The 1105 model TEOM diesel particulate monitor manufactured by Rupprecht and Patashnick Co. replaced the 1100 series monitor in 1997. Effects of sampling temperatures, sampling rate, filter pressure drop, and filter conditioning were investigated to optimize data quality. The variable that affected the data quality most was sampling temperature. It was found that the temperature did not affect the total mass collected on the filter, but did effect the negative mass trend. By comparing a test run at $35^{\circ} \mathrm{C}$ and $55^{\circ} \mathrm{C}$, it was shown that the amount of negative mass displayed in the data were less in the test sampled at the higher temperature. Okrent proposed that more VOC were collecting on the filter at lower temperatures. Sampling rate was varied from 2 liters per minute to 5 liters per minute, test results concluded that there is no correlation between TEOM and conventional PM filter values as sampling rate was changed. Furthermore, the high filter face velocities caused by sampling at these rates across a 
small filter area caused no visual stripping of VOC or water from the filter face. Pressure drop across the filter due to particulate build up was allowed to reach a maximum of 18 inches of mercury and, after this point in loading, flow rate was beginning to be sacrificed. These tests were designed to measure the VOC and water desorption rate. Okrent expected the desorption rate to increase due to the high pressure drop, causing the baseline drift observed by Saito. However, this trend was not observed. Okrent stated that the results were similar at other sampling locations also. Filter conditioning time, or time given for the filter to stabilize in the TEOM unit, was found to be a minimum of 500 seconds.

All of the covered literature compared TEOM results to conventional PM style collection. This method of collection is thought to be reliable because of its acceptance by the EPA. However, a committee correspondence from the Engine Manufacturers Association suggests that laboratory to laboratory variations are significant [12]. A round robin engine test was implemented where three labs tested the same engine to compare results. Lab to lab variations of work specific PM (g/bhp-hr) yielded a coefficient of variation for the hot start FTP test of 17\%. The internal coefficient of variation for each lab was reported to be $5 \%$. The TEOM collects mass by the same mechanism and may be susceptible to the same outcome. This could explain at least part of the wide range of TEOM results reported in the literature.

Within the year of 2001, R\&P released a new filer cartridge. The new design utilizes a thermoset plastic carrier to replace the plastic base and aluminum backing, as shown in figure 1. The new design does not utilize a screen under the filter. The functionality of the screen is incorporated into the plastic carrier by molded ridges under the filter. The ridges are directed radially from the center of the filter. The filter material is TX40 and the amount of exposed material is dimensionally the same between the new and old filter. For this study, time limitations hindered testing with this new filter design. Using the new filter, other research at West Virginia University [13] has reported improved initial collection efficiency and correlation with the conventional filter method. 


\section{Experimental Setup}

\subsection{Engines and Testing Equipment}

The experiments for this research were conducted at two laboratories: the West Virginia University Mechanical and Aerospace Engineering Department Engine and Emissions Research Laboratory (EERL) and the West Virginia University Mechanical and Aerospace Engineering Department Transportable Heavy Duty Vehicle Emissions Testing Laboratory (THDVETL).

\subsubsection{Engine and E missions Research Laboratory}

\subsubsection{Engines and Engine Dynamometer}

Two engines were used, a Cummins ISM 370 ESP and a Navistar T444E. Both engines are after cooled direct injection compression ignition engines using 3 parts per million (PPM) sulfur level fuel. The Cummins was an inline 6 cylinder configuration, while the Navistar was a V8 configuration. Engine details are outlined in table 1.

Table 1: Information detailing the specifications of each engine used at the EERL for this testing.

\begin{tabular}{|c|c|c|}
\hline Manufacturer & Cummins & Navistar International \\
\hline Model & 1999 ISM 370 ESP & 1999 T444E HT BH210 \\
\hline Displacement & 10.8 Liter & 7.3 Liter \\
\hline Advertised Horsepower & 370 Hp at 2100 RPM & 210 Hp at 2300 RPM \\
\hline Fuel & 3 PPM Sulfur D2 & 3 PPM Sulfur D2 \\
\hline
\end{tabular}

A General Electric DC dynamometer system was used to load and control the speed of the engines. An IBM-based personal computer ( $\mathrm{PC}$ ) was used to control the dynamometer, using control logic that holds engine speed, while using the fueling rate to match the torque set point. The engine speed and load points came from the Federal Test Procedure (FTP) [2] and an in-house simulation of the light duty chassis FTP 75 (WVU FTP 75) test cycles, illustrated in figures 2 and 3 respectfully. No steady state testing was addressed in this study. It was the focus of this research to evaluate the TEOM applied to transient test cycles. 


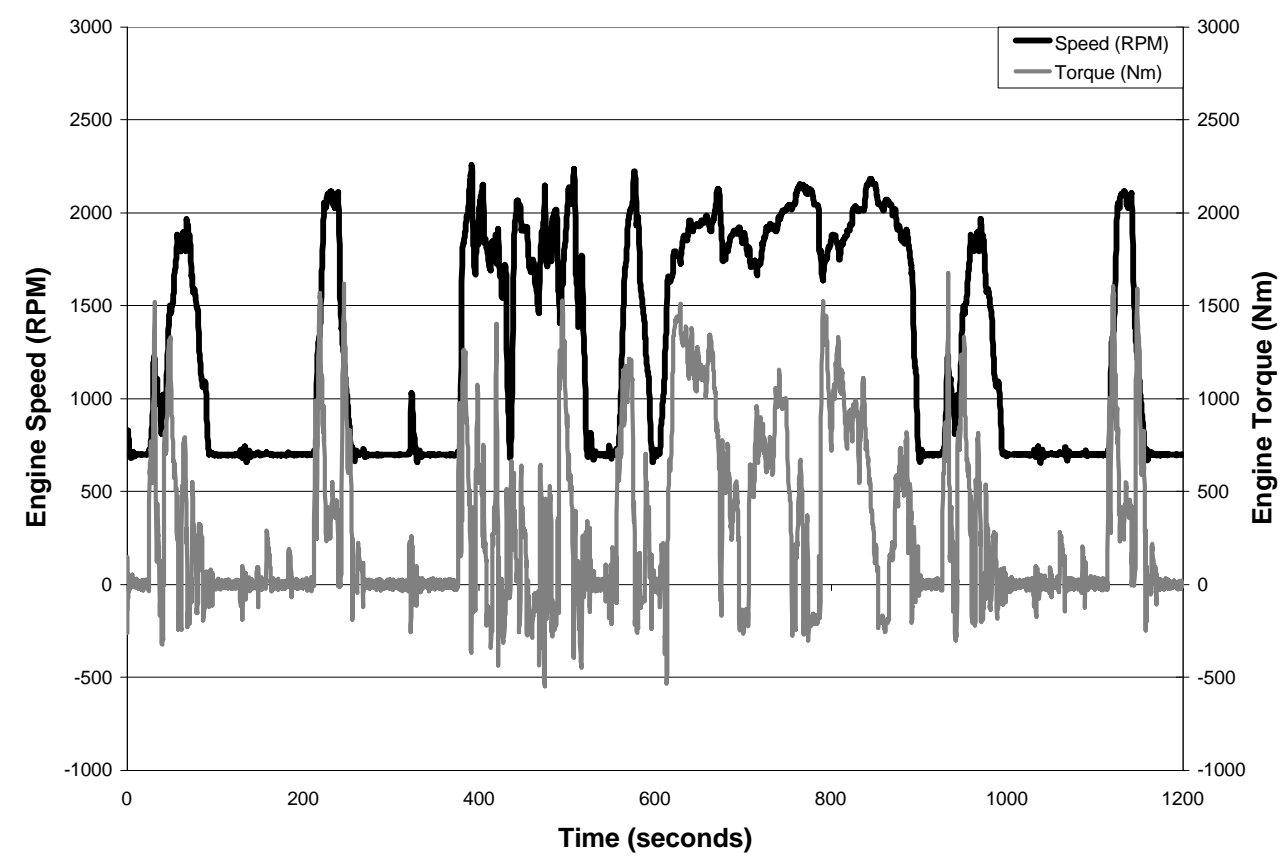

Figure 2: Engine speed and load for a 10.8 liter Cummins during a FTP test cycle.

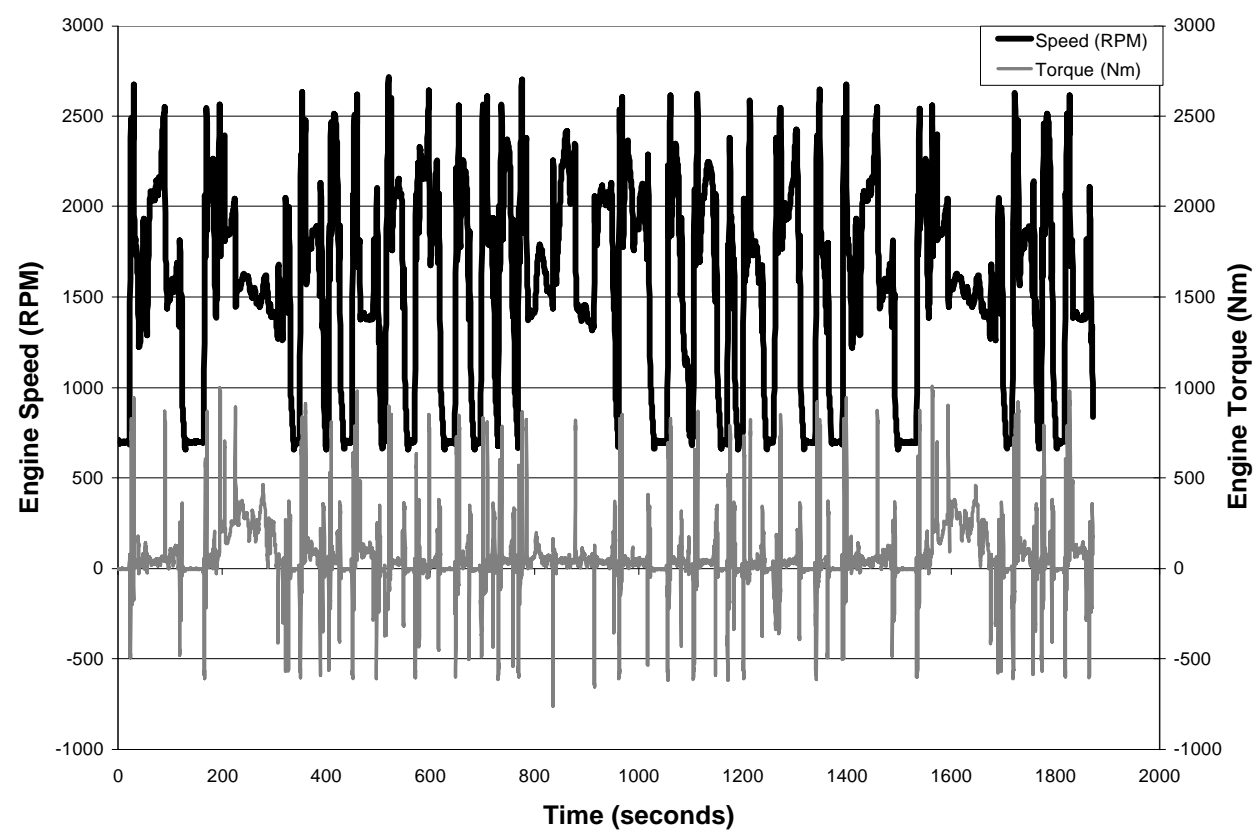

Figure 3: Engine speed and load for a 7.3 liter Navistar for a WVU FTP 75 test cycle. 


\subsubsection{Exhaust Dilution and Instrumentation}

Exhaust gases were ducted from the engine to the primary dilution tunnel through a five inch $(12.7 \mathrm{~cm})$ diameter insulated carbon steel pipe approximately 26 feet $(7.9 \mathrm{~m})$ long. The primary dilution tunnel was 18 inches $(45.7 \mathrm{~cm})$ in diameter, incorporating a mixing orifice to promote mixing of the engine emissions with the temperature conditioned test cell air. Sampling probes were placed radially from the longitudinal centerline to form a sampling plane that was perpendicular to the flow 180 inches $(457 \mathrm{~cm})$ down stream of the tunnel opening. Analyzers sampling from this location measured HC, oxides of nitrogen $\left(\mathrm{NO}_{\mathrm{x}}\right)$, carbon monoxide $(\mathrm{CO})$, carbon dioxide $\left(\mathrm{CO}_{2}\right)$, and TEOM PM. The volume of mixed air and exhaust was controlled by a critical flow venturi operating in a choked flow condition.

The venturi was set at $1000 \mathrm{cfm}$ and $2400 \mathrm{cfm}$ for the Navistar and Cummins, respectively. The diluted exhaust was pulled through the venturi by a blower and then vented to the atmosphere. By injecting a known amount of propane into the tunnel and measuring the amount recovered by the HC analyzer, the tunnel integrity and accuracy was tested. Sampling probes and sample lines were heated to prevent condensation of moisture and hydrocarbons while transferring diluted exhaust gases to the analyzers.

The HC analyzer was a model 402 flame ionization detector made by Rosemount Analytical, Inc. The $\mathrm{NO}_{\mathrm{x}}$ analyzer used was a Rosemount Analytical, Inc chemiluminescent model 955. The CO analyzer used was a Rosemount Analytical, Inc model 880A non-dispersive infraned unit. The $\mathrm{CO}_{2}$ analyzer used was also a non-dispersive infrared instrument, however, some tests used a Beckman Industrial model 868, and other tests used a Rosemount Analytical, Inc model 880A. All gas instruments were calibrated and set to zero air and spanned with calibration gases before testing.

To collect PM in spirit of the EPA regulations, as specified in Title 40 of the Code of Federal Regulations [2], a sample of diluted exhaust gas was pulled from the sampling plane in the primary dilution tunnel into a secondary dilution tunnel. The sample was passed across a pair of $70 \mathrm{~mm}$ diameter microfiber filters in series at a set volumetric flow rate via a mass flow controller and vacuum pump. The filters used were Pall-Gelman Science "Pallflex Fiberfilm" T60A20 heat resistant borosilicate glass fiber coated with TFE, as seen in figure 6. Figures 4 and 5 illustrate the cartridge that contained the filters during the test cycle. 


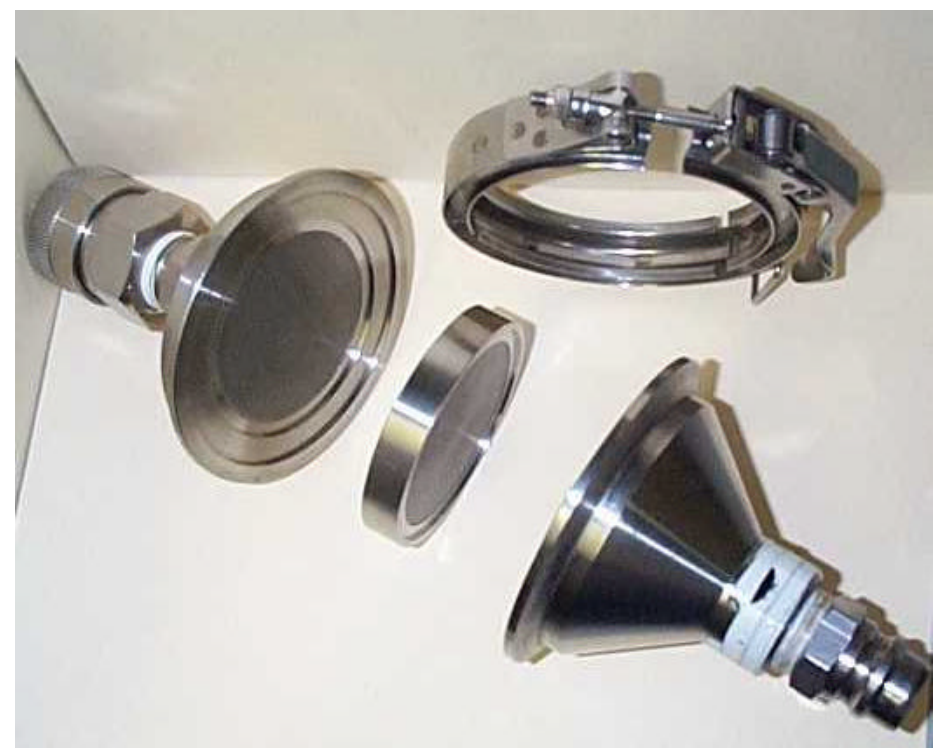

Figure 4: The $70 \mathrm{~mm}$ diameter PM filter cartridge disassembled. This filter module was used for the conventional, EPA-style, PM collection.

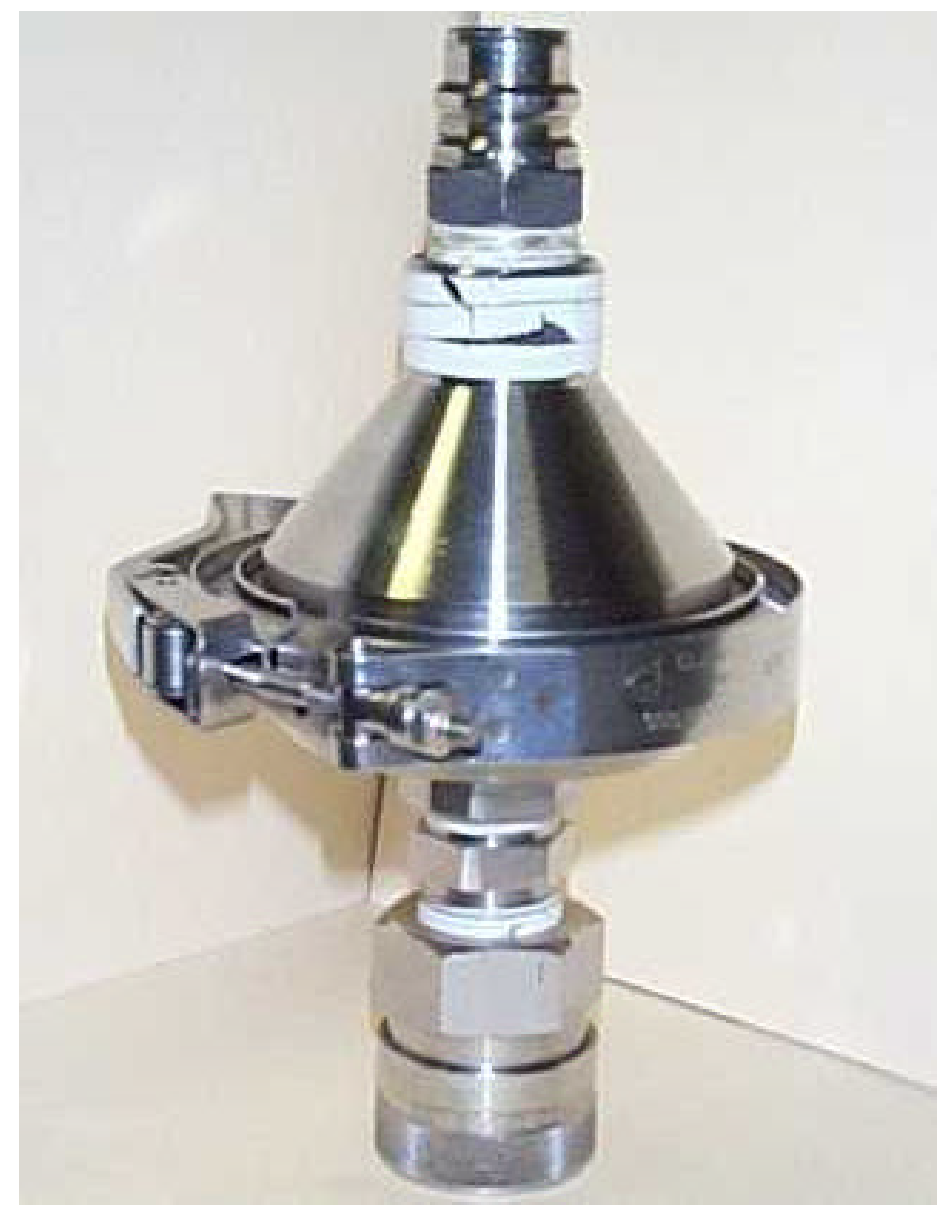

Figure 5: The PM filter cartridge assembled. 


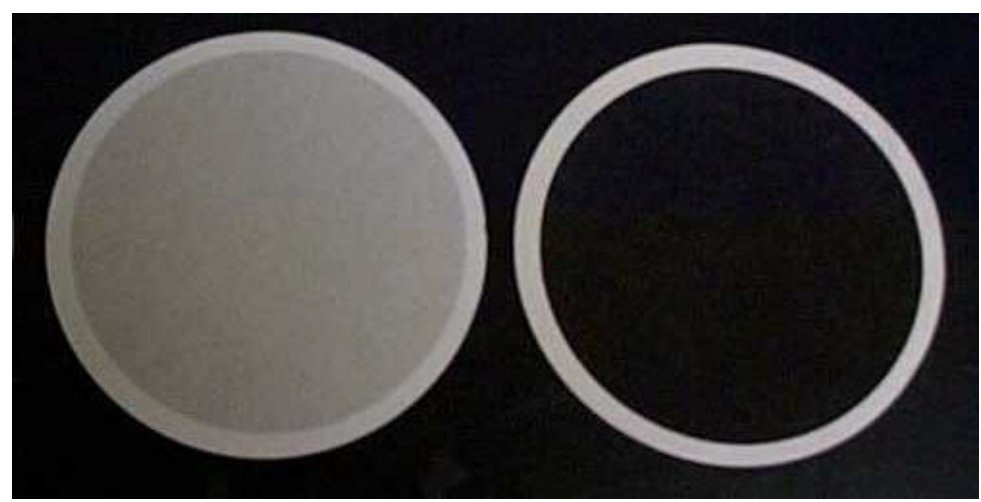

Figure 6: Typical used secondary (left) and primary (right) PM filters. This photo shows the inefficiency of the T60A20 filter by the amount of PM collected on the secondary filter.

No secondary dilution was necessary, as the sample filter face temperature remained below $125^{\circ} \mathrm{F}\left(52^{\circ} \mathrm{C}\right)$. The set volumetric sample rate was five scfm $(141 \mathrm{lpm})$. The filters were conditioned in an environmentally controlled chamber where the temperature remained at $70^{\circ} \mathrm{F}+/-10^{\circ} \mathrm{F}$ and the relative humidity was constrained to $50 \%+/-10 \%$. The filters were conditioned and weighed before and after each test with a Cahn C-32 microbalance to calculate the collected PM mass. The PM concentration was calculated by dividing the collected PM mass by the total volume passed through the filter set during the test cycle.

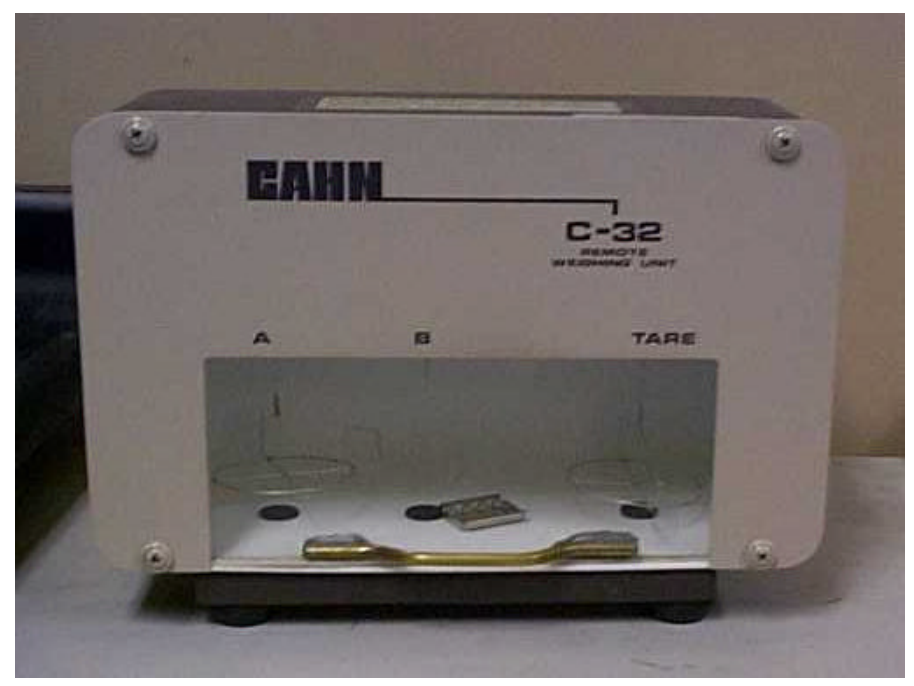

Figure 7: The microbalance used weigh conventional PM filters before and after each test.

The TEOM model 1105 was used to sample in two locations. The first location was at the sampling plane in the primary dilution tunnel, see figures 8 and 9 for illustration. The second location was at the bottom of the secondary dilution tunnel, above the PM filters. The sample location from the 
secondary tunnel is illustrated in figures 10 and 11. This second location was to investigate the possible effect of concentration or pressure variations on TEOM data.

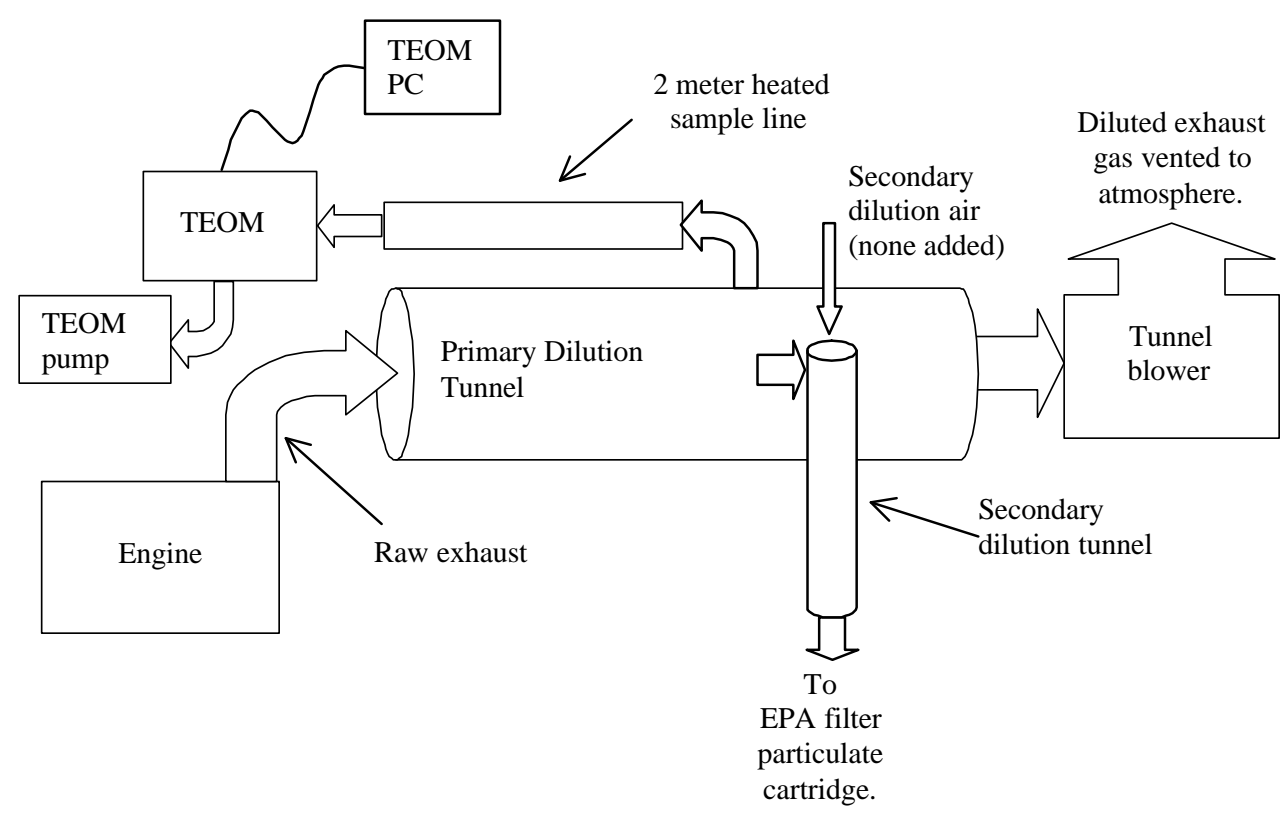

Figure 8: The particulate sampling system with the TEO M sampling from the primary dilution tunnel.

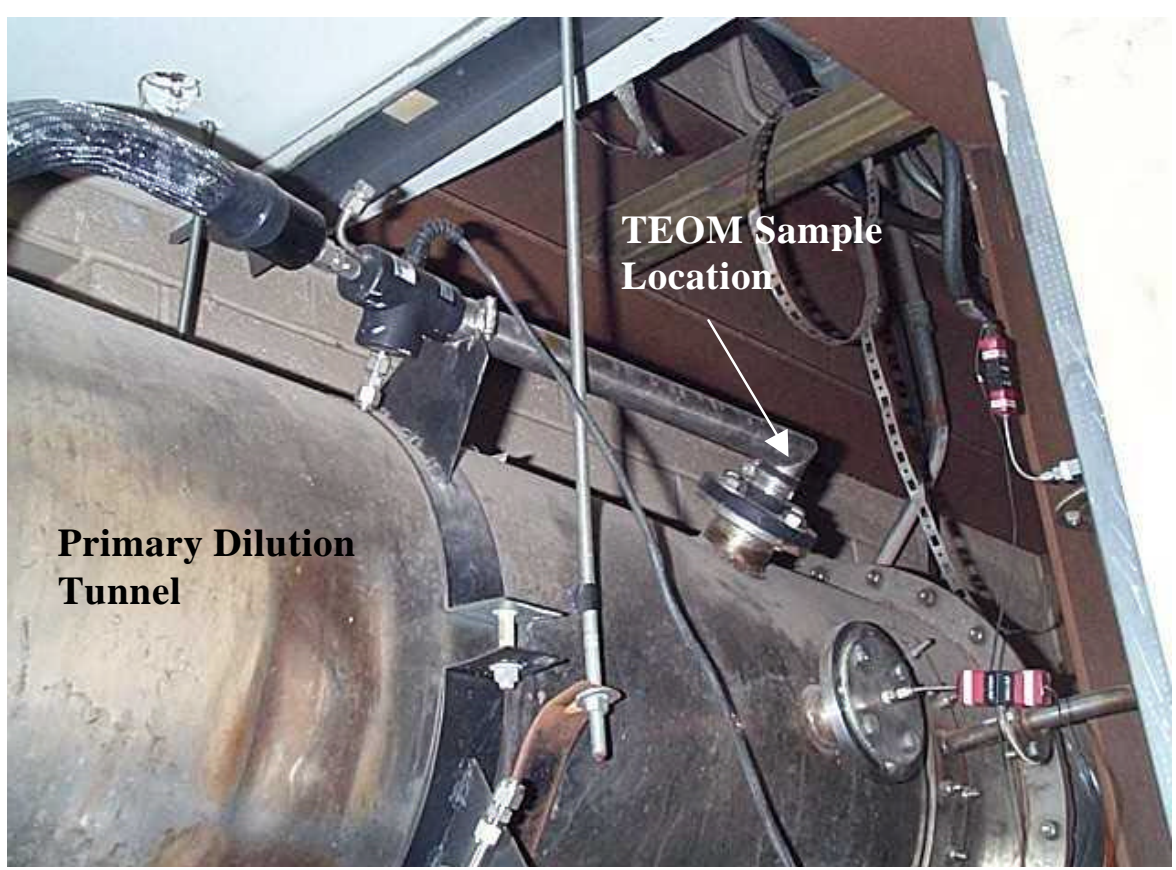

Figure 9: The TEOM sampling location on the primary dilution tunnel. 


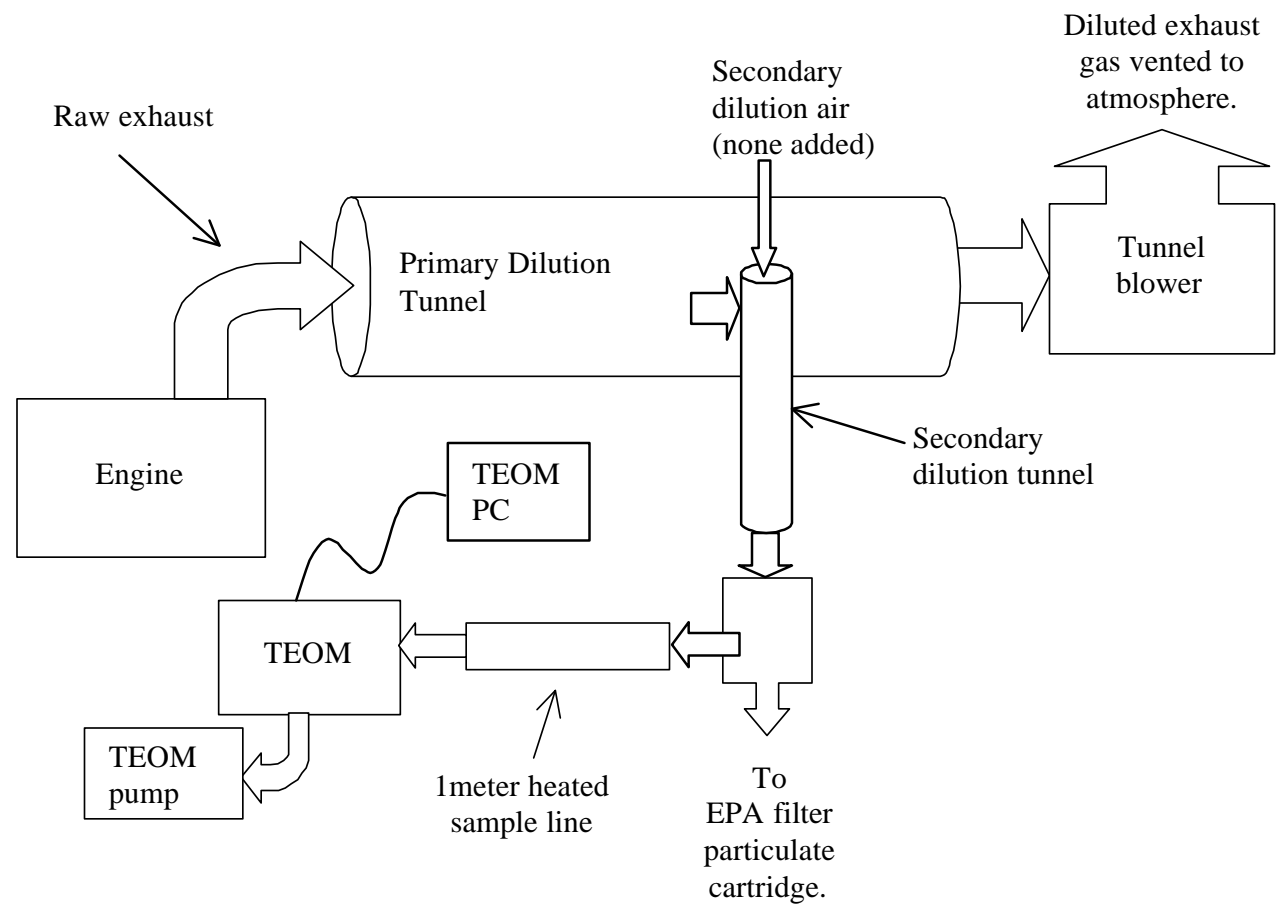

Figure 10: The particulate sampling system with the TEOM sampling from the secondary dilution tunnel.

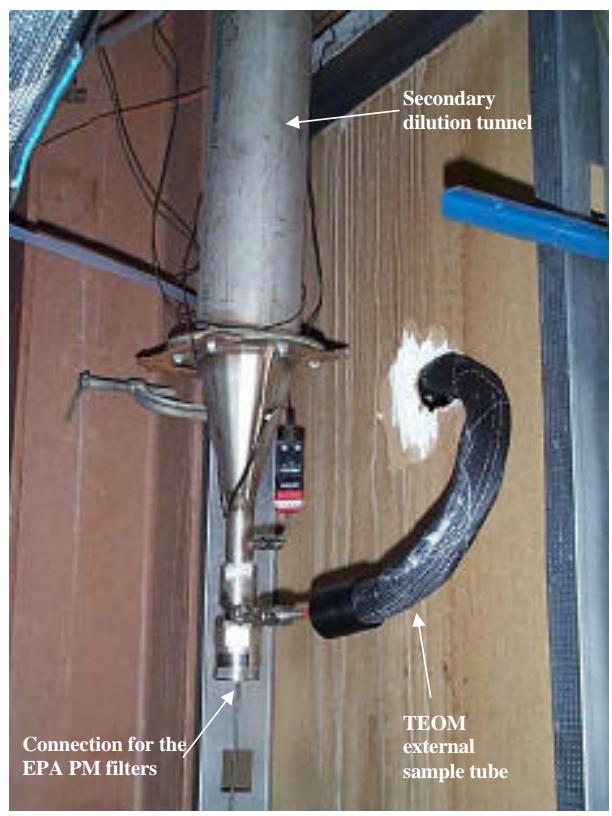

Figure 11: The TEOM sampling location on the secondary dilution tunnel 


\subsubsection{Transportable Heavy Duty Vehicle and E missions Laboratory}

\subsubsection{Vehicle and Chassis Dynamometer}

The chassis dynamometer was designed to test medium to heavy-duty highway vehicles [14]. The chassis dynamometer utilized rollers to support the drive axle of a vehicle as with a conventional chassis dynamometer. However, power was taken from the vehicle through hub adapters bolted to each side of the driven axle on the wheel flanges. The rollers were coupled to ensure even torque distribution between left and right wheels. Road loads were simulated through a combination of flywheels and eddy current absorbers. The flywheels were used to simulate the inertia of the vehicle, while the eddy current absorbers simulated additional forces due to acceleration. The vehicle speed points came from the Central Business D istrict (CBD) test cycle, as depicted in figure 12. The vehicle used for the test sequence was a transit bus manufactured by Collins. Specific information on the test vehicle can be found in table 2. Although illustrations 13 and 14 do not show the transit bus used, illustrated is a typical vehicle operation on the portable heavy-duty chassis dynamometer

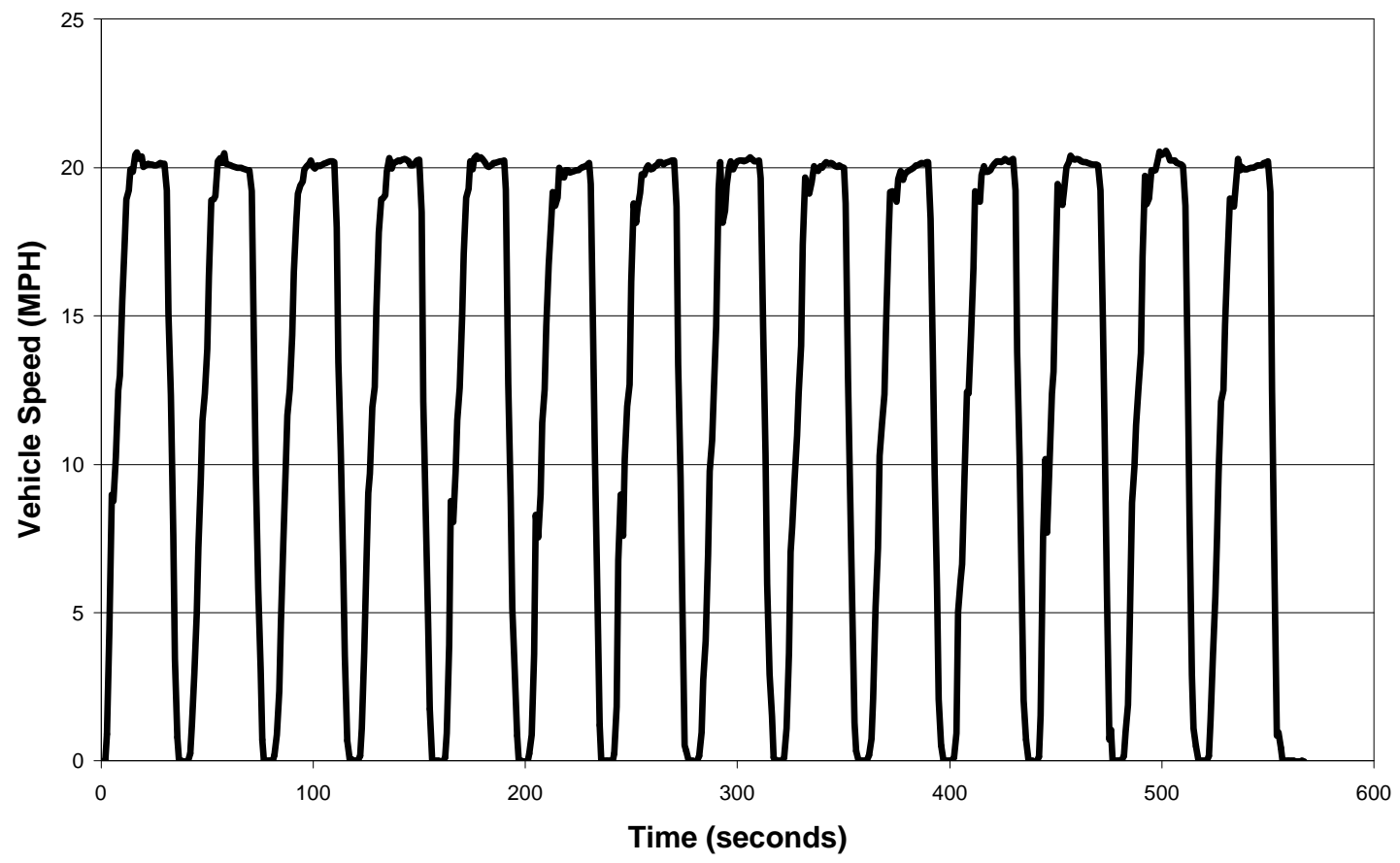

Figure 12: Measured vehicle speed for a Collins transit bus driving the CBD cycle on the transportable laboratory. 
Table 2: Transit bus tested on the mobile emission laboratory.

\begin{tabular}{|c|c|}
\hline Fleet O wner & D enver Regional Transit D istrict \\
\hline Vehicle Type & Transit Bus \\
\hline Vehicle Manufacturer & CO LLINS \\
\hline Vehicle Model Year & 1997 \\
\hline Gross Vehicle Weight & $18780 \mathrm{lb}$. \\
\hline Vehicle Total Curb Weight & $14525 \mathrm{lb}$. \\
\hline Vehicle Tested Weight & $17914 \mathrm{lb}$. \\
\hline Odometer Reading & 18700 miles \\
\hline Transmission Type & 4-speed Automatic \\
\hline Number of Axles & 2 \\
\hline Engine Type & Cummins B5.9 - 175 \\
\hline Engine Displacement & 5.9 Liter \\
\hline Number of Cylinders & 6 \\
\hline Engine Rated Power & $175 \mathrm{hp}$ \\
\hline Fuel & D 2 \\
\hline
\end{tabular}

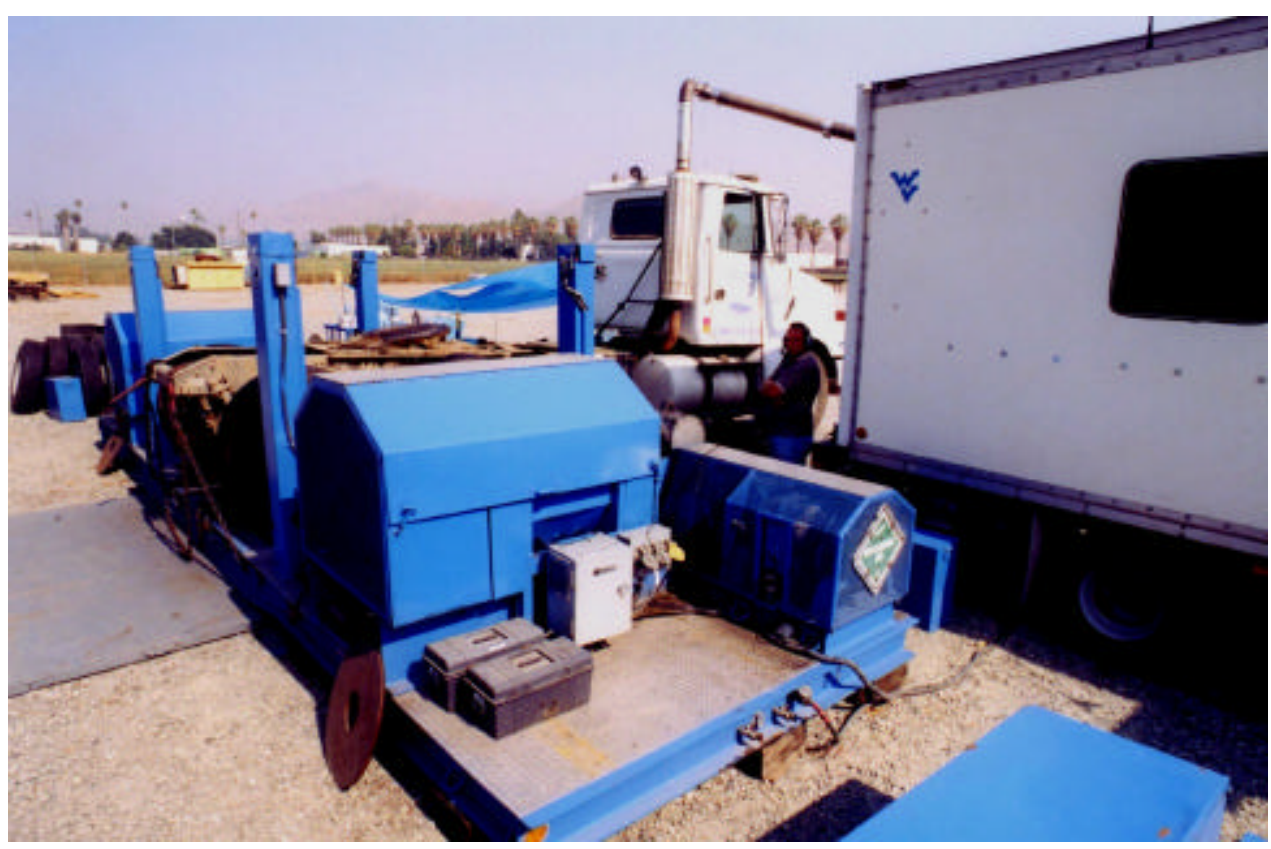

Figure 13: Although this illustration does not show the transit busses used, illustrated here is a typical vehicle operation on the portable heavy-duty chassis dynamometer. 


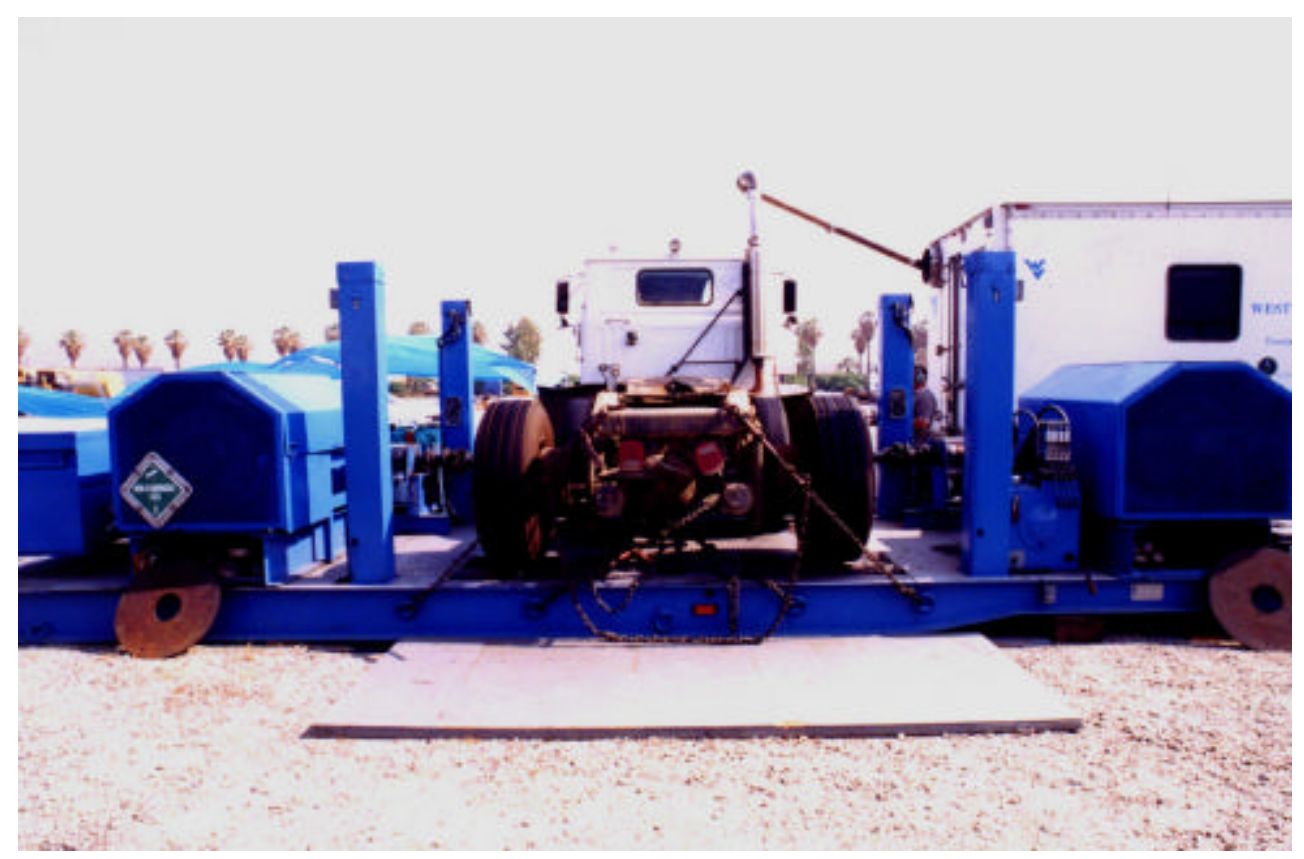

Figure 14: Typical routing of vehicle exhaust into the emissions trailer of the mobile laboratory.

\subsubsection{Emission Dilution and Instrumentation}

The dilution system in the THDVETL parallels the design in the EERL and its description can be found in section 3.1.1.2. However, the transportable laboratory does not have the capability of conditioning the air used for combustion and dilution. The $\mathrm{HC} \mathrm{NO}_{\mathrm{x}}$ and $\mathrm{CO}$ analyzers were the same models as used in the Engine and Emission Research Center and their descriptions can be found in section 3.1.1.2. The $\mathrm{CO}_{2}$ analyzer used was a Rosemount Analytical, Inc model 880A non-dispersive infrared unit. Particulate sampling was also parallel in design and operation as the system used at the EERL. However, the TEOM was only setup to sample at the bottom of the secondary dilution tunnel as illustrated in Figure 10.

\subsection{Description and Setup of the TEOM}

\subsubsection{Description}

The essential component to the TEOM is a hollow, tapered, cantilever element, which is forced to oscillate at its natural frequency via magnetic field plates and a feedback system. The filter is mounted onto the free end of the cantilevered, tapered element. An intemal volumetric flow controller regulates a constant sample of diluted exhaust gas pulled across the filter. Simplistically, the element and filter system can be represented by a spring-mass system, where a change in mass correlates to a change in frequency. As the filter weight changes due to PM accumulation, the frequency of the element's oscillation changes. The TEOM measured the frequency of the tapered element oscillation 
and calculated a new filter weight. A new weight was calculated approximately every one fifth of a second.

The TEOM was controlled by a PC via counter timer and analog/ digital input output boards. These boards are managed through TEO MPLUS ${ }^{\circledR}$ software supplied by Rupprecht \& Patashnick. This software provides an easy interface for instrument set up and data acquisition. Critical instrument set up parameters include sample volumetric flow rate and internal and external sample line temperatures. User defined data acquisition variables include sampling rate and time window averaging.

\subsubsection{TEOM Setup}

The instrument was placed on a stable shelf in a position as close as possible to the sampling location. A Pentium-class IBM compatible PC was used to control the sampling unit. Two printed circuit boards were installed into the PC to interface with the TEOM. The Robotrol data acquisition board was used for data and communication while the R\&P counter timer board controls frequency of data acquisition. The jumper on the counter timer board was set to position $\mathrm{E}$ which corresponds to a data cycle time of 0.1048576 seconds. This jumper setting was chosen because the PC could not update the time axis on the display screen without affecting TEOM acquisition sampling at a faster data cycle time. TEOM setup parameters were established in the instrument configuration file and the user configuration file. The instrument configuration file, "1105.INS", configuration file, "1105P.CON", and TEOM channel assignments are described in Appendix A. At the EERL, the TEOM total mass and TEOM mass concentration data were acquired in parallel with other real time analyzers and engine parameters through the existing data acquisition system. Also, for use at the EERL, the TEOM acquisition was started, stopped, and reinitialized by sending TTL level signals to user digital input channels of the user I/ O port. The pin designations for the user I/ O port and logic for remote

collection can be found in Appendix A. Collecting data at the portable emission laboratory was done manually and data were acquired with the TEOM PC. For all testing in this study, a 3 second moving window average was applied to the data. This averaging was applied by the TEOM and the duration can be user defined in the configuration files. The significance of data averaging was not investigated because of the direct influence on system response. Figure 15 reveals the internals of the TEOM unit. 


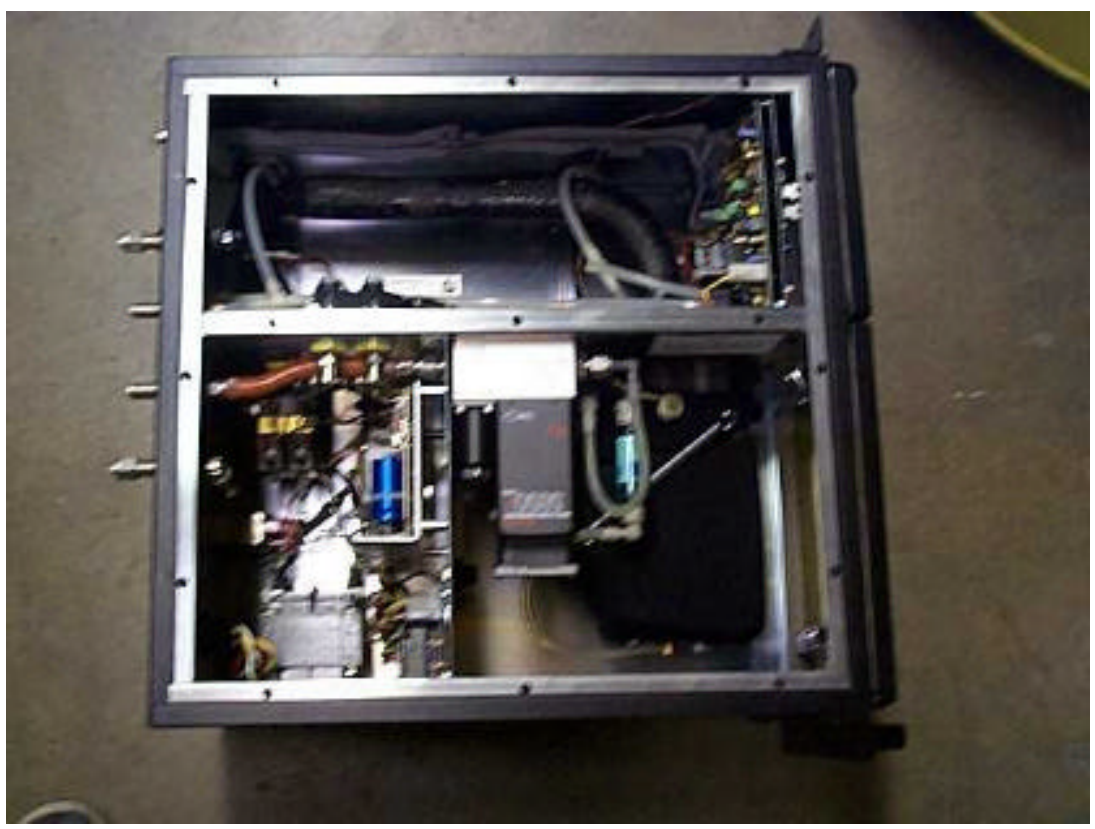

Figure 15: Internal view of the TEOM showing the mass flow controller, amplification boards, TE housing, and the internal sample line.

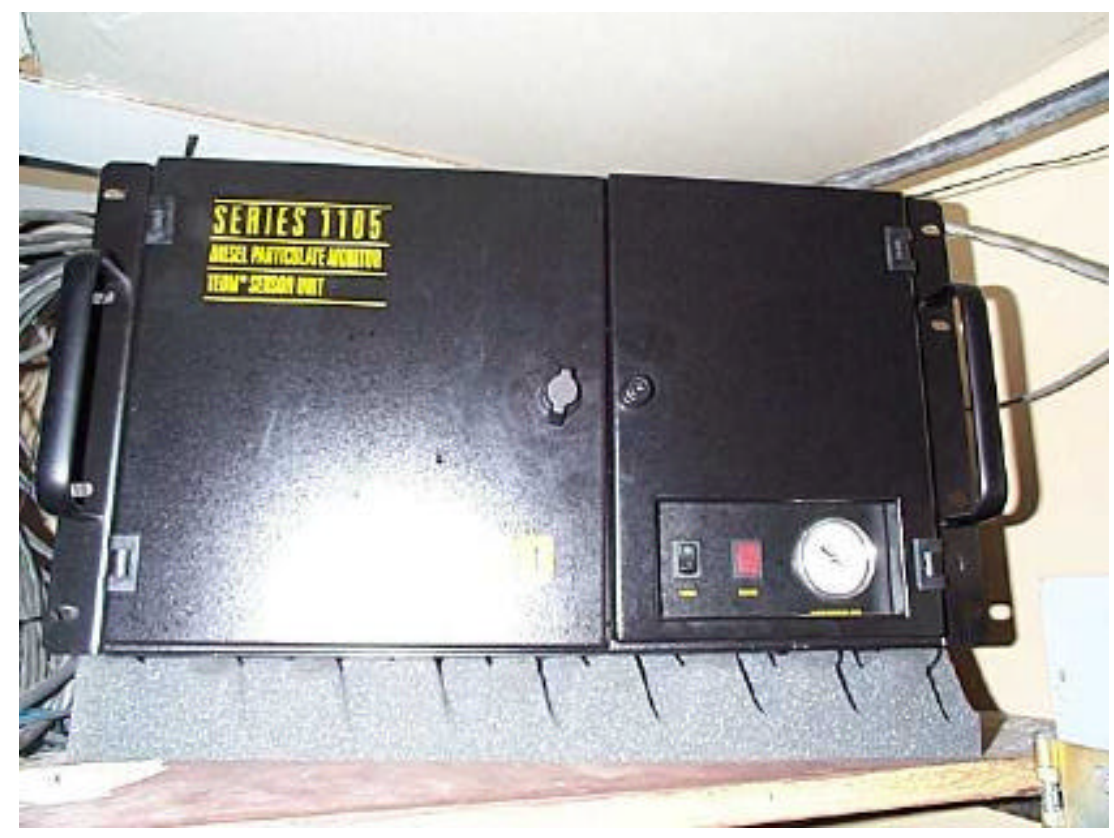

Figure 16: The front panel of the TEOM. Although the results were not verified, the foam that the TEOM was resting upon was to help eliminate external vibration. 


\section{Expenimental Approach}

\subsection{Temperature Effects}

To investigate and validate further the effect of sample tube temperature on TEOM data, the TEOM end-of-test mass was compared to the conventional PM collection and real-time TEOM data were scrutinized. The first phase of tests involved exploring four temperature set points while the flow rate was held constant. Results were compared by using flow normalized end-of-test particulate mass, referred to as mass concentration (mc), reported in milligrams of PM per cubic meter of sample. The end-of-test particulate mass used for calculation were the reported value from the TEOM and the conventional PM gravimetrically measured mass. The end-of-test particulate mass was then divided by the total volume of sample that was passed across the filter. The sample volume was measured and controlled by separate electronic volumetric flow controllers for each collection method. No corrections for background PM were applied to the data. It was assumed that an equivalent amount of background PM was collected by each method. Further more, the error stacking would add randomness to the study. Equations 1 and 2 represent the formulas used to calculate mass concentration for the conventional and TEOM measurement methods respectively.

$$
\begin{aligned}
& \text { Conventional }_{m c}=\frac{\text { Mass }_{\text {filter_post-test }}-\text { Mass }_{\text {filter } \_ \text {pre-test }}}{\text { Volume }_{\text {conventional }}} \\
& \text { TEOM }_{m c}=\frac{\text { End_of_Test_Mass }}{\text { TEOM }} \\
& \text { Volume }_{\text {TEOM }}
\end{aligned}
$$

The comparisons of TEOM-to-conventional PM values were made by using percent difference from conventional PM, equation 3.

$$
\text { PercentDifference }=\frac{\left(\text { Conventional }_{m c}-\text { TEOM }_{m c}\right)}{\text { Conventional }_{m c}} \times 100 \%
$$

For these evaluations, a percent difference from conventional PM value of one hundred percent was desirable. To quantify the overall variability in TEOM results, a t-distribution [17] was compiled to calculate the $99 \%$ confidence level for the temperature data taken with the Navistar engine. This method assumes that the distribution of end-of-test TEOM mass data distribution is Guassian. Furthermore, to increase the sample size, the $99 \%$ confidence level was calculated by treating the data as a single set, or videlicet, assuming the effect of TEOM sample temperature has a negligible effect on the statistical confidence value. This method served as a conservative representation of uncertainty due to the true effect of TEOM sample temperatures on PM collection. Conventional PM concentration 
values provided a baseline for the validation of the TEOM instrument. However, the primary purpose of the instrument is to measure real-time PM, so a criterion was needed to evaluate this feature.

Two mass vectors describe the filter loading. One positive vector represents VOC, moisture, and particulate collecting on the filter. One negative vector represents VOC and moisture coming off the filter. During light loading conditions, such as idle or no-load conditions, the VOC and moisture that had built up during heavy loading continued to evaporate from the filter. This exodus of mass from the filter surfaced in the data as a negative mass change. Although previous work [7-11] suggests that the negative mass rate data trends are real phenomena, it is generally thought that the ideal realtime PM results should only be positive. This is a semantic debate, which rests in the definition of PM and its creation. To judge the overall negative mass rate occurrence of the data, the real-time results were separated into positive values and negative values. These two fractions were numerically integrated to provide values for the total amount of positive and "negative" mass collected. The summation of these two integrated values would be the total mass collected on the filter during the test. The ratio of the positive mass over the negative mass yielded one effective criterion for the evaluation of real-time results. A high positive-to-negative mass ratio was desirable. For these temperature sweeps, a flow rate of $3 \mathrm{lpm}$ was chosen as per the previous work performed by Okrent [8] and Shore [7].

\subsection{Flow Effects}

Using the temperature set point that gave the best compromise of conventional PM agreement and real-time results from the section above, a sweep of four TEOM sample flow set points was taken holding the temperature set point constant. The end-of-test TEOM results were compared with conventional PM filter collection results. A t-distribution was calculated, using the entire Cummins engine set. The temperature and flow studies were regarded as one set of consistent data to calculate the 99\% confidence level. By grouping all Cummins engine tests together in the 99\% confidence calculation, it is assumed that the effects of temperature and flow variations are negligible in the

statistical confidence value. In addition, the real-time data were evaluated in the same manor as the temperature effect tests outlined above.

\subsection{Sampling Location Effects}

The sampling location was changed from the primary dilution tunnel to the secondary dilution tunnel, again comparing TEO M results with conventional PM filter collection results and real-time data evaluation was conducted in the same manor as the temperature effect tests outlined above. The TEOM temperature and flow set points that yielded the best results were used to compare the two sampling locations. 


\subsection{Filter Conditioning}

Five types of tests were performed to investigate the effect of filter pre-conditioning on start up delay after filter replacement. Each test consisted of a different type of filter storage, or conditioning. For bag, chamber, room, and 100\% relative humidity (RH) conditioning, a new filter was placed in the TEOM and sampling was started immediately. For each of these conditioning criteria, filters were allowed to condition for at least 24 hours. Bag conditioned filters were stored in the R\&P Company supplied resealable bag containing a silica gel package. Chamber conditioned filters were stored in the same environmental chamber where conventional PM filters were stored. Temperature and humidity readings were $22^{\circ} \mathrm{C}$ and $45 \% \mathrm{RH}$ respectively. Room conditioned filters were allowed to condition in a petri dish in the ambient temperature and humidity conditions at $21^{\circ} \mathrm{C}$ and $30 \% \mathrm{RH}$. Filters conditioned at $100 \% \mathrm{RH}$ were stored at room temperature in a petri dish containing a damp wick. The saturated tests were conducted by placing a drop of water on the filter while installed in the TEOM unit, then immediately starting sampling. The TEOM was set to sample at $50^{\circ} \mathrm{C}$ and $2 \mathrm{lpm}$ during all tests except the $100 \% \mathrm{RH}$ tests. In the $100 \% \mathrm{RH}$ tests, results from $50^{\circ} \mathrm{C}, 2 \mathrm{lpm}$ settings were compared to $40^{\circ} \mathrm{C}, 3$ lpm settings.

\subsection{Effect of Filter Type}

There are two types of filter media popularly used in particulate collection, the Pall-G elman Science "Pallflex Fiberfilm" T60A20 and TX40. The only filter medium used in this research was a conventional PM filter was the T60A20. The efficiency of the conventional PM filter method was not questioned due to its two stage series filter design. The TX40 is the most common filter to use in the TEOM due to its higher initial filtration efficiency. Both filters are very similar in material and construction; their properties are outlined in tables 3 and 4 . The application of T60A20 filter use in the TEOM was tested against the more commonly used TX40. The TEOM temperature and flow set points that yielded the best results in the previous experiments were used to compare the two filter types.

Table 3: T60A20 filter properties [15].

\begin{tabular}{|l|l|}
\hline Filter Media & $\begin{array}{l}\text { Heat resistant borosilicate glass fiber coated } \\
\text { with fluorocarbon (TFE). }\end{array}$ \\
\hline Typical Thickness & $8 \mathrm{mils}(0.20 \mathrm{~mm})$ \\
\hline Typical Weight & $3.4 \mathrm{mg} / \mathrm{cm}^{2}$ \\
\hline Typical Air Flow Rate & $180 \mathrm{l} / \mathrm{min} / \mathrm{cm}^{2}$ at $10 \mathrm{psi}$ \\
\hline Maximum O perating Temperature - Air & $315.5^{\circ}$ Celsius $(600 \mathrm{~F})$ \\
\hline
\end{tabular}


Table 4: TX 40 filter properties [15].

\begin{tabular}{|l|l|}
\hline Filter Media & $\begin{array}{l}\text { Borosilicate microfibers reinforced with woven } \\
\text { glass cloth and bonded with PTFE. }\end{array}$ \\
\hline Typical Thickness & $7 \mathrm{mils}(0.17 \mathrm{~mm})$ \\
\hline Typical Weight & $5.0 \mathrm{mg} / \mathrm{cm}^{2}$ \\
\hline Typical Air Flow Rate & $68 \mathrm{l} / \mathrm{min} / \mathrm{cm}^{2}$ at $10 \mathrm{psi}$ \\
\hline Maximum O perating Temperature - Air & $260^{\circ}$ Celsius $(500 \mathrm{~F})$ \\
\hline
\end{tabular}

\subsection{Real Time Observations}

The use of the TEOM as a real-time tool was investigated through graphical analyses by comparison of other real-time analyzers and engine parameters such as $\mathrm{HC}, \mathrm{CO}, \mathrm{NO}$, and torque. Due to the unique response time of each instrument, it was necessary to time shift each emission individually. A Microsoft Visual Basic program was written to find an optimal time shift. The code for the program can be seen in Appendix B. The programs' design was inspired by Messer's [18] work at WVU. Messer proposed that emissions increase with power and that the correlation between the two will be at a maximum when emissions are shifted correctly. Correlating the entire length of the test compensates for exhaust flow rate variations and thus inconsistency in time shift. The correlation equation is as follows:

$$
\text { Correlation }_{x, y}=\frac{\frac{1}{n} \sum_{j=1}^{n}\left(x_{j}-\bar{x}_{j}\right)\left(y_{j}-\bar{y}\right)}{\sigma_{x} \sigma_{y}}
$$

Where, in equation 1, $\mathrm{x}$ and yare vectors of data. The numerator of equation 4 is the covariance, and the denominator is the product of the standard deviations. The yvector was moved in relation to $\mathrm{x}$ for every time shift and correlation values, the result from equation 4, were recorded. In an effort to account for engine and fuel variations, it was deemed necessary to simplify these data by normalizing each emission and engine parameter by dividing each real-time point by the respective test average value. 


\section{Data, Results, and Discussion}

\subsection{Temperature Effects}

\subsubsection{N avistar}

The general scope of this testing was to vary the temperature settings of the TEOM while keeping flow constant. There was no attempt to match the sample temperatures of the TEOM directly to the sample temperatures of the conventional PM filters. Two engines were used to evaluate the effect of temperature settings on the TEOM particulate sampler. The first tests were conducted on the Navistar engine. The engine was run through an FTP speed-load cycle to bring the engine and tunnel to operating temperature before data were taken. Twelve FTP speed-load cycles were run back to back with a nominal engine off time of 10 minutes between tests. Three FTP speed-load cycles were used for each TEOM sample tube temperature set point. The TEOM TE housing, external and internal sample tube temperature set points were $35^{\circ} \mathrm{C}, 40^{\circ} \mathrm{C}, 50^{\circ} \mathrm{C}$, and $60^{\circ} \mathrm{C}$. To remain consistent and identify new filter collection efficiency, a new TEOM filter was used at the start of every test set. It is conceded that new filters may pass some PM species before deposition increased capture efficiency. Only on this set of experiments was the initial test reported and included in calculations. The coefficient of variance (COV) of the conventional PM flow normalized data were $2.6 \%$, proving data viability. The COV for the average air temperature for the conventional PM sampling system was $3.3 \%$, proving the consistency of the sample temperatures.

For the first set of three tests, the TE housing, external and internal sample tube temperatures were set to $35^{\circ} \mathrm{C}$, resulting in a sample air temperature of $34^{\circ} \mathrm{C}$. A new TX 40 filter was installed in the TEOM before the test series began. The percent difference calculated in Table 5 was based on the deviation of the TEOM value from the conventional PM value. Figure 17 displays the TEOM to Conventional PM collection ratio.

Table 5: Results from the $35^{\circ} \mathrm{C}$ TEOM set point on the Navistar.

\begin{tabular}{|c|c|c|c|c|c|}
\hline $\begin{array}{c}\text { Test } \\
\text { Number }\end{array}$ & $\begin{array}{c}\text { Conventional } \\
\text { PM Average Air } \\
\text { Temperature } \\
\left({ }^{\circ} \mathrm{C}\right)\end{array}$ & $\begin{array}{c}\text { TEOM Average } \\
\text { Air Temperature } \\
\left({ }^{\circ} \mathrm{C}\right)\end{array}$ & $\begin{array}{c}\text { Conventional PM } \\
\text { Concentration } \\
\left(\mathrm{mg} / \mathrm{m}^{3}\right)\end{array}$ & $\begin{array}{c}\text { TEOM } \\
\text { Concentration } \\
\left(\mathrm{mg} / \mathrm{m}^{3}\right)\end{array}$ & $\begin{array}{c}\text { Percent } \\
\text { Difference } \\
\text { from } \\
\text { Conventional }\end{array}$ \\
\hline 1 & 36 & 34 & 1.16 & 0.90 & $22.41 \%$ \\
\hline 2 & 38 & 34 & 1.16 & 1.06 & $9.06 \%$ \\
\hline 3 & 39 & 34 & 1.19 & 1.16 & $2.89 \%$ \\
\hline
\end{tabular}




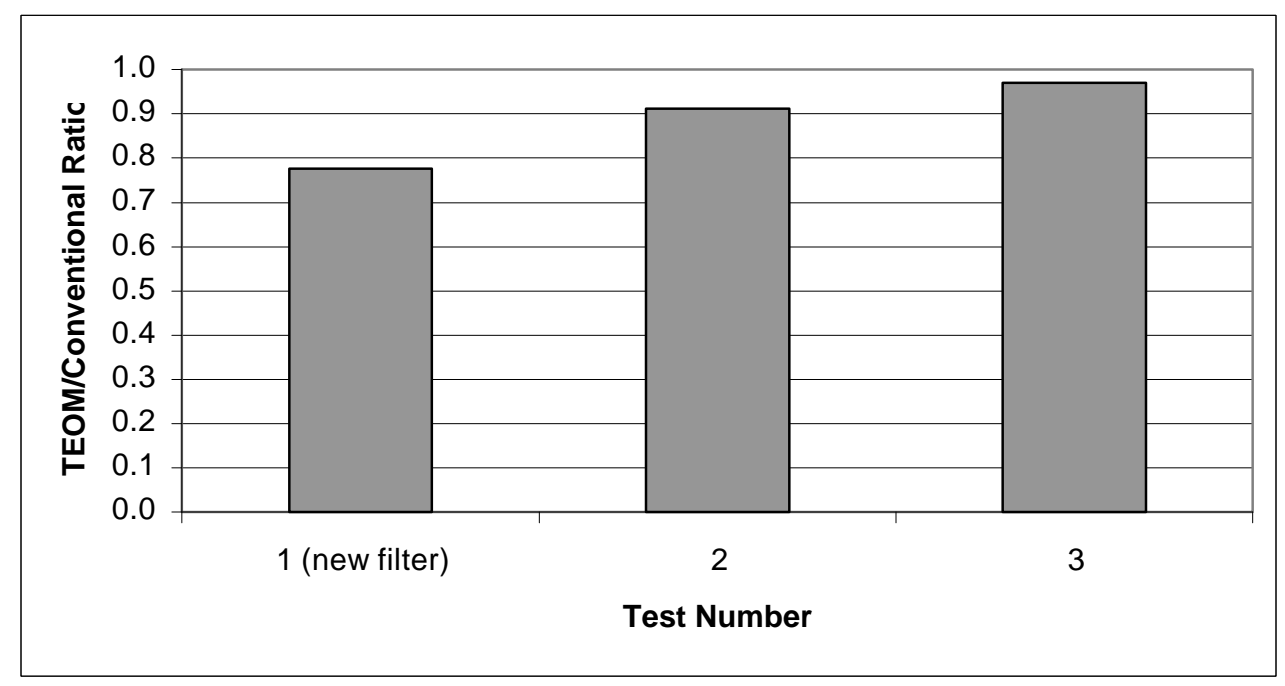

Figure 17: TEOM/ conventional PM ratio for the $35^{\circ} \mathrm{C}$ TEOM set point on a Navistar 7.3 liter diesel. The improvement in filter efficiency was evident as the test sequence proceeds due to PM loading.

The first test in this set displays the poor collection efficiency relative to the conventional PM filters. The conventional PM filter system utilizes a two stage filter system, where as the TEOM only uses a single stage. For the second set of FTP tests, the TEOM temperatures were set to $40^{\circ} \mathrm{C}$, resulting in a sample air temperature of $38^{\circ} \mathrm{C}$. A new TX 40 filter was installed in the TEOM before the test series began. Results from this test set are shown in table 6. Figure 18 shows a bar graph of the TEOM to Conventional PN collection ratio.

Table 6: Results from the $40^{\circ} \mathrm{C}$ TEOM set point on a Navistar 7.3 liter diesel engine.

\begin{tabular}{|c|c|c|c|c|c|}
\hline $\begin{array}{c}\text { Test } \\
\text { Number }\end{array}$ & $\begin{array}{c}\text { Conventional } \\
\text { PM Average Air } \\
\text { Temperature } \\
\left({ }^{\circ} \mathrm{C}\right)\end{array}$ & $\begin{array}{c}\text { TEOM Average } \\
\text { Air Temperature } \\
\left({ }^{\circ} \mathrm{C}\right)\end{array}$ & $\begin{array}{c}\text { Conventional PM } \\
\text { Concentration } \\
\left(\mathrm{mg} / \mathrm{m}^{3}\right)\end{array}$ & $\begin{array}{c}\text { TEOM } \\
\text { Concentration } \\
\left(\mathrm{mg} / \mathrm{m}^{3}\right)\end{array}$ & $\begin{array}{c}\text { Percent } \\
\text { Difference } \\
\text { from } \\
\text { Conventional }\end{array}$ \\
\hline 4 & 38 & 39 & 1.21 & 0.83 & $32.0 \%$ \\
\hline 5 & 39 & 39 & 1.20 & 0.95 & $20.8 \%$ \\
\hline 6 & 40 & 39 & 1.21 & 1.03 & $14.4 \%$ \\
\hline
\end{tabular}




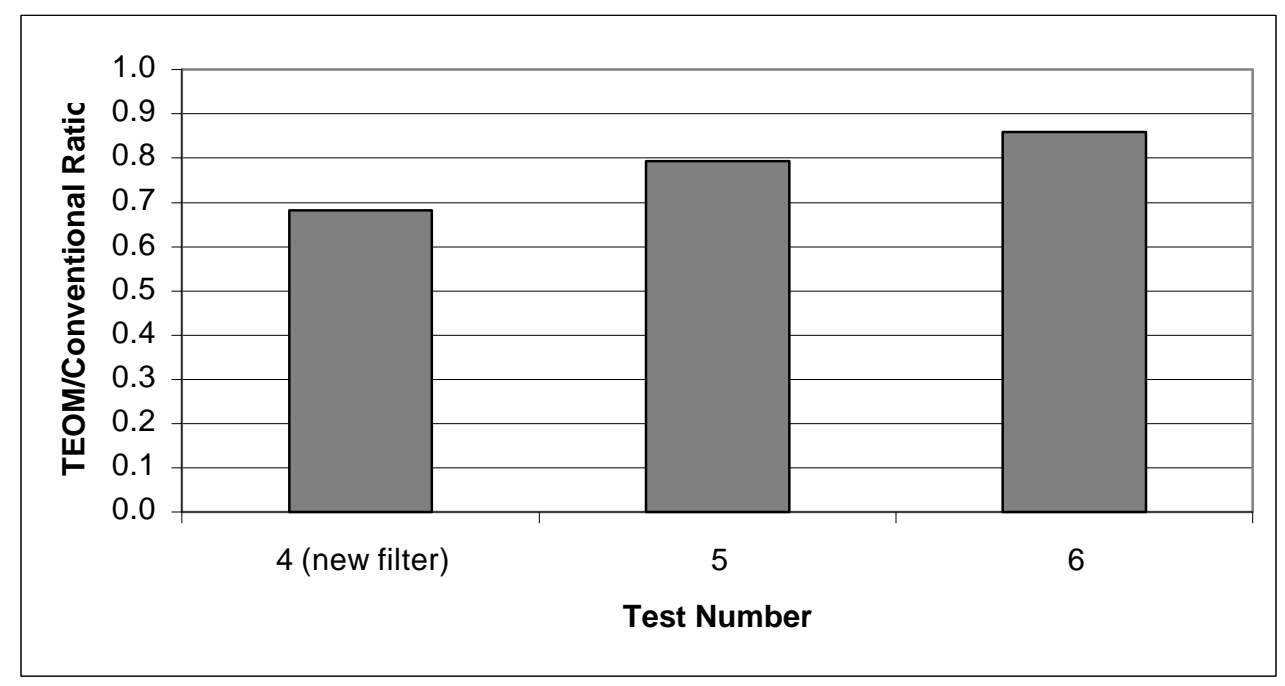

Figure 18: TEOM/ conventional PM ratio for the $40^{\circ} \mathrm{C}$ TEOM set point on a Navistar 7.3 liter diesel. The improvement in filter efficiency was repeats as the test sequence proceeded due to PM loading.

Again, the relative initial inefficiency of the TEOM filter was apparent in the first test of this set. The rise in TEOM sampling temperature caused an increase in the average error from $11.45 \%$ to $22.40 \%$. The error increase could possibly be due to the lack of moisture and VOC collecting on the TEOM filter due to the increase in temperature. For the third set of FTP tests, the TEOM temperatures were set to $50^{\circ} \mathrm{C}$, resulting in a sample air temperature of $48^{\circ} \mathrm{C}$. A new TX 40 filter was installed in the TEOM before the test series began. Results for the third set are catalogued in table 7. TEOM to Conventional PM collection ratios are shown in figure 19.

Table 7: Results from the $50^{\circ} \mathrm{C}$ TEOM set point on a Navistar 7.3 liter diesel engine.

\begin{tabular}{|c|c|c|c|c|c|}
\hline $\begin{array}{c}\text { Test } \\
\text { Number }\end{array}$ & $\begin{array}{c}\text { Conventional } \\
\text { PM Average Air } \\
\text { Temperature } \\
\left({ }^{\circ} \mathrm{C}\right)\end{array}$ & $\begin{array}{c}\text { TEOM Average } \\
\text { Air } \\
\text { Temperature } \\
\left({ }^{\circ} \mathrm{C}\right)\end{array}$ & $\begin{array}{c}\text { Conventional PM } \\
\text { Concentration } \\
\left(\mathrm{mg} / \mathrm{m}^{3}\right)\end{array}$ & $\begin{array}{c}\text { TEOM } \\
\text { Concentration } \\
\left(\mathrm{mg} / \mathrm{m}^{3}\right)\end{array}$ & $\begin{array}{c}\text { Percent } \\
\text { Difference } \\
\text { from } \\
\text { Conventional }\end{array}$ \\
\hline 7 & 37 & 47 & 1.27 & 0.69 & $46.0 \%$ \\
\hline 8 & 39 & 48 & 1.20 & 0.98 & $18.0 \%$ \\
\hline 9 & 38 & 48 & 1.21 & 0.98 & $19.1 \%$ \\
\hline
\end{tabular}




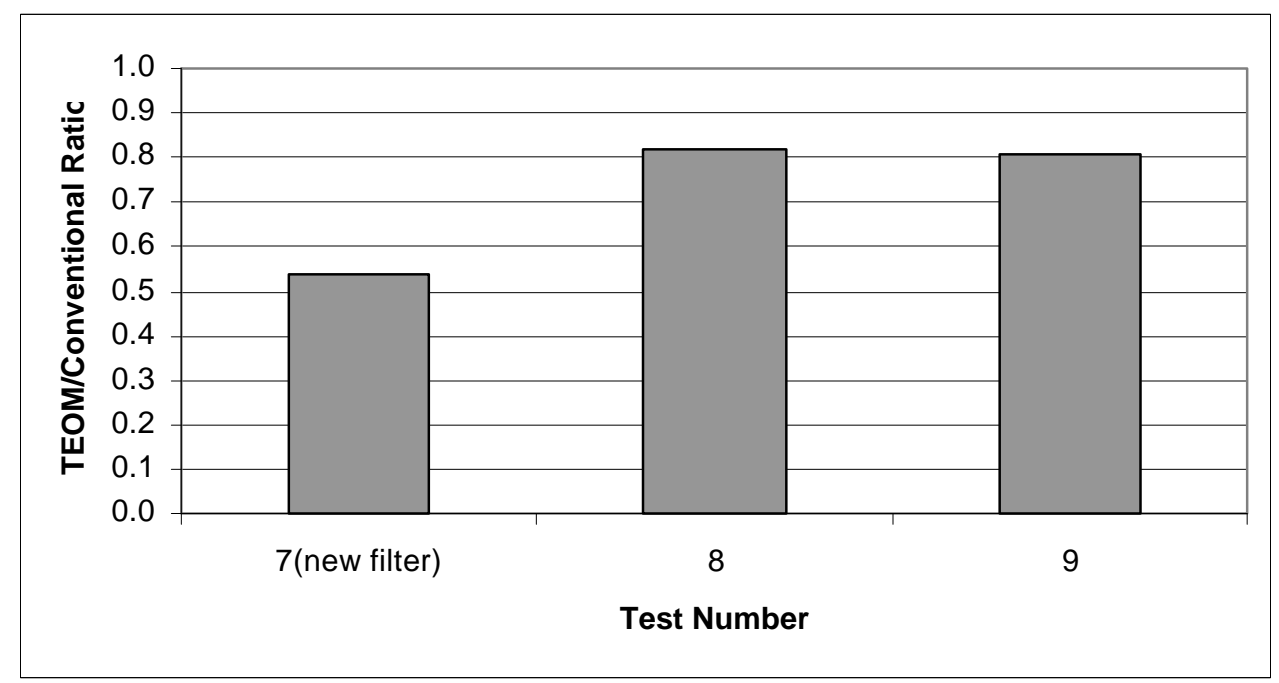

Figure 19: TEOM/ conventional PM ratio for the $50^{\circ} \mathrm{C}$ TEOM set point on a Navistar 7.3 liter diesel. The TEOM continues to deviate from conventional PM filters as temperature increased.

As expected, the first test in the series had a significantly higher error than the other two tests. The rise in TEOM sampling temperature caused an increase in the average error from $22.40 \%$ to $27.70 \%$. The forth and final set of three tests, the TEOM temperatures were set to $60^{\circ} \mathrm{C}$, resulting in a sample air temperature of $56^{\circ} \mathrm{C}$. A new TX 40 filter was installed in the TEOM before the test series began. Table 8 displays data captured from this set, while the TEOM to Conventional PM collection ratio is displayed in figure 20 .

Table 8: Results from the $60^{\circ} \mathrm{C}$ TEOM set point on a Navistar 7.3 liter diesel engine.

\begin{tabular}{|c|c|c|c|c|c|}
\hline $\begin{array}{c}\text { Test } \\
\text { Number }\end{array}$ & $\begin{array}{c}\text { Conventional PM } \\
\text { Average Air } \\
\text { Temperature }\left({ }^{\circ} \mathrm{C}\right)\end{array}$ & $\begin{array}{c}\text { TEOM Average } \\
\text { Air } \\
\text { Temperature } \\
\left({ }^{\circ} \mathrm{C}\right)\end{array}$ & $\begin{array}{c}\text { Conventional PM } \\
\text { Concentration } \\
\left(\mathrm{mg} / \mathrm{m}^{3}\right)\end{array}$ & $\begin{array}{c}\text { TEOM } \\
\text { Concentration } \\
\left(\mathrm{mg} / \mathrm{m}^{3}\right)\end{array}$ & $\begin{array}{c}\text { Percent } \\
\text { Difference } \\
\text { from } \\
\text { Conventional }\end{array}$ \\
\hline 10 & 36 & 56 & 1.24 & 0.11 & $91.3 \%$ \\
\hline 11 & 38 & 56 & 1.23 & 0.77 & $37.3 \%$ \\
\hline 12 & 39 & 56 & 1.22 & 0.96 & $21.4 \%$ \\
\hline
\end{tabular}




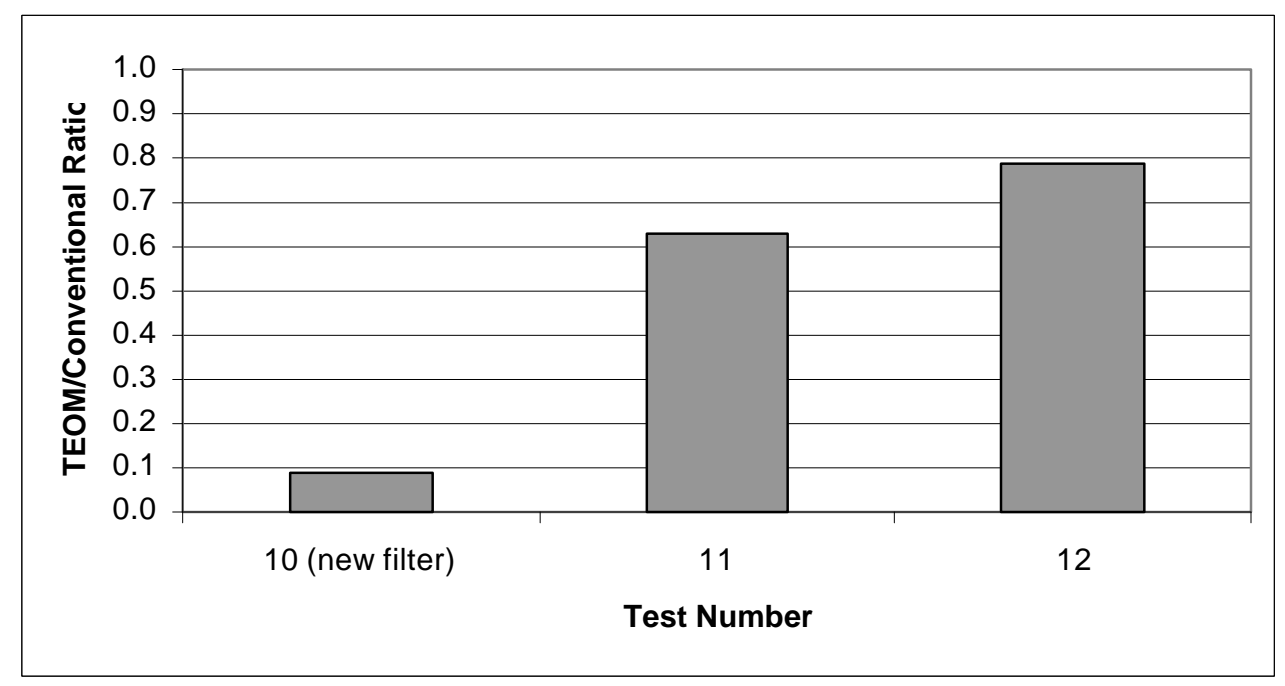

Figure 20: TEOM/ conventional PM ratio for the $60^{\circ} \mathrm{C}$ TEOM set point on a Navistar 7.3 liter diesel.

The average error continued to increase with temperature, from the previous test sequence average value of $27.70 \%$ to $49.97 \%$. A trend in initial collection efficiency becomes apparent. As the temperature increased, the error, or percent difference from conventional, associated with the initial collection increased rapidly, looking as if it were following an exponential trend as shown in figure 21.

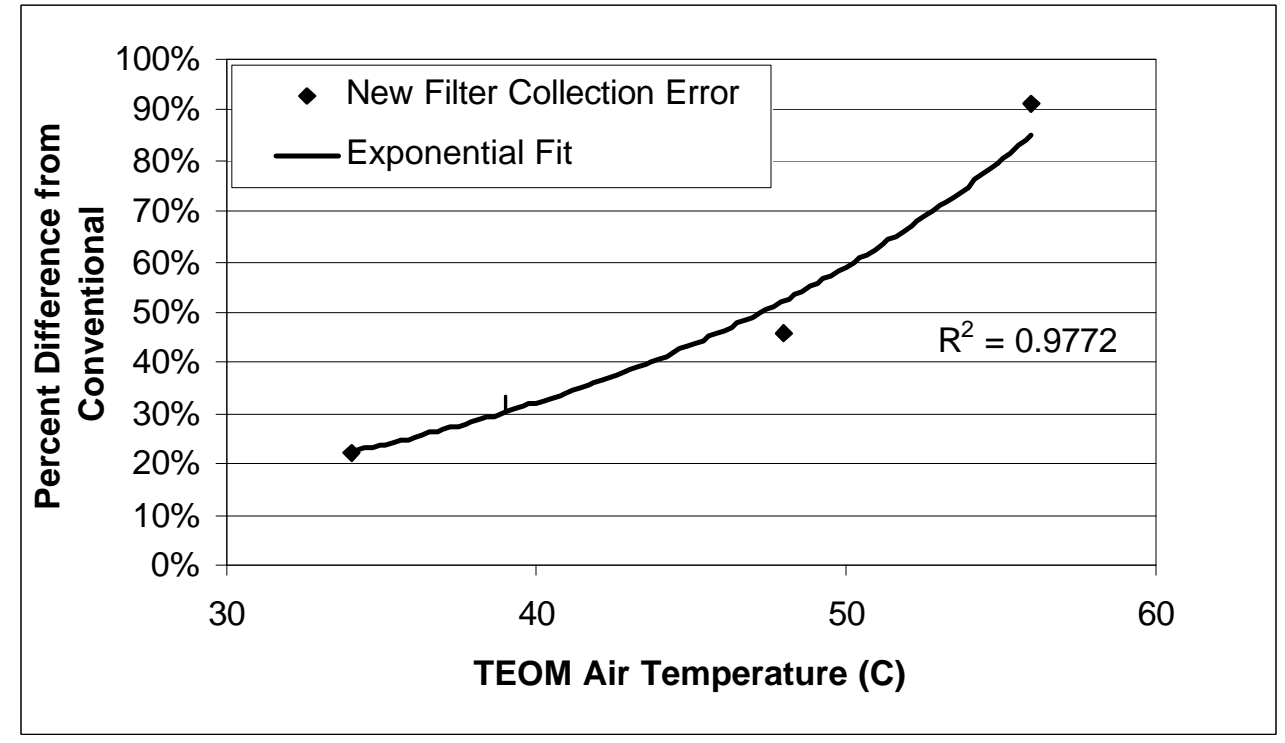

Figure 21: New filter collection error increased as TEOM air temperature increased with an apparent expontial relationship.

This exponential trend shows the true collection characteristics of the filter. The second and third tests in each series may not show this trend due to the ability of the moisture and VOC being absorbed readily into the PM present on a soiled filter. On average, the first filter captured $40 \%$ less 
than the third filter. A filter cartridge that housed two filters would improve the initial collection efficiency. The $99 \%$ confidence of the conventional PM concentration over the 12 sample set was \pm $2.3 \%$, or $1.21 \pm 0.028 \mathrm{mg} / \mathrm{m}^{3}$. Assuming that the variation in TEOM sampling temperature was negligible in the confidence value, the $99 \%$ confidence of the TEOM concentration over the 12 sample set was $\pm 28.0 \%$, or $0.868 \pm 0.243 \mathrm{mg} / \mathrm{m}^{3}$.

\subsubsection{Cummins}

The second set of tests was conducted on the Cummins 10.8 liter DI diesel engine. The engine was run through an FTP cycle to bring the engine and tunnel to operating temperature before data were taken. Nine FTP speed-load cycles were run back to back with a nominal heat soak time of 10 minutes between tests. When the TEOM filter was changed, an FTP was run to condition the filter in an attempt to minimize the filter capture efficiency variability. These conditioning FTPs were not included in the analysis of the data. However, even the second test on a new TEOM filter will show effects of efficiency changes. Three FTP speed load cycles were run for each TEOM temperature. These set points were $30^{\circ} \mathrm{C}, 40^{\circ} \mathrm{C}$, and $50^{\circ} \mathrm{C}$. The COV\% of the conventional PM flow normalized data was $1.3 \%$, proving data viability. The COV\% for the average air temperature for the conventional PM sampling system was $4.1 \%$, proving the consistency of the sample temperatures. The average relative humidity of the ambient air for the duration of the test series was $25 \%$.

For the first set of FTP tests, the TEOM temperatures were set to $30^{\circ} \mathrm{C}$, resulting in a sample air temperature of $30^{\circ} \mathrm{C}$. D ata is tabulated in table 9. Figure 22 is a bar chart showing the TEOM to Conventional PM collection ratio for each run.

Table 9: Results from the $30^{\circ} \mathrm{C}$ TEOM set point on a Cummins 10.8 liter diesel engine.

\begin{tabular}{|c|c|c|c|c|c|}
\hline $\begin{array}{c}\text { Test } \\
\text { Number }\end{array}$ & $\begin{array}{c}\text { Conventional } \\
\text { PM Average Air } \\
\text { Temperature } \\
\left({ }^{\circ} \mathrm{C}\right)\end{array}$ & $\begin{array}{c}\text { TEOM Average } \\
\text { Air Temperature } \\
\left({ }^{\circ} \mathrm{C}\right)\end{array}$ & $\begin{array}{c}\text { Conventional PM } \\
\text { Concentration } \\
\left(\mathrm{mg} / \mathrm{m}^{3}\right)\end{array}$ & $\begin{array}{c}\text { TEOM } \\
\text { Concentration } \\
\left(\mathrm{mg} / \mathrm{m}^{3}\right)\end{array}$ & $\begin{array}{c}\text { Percent } \\
\text { Difference } \\
\text { From } \\
\text { Conventional }\end{array}$ \\
\hline 1 & 38 & 30 & 1.24 & 1.11 & $10.6 \%$ \\
\hline 2 & 39 & 30 & 1.24 & 1.14 & $8.3 \%$ \\
\hline 3 & 39 & 30 & 1.26 & 1.14 & $9.2 \%$ \\
\hline
\end{tabular}




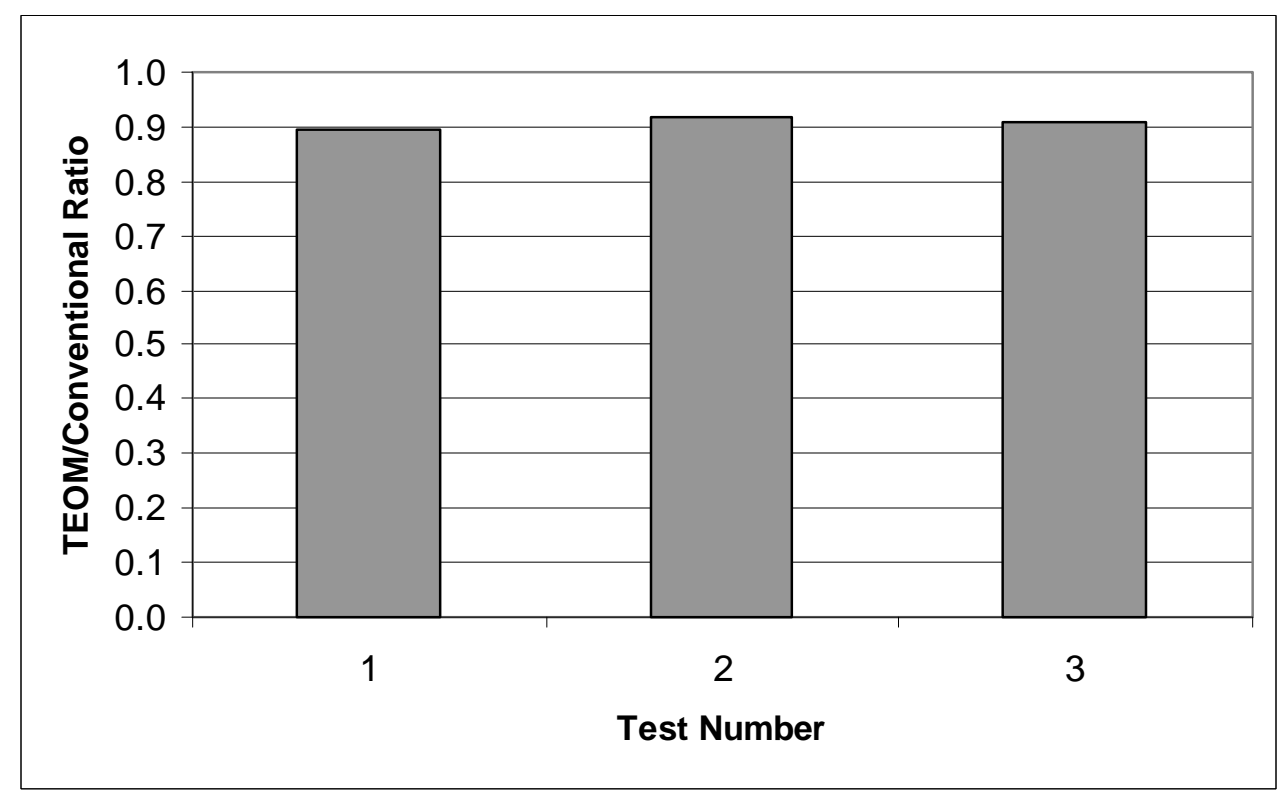

Figure 22: TEOM/ conventional PM ratio for the $30^{\circ} \mathrm{C}$ TEOM set point on a Cummins 10.8 liter diesel engine. A test cycle was performed prior to test 1 shown above. This provided and increased consistency (COV\% of $1.28 \%$ ) during this test series.

The TEOM gives repeatable results with a preconditioned filter. The Cummins $30^{\circ} \mathrm{C}$ results were not as close as the Navistar $35^{\circ} \mathrm{C}$ results. However, for the Cummins tests, there was almost a $10^{\circ} \mathrm{C}$ difference between TEOM and conventional PM temperatures. For the Navistar tests, the difference between TEOM and conventional PM temperatures was only $4^{\circ} \mathrm{C}$. It was the experience of the author as the TEOM sample temperature reached the temperatures of the conventional sample, the difference between TEOM and conventional PM decreased. For the second set of FTP tests, the TEOM temperatures were set to $40^{\circ} \mathrm{C}$, resulting in a sample air temperature of $39^{\circ} \mathrm{C}$. The following table (10) and chart (figure 23) display data from these tests.

Table 10: Results from the $40^{\circ} \mathrm{C}$ TEOM set point on a Cummins 10.8 liter diesel.

\begin{tabular}{|c|c|c|c|c|c|}
\hline $\begin{array}{c}\text { Test } \\
\text { Number }\end{array}$ & $\begin{array}{c}\text { Conventional PM } \\
\text { Average Air } \\
\text { Temperature }\left({ }^{\circ} \mathrm{C}\right)\end{array}$ & $\begin{array}{c}\text { TEOM Average } \\
\text { Air Temperature } \\
\left({ }^{\circ} \mathrm{C}\right)\end{array}$ & $\begin{array}{c}\text { Conventional PM } \\
\text { Concentration } \\
\left(\mathrm{mg} / \mathrm{m}^{3}\right)\end{array}$ & $\begin{array}{c}\text { TEOM } \\
\text { Concentration } \\
\left(\mathrm{mg} / \mathrm{m}^{3}\right)\end{array}$ & $\begin{array}{c}\text { Percent } \\
\text { Difference } \\
\text { From } \\
\text { Conventional }\end{array}$ \\
\hline 4 & 39 & 39 & 1.22 & 1.11 & $8.4 \%$ \\
\hline 5 & 35 & 39 & 1.20 & 1.10 & $8.6 \%$ \\
\hline 6 & 36 & 40 & 1.24 & 1.13 & $8.3 \%$ \\
\hline
\end{tabular}




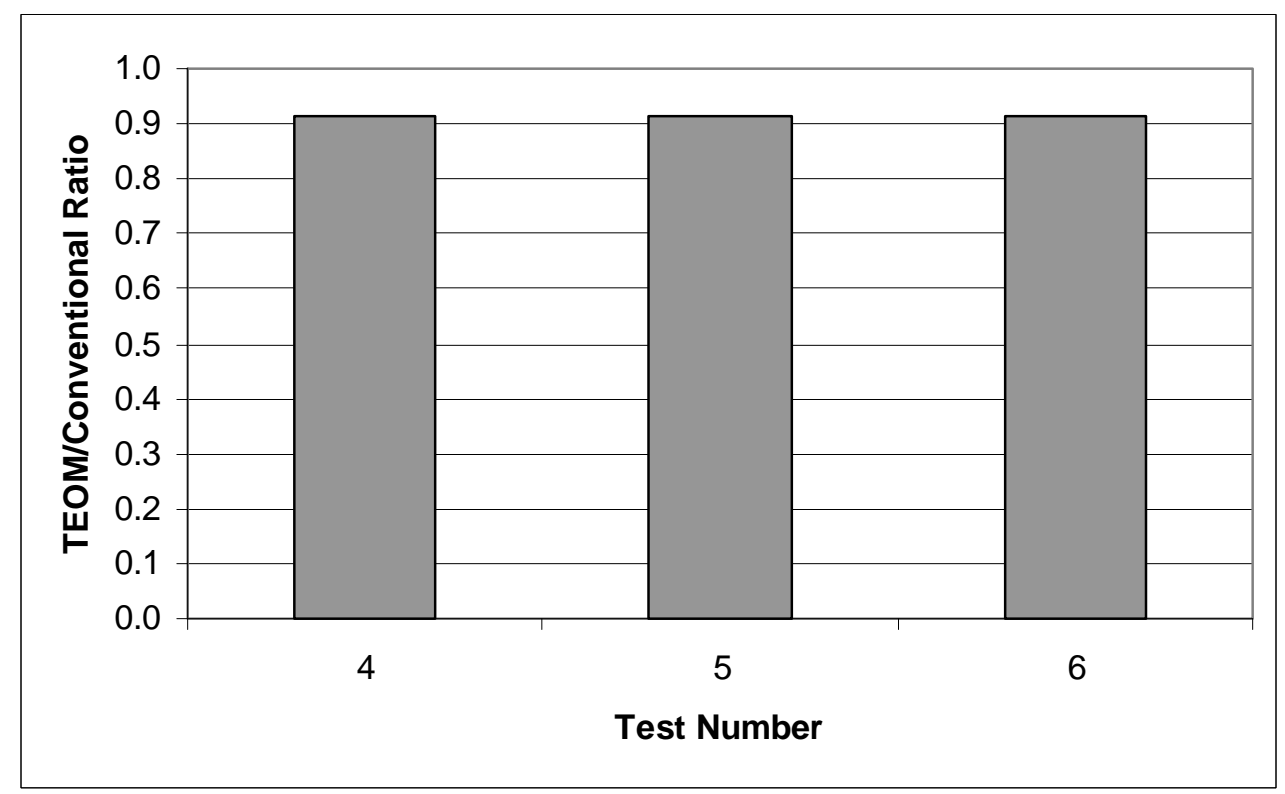

Figure 23: TEOM/ conventional PM ratio for the $40^{\circ} \mathrm{C}$ TEOM set point on a Cummins 10.8 liter diesel engine. This series proved to be a very consistent set of tests, COV\% of the ratio was $0.15 \%$.

The final set of tests was taken at a sample path temperature of $50^{\circ} \mathrm{C}$, resulting in a PM sample temperature of $48^{\circ} \mathrm{C}$. A test was run on a new filter for conditioning purposes. The difference between convention and TEOM measurement increased from an average percent difference of 8.43\% to an average percent difference of $20.53 \%$ respectively. In addition, test variability increased. The TEOM COV at $40^{\circ} \mathrm{C}$ was $0.2 \%$ while TEOM COV at $50^{\circ} \mathrm{C}$ was $5.2 \%$. Conventional PM measurement $\mathrm{COV}$ remained stable between the two test batteries, ruling out engine variability. Table 11 and figure 24 reflect the results for these $50^{\circ} \mathrm{C}$ tests. Figure 25 shows all the percent difference values for the Cummins temperature testing to reflect the increase at $50^{\circ} \mathrm{C}$. 
Table 11: Results from the $50^{\circ} \mathrm{C}$ TEOM set point on a Cummins

10.8 liter diesel engine.

\begin{tabular}{|c|c|c|c|c|c|}
\hline $\begin{array}{c}\text { Test } \\
\text { Number }\end{array}$ & $\begin{array}{c}\text { Conventional } \\
\text { PM Average Air } \\
\text { Temperature } \\
\left({ }^{\circ} \mathrm{C}\right)\end{array}$ & $\begin{array}{c}\text { TEOM Average } \\
\text { Air Temperature } \\
\left({ }^{\circ} \mathrm{C}\right)\end{array}$ & $\begin{array}{c}\text { Conventional PM } \\
\text { Concentration } \\
\left(\mathrm{mg} / \mathrm{m}^{3}\right)\end{array}$ & $\begin{array}{c}\text { TEOM } \\
\text { Concentration } \\
\left(\mathrm{mg} / \mathrm{m}^{3}\right)\end{array}$ & $\begin{array}{c}\text { Percent } \\
\text { Difference } \\
\text { From } \\
\text { Conventional }\end{array}$ \\
\hline 7 & 36 & 48 & 1.25 & 0.94 & $25.3 \%$ \\
\hline 8 & 39 & 48 & 1.24 & 1.01 & $18.3 \%$ \\
\hline 9 & 39 & 48 & 1.24 & 1.02 & $18.1 \%$ \\
\hline
\end{tabular}

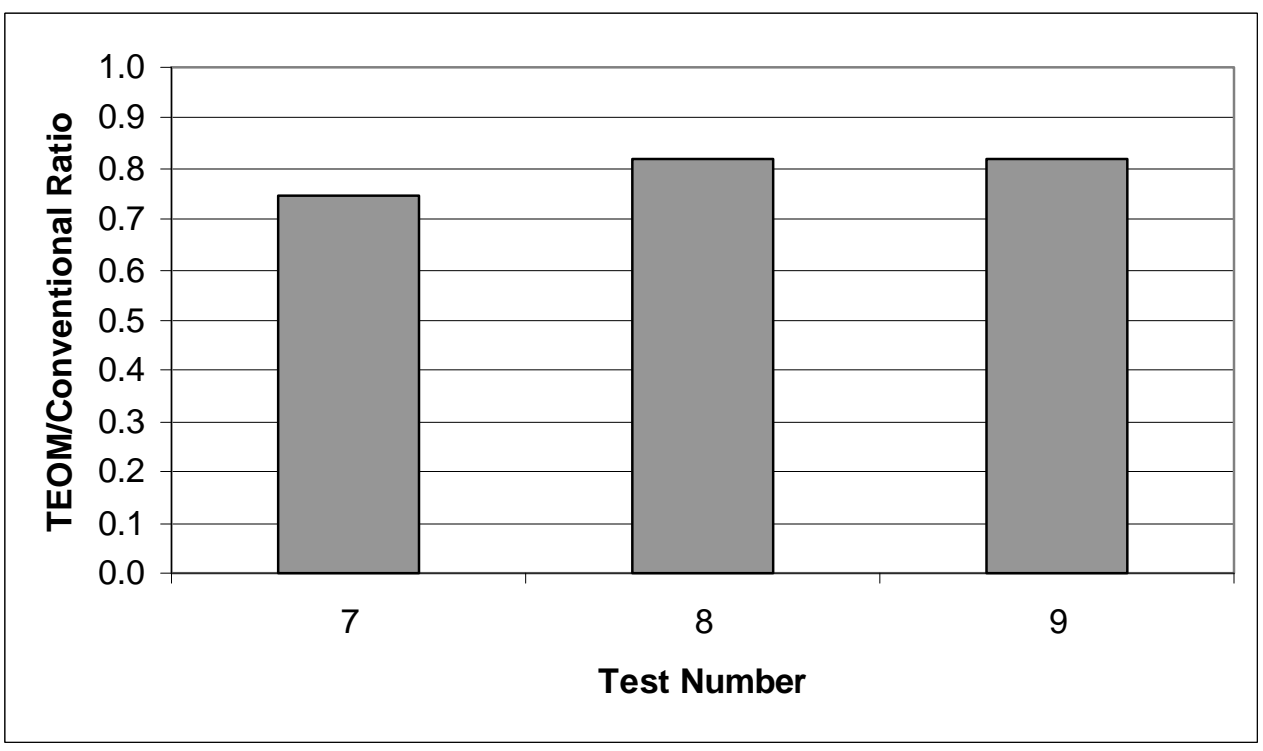

Figure 24: TEOM/ conventional PM ratio for the $50^{\circ} \mathrm{C}$ TEOM set point on a Cummins 10.8 liter diesel engine. As with the temperature test on the Navistar engine, a $50^{\circ} \mathrm{C}$ sampling temperature yielded a decrease in the TEOM/ conventional PM ratio. 


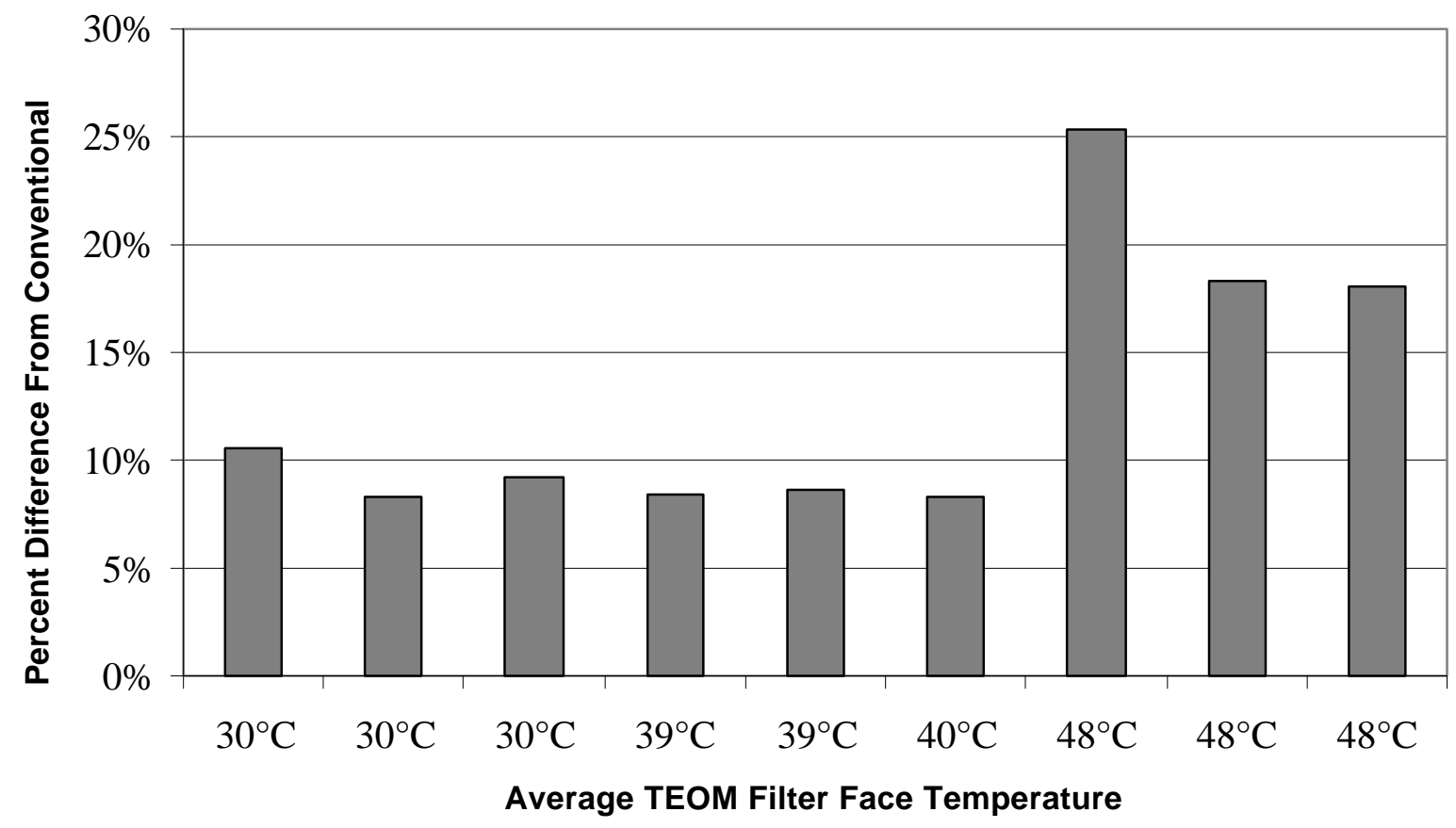

Figure 25: Error data for varying TEOM sample tube temperatures. The greatest error occurred at $50^{\circ} \mathrm{C}$.

For the Navistar, the best measured TEOM to conventional PM agreement sampling temperature was $35^{\circ} \mathrm{C}$. This was also the closest applied TEOM temperature to the conventional PM temperature. This trend continues in the Cummins data. For the best agreement with conventional PM results, the TEOM temperature set point was close to the conventional PM filter temperature. This ideal temperature can be adjusted in the test rig by varying the dilution ratio of the dilution tunel (see section 3.1.1.2).

Temperature also affects real-time TEOM data. The Cummins data were chosen to evaluate real-time results due to the consistent trend of the data. Tests 2, 6 and 9 were chosen to represent 30 ${ }^{\circ} \mathrm{C}, 40{ }^{\circ} \mathrm{C}$ and $50{ }^{\circ} \mathrm{C}$ set points on least error criteria. FTP data shows that as TEOM temperature increased, amplitude of the response decreased, both positive and negative. Figure 26 shows a section of the FTP cycle to illistrate this trend. However, as TEOM temperature increased, the ratio of the total positive mass collected to negative mass collected increased, as shown in table 12 . The $50{ }^{\circ} \mathrm{C}$ set point yielded the least collection of negative mass per positive mass collection. The $50^{\circ} \mathrm{C}$ set point also yielded a $11 \%$ lower total collection, whereas the $30{ }^{\circ} \mathrm{C}$ and $40{ }^{\circ} \mathrm{C}$ set points yielded total collection mass less than $1 \%$ from each other. Figure 27 illustrates this real-time total collection data. 


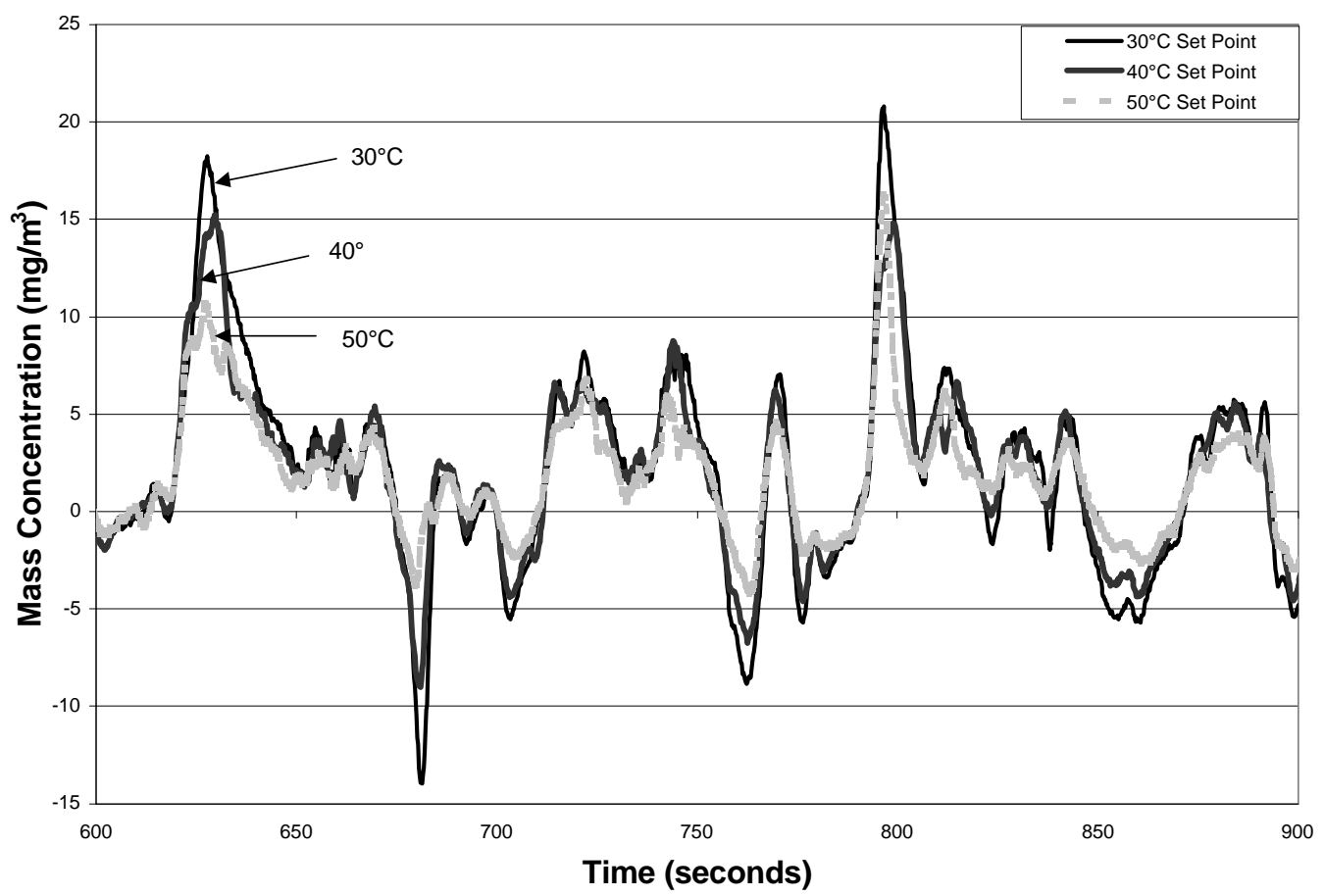

Figure 26: A section of the FTP illustrating that increased temperature decreased TEO M real-time data amplitude.

Table 12: Real-time positive/ negative collection evaluation for varying air temperature.

\begin{tabular}{|c|c|c|c|}
\hline TEO M Temperature Set Point & $30^{\circ} \mathrm{C}$ & $40^{\circ} \mathrm{C}$ & $50^{\circ} \mathrm{C}$ \\
\hline Positive Collected Mass (micrograms) & 120.83 & 107.96 & 85.43 \\
\hline Negative Collected Mass (micrograms) & 49.61 & 38.47 & 23.48 \\
\hline Positive/ Negative Ratio & 2.44 & 2.81 & 3.64 \\
\hline
\end{tabular}




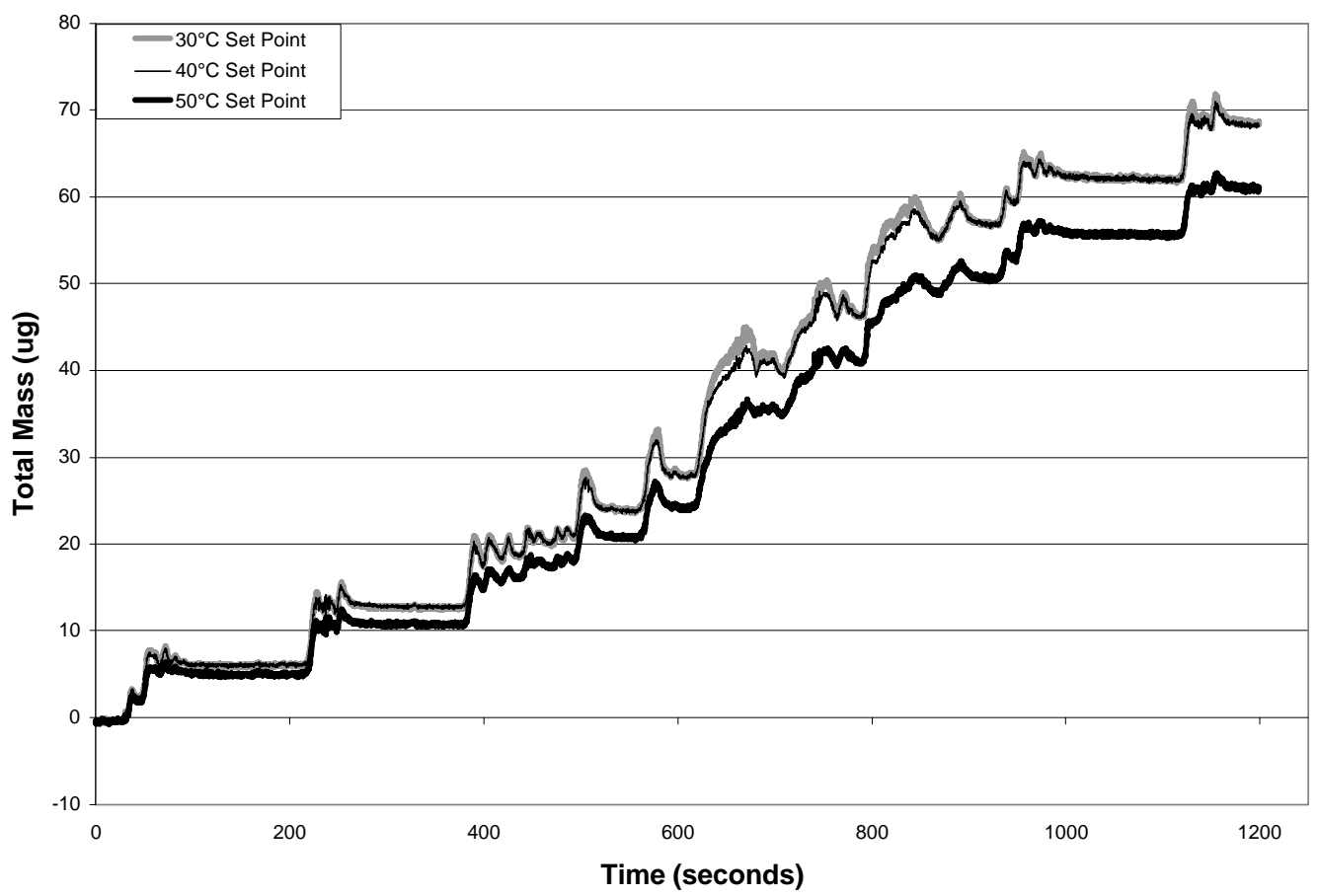

Figure 27: TEOM sampling temperature effects on total mass. The $50{ }^{\circ} \mathrm{C}$ set point yielded an undercollection compared to the other two set points.

To illustrate the repeatability of the data, figures 28 and 29 display mass rate and total mass respectivally for two sequential tests at the same TEOM temperature and flow set points. The sequential experiments graphed were tests 2 and 3 from the Cummins temperature study. Note that both real-time mass rate and total mass traces follow closely to each other. The real-time mass rate traces do deviate as could be expected due to variations in engine output from test to test. 


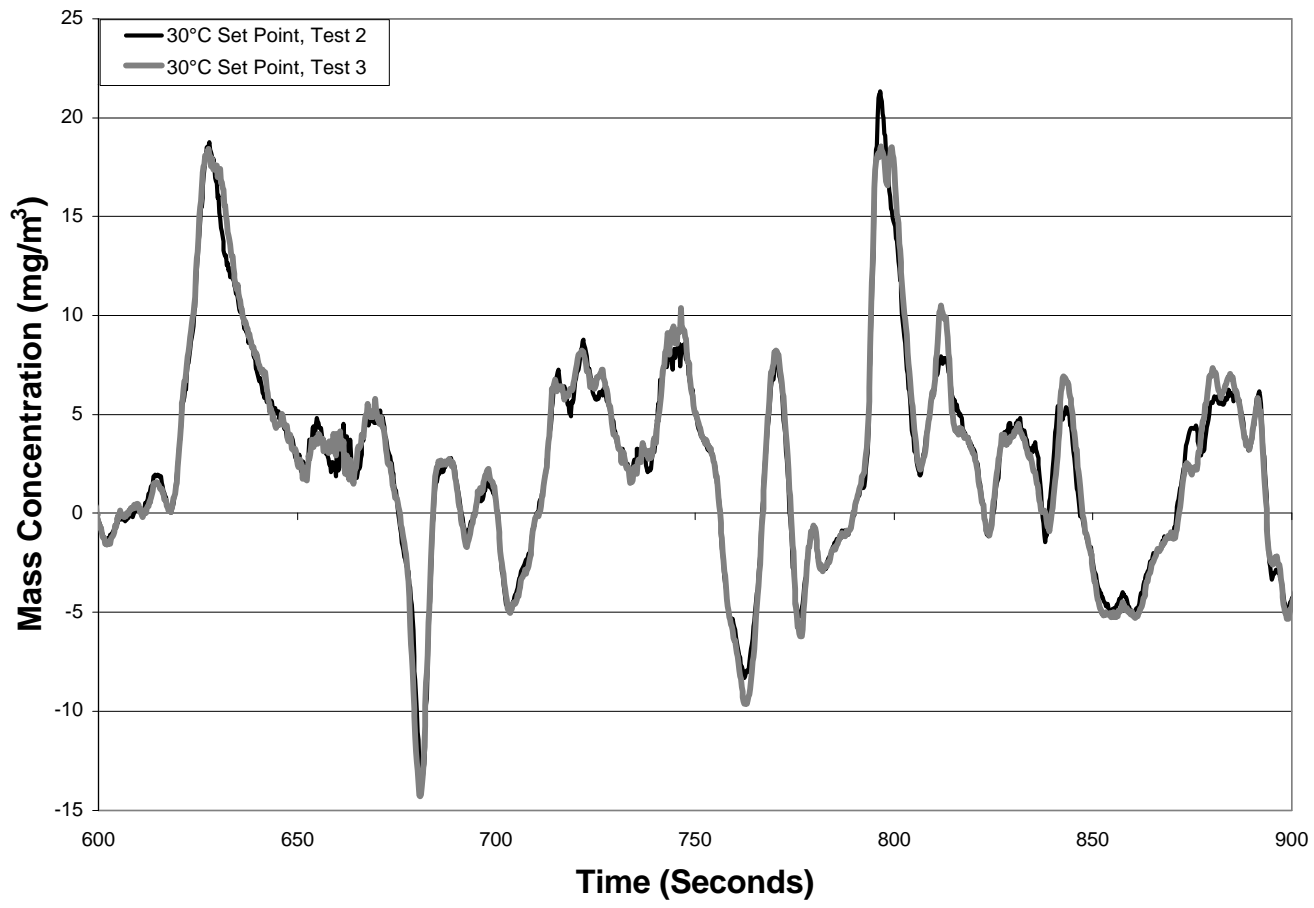

Figure 28: A section of the FTP illustrating the repeatability of the real-time results. The deviation of the two traces could be from variation of engine output.

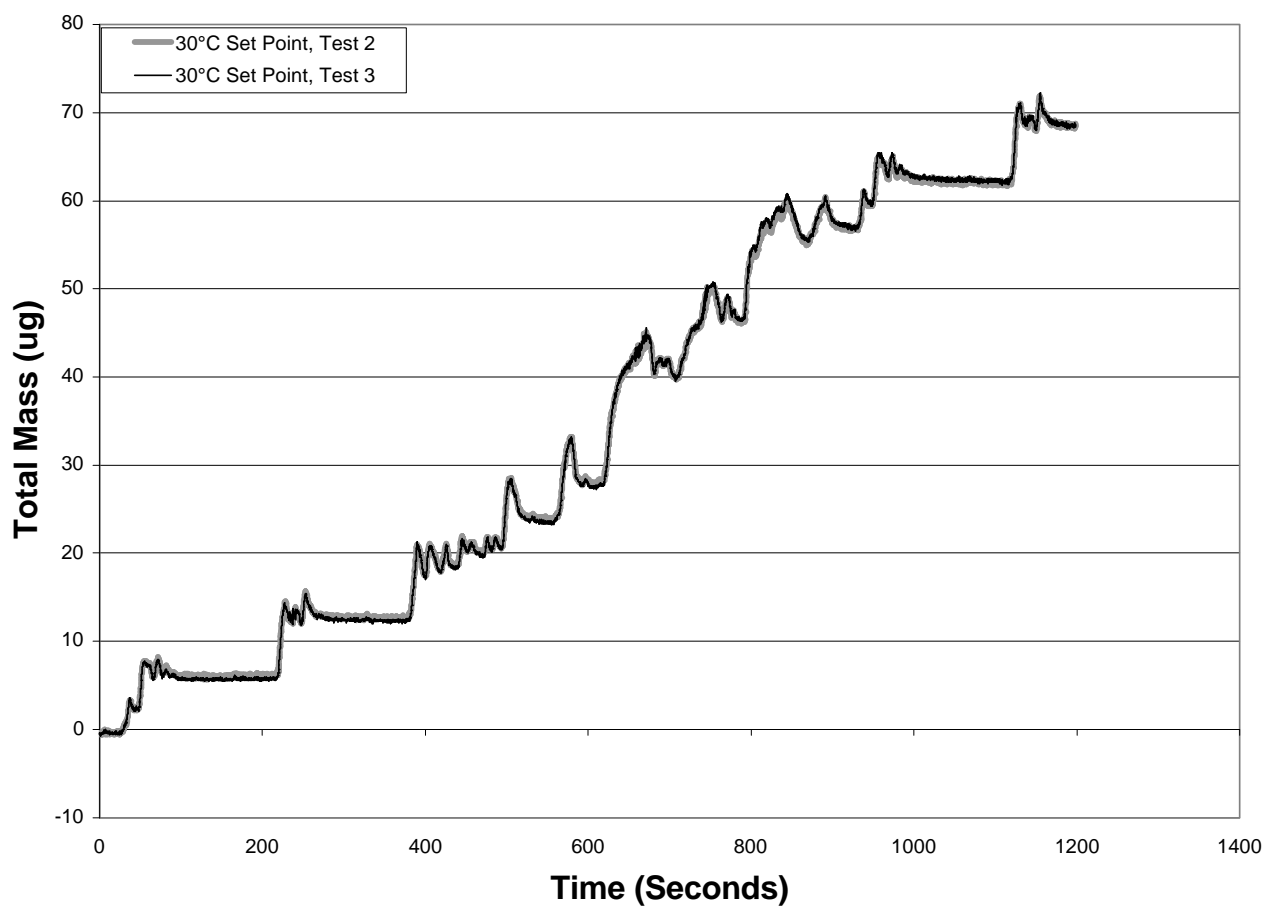

Figure 29: The accumulated mass as measured by the TEOM, illustrating test to test repeatability. 
In closing, due to the better conventional PM agreement and medium positive/ negative collection ratio, the $40^{\circ} \mathrm{C}$ set point was chosen to perform the flow effects investigation described in the next section.

\subsection{Flow Effects}

Using the $40^{\circ} \mathrm{C}$ set point, flow was varied from 1 to $4 \mathrm{lpm}$. The EPA range for filter face flux is 0.792 liters per $\mathrm{cm}^{2}$-minute to 2.638 liters per $\mathrm{cm}^{2}$-minute. The TEOM effective filter face was approximately $1.23 \mathrm{~cm}$ in diameter, giving an EPA allowable TEOM sample rate of $0.97 \mathrm{lpm}$ to 3.24 lpm. The conventional PM filter system had an effective filter face diameter of $6.2 \mathrm{~cm}$. All conventional PM samples were taken at approximately five SCFM, or 141 lpm, yielding 4.69 liters per $\mathrm{cm}^{2}$-minute. Sampling at four lpm is outside of the EPA allowable range, however investigation could yield interesting results. The tests were conducted on the Cummins 10.8 liter DI diesel engine. The use of this engine was mandatory due to the precedence of other engine programs at the EERC. The engine was operated through a FTP cycle to bring the engine and tunnel to operating temperature before data were taken. Eight FTP cycles were run back to back with a nominal engine off time of 10 minutes between tests. When the TEOM filter was changed, an FTP was run to condition the filter in an attempt to eliminate the variable of filter efficiency. These conditioning FTPs were not included in the analysis of the data. However, sampling at $4 \mathrm{lpm}$ caused a filter loading high enough to restrict multiple tests per TEOM filter, so a new filter was used for each test. The COV\% for the eight tests of conventional PM flow normalized data was 3.2\%, proving data viability. The average relative humidity of the ambient air for the duration of the test series was $25 \%$. Table 13 and figure 30 show data results for the flow tests. As a general trend, as flow increased, so did the percent difference. Although the exception is at $2 \mathrm{lpm}$, where there was not as a significant increase.

Table 13: Error variation with TEOM sample flow rate.

\begin{tabular}{|c|c|c|c|c|}
\hline Test \# & $\begin{array}{c}\text { TEOM Sample } \\
\text { Flow Rate (lpm) }\end{array}$ & $\begin{array}{c}\text { Conventional PM } \\
\text { Concentration } \\
\left(\mathrm{mg} / \mathrm{m}^{3}\right)\end{array}$ & $\begin{array}{c}\text { TEOM } \\
\text { Concentration } \\
\left(\mathrm{mg} / \mathrm{m}^{3}\right)\end{array}$ & $\begin{array}{c}\text { Percent } \\
\text { Difference } \\
\text { From } \\
\text { Conventional }\end{array}$ \\
\hline 1 & 1.00 & 1.20 & 1.09 & $9.7 \%$ \\
\hline 2 & 1.00 & 1.25 & 1.13 & $10.2 \%$ \\
\hline 3 & 2.00 & 1.29 & 1.15 & $10.7 \%$ \\
\hline 4 & 2.00 & 1.25 & 1.12 & $10.1 \%$ \\
\hline 5 & 3.00 & 1.17 & 1.01 & $14.4 \%$ \\
\hline 6 & 3.00 & 1.25 & 1.10 & $12.1 \%$ \\
\hline 7 & 4.00 & 1.29 & 1.05 & $18.3 \%$ \\
\hline 8 & 4.00 & 1.27 & 0.97 & $23.4 \%$ \\
\hline
\end{tabular}




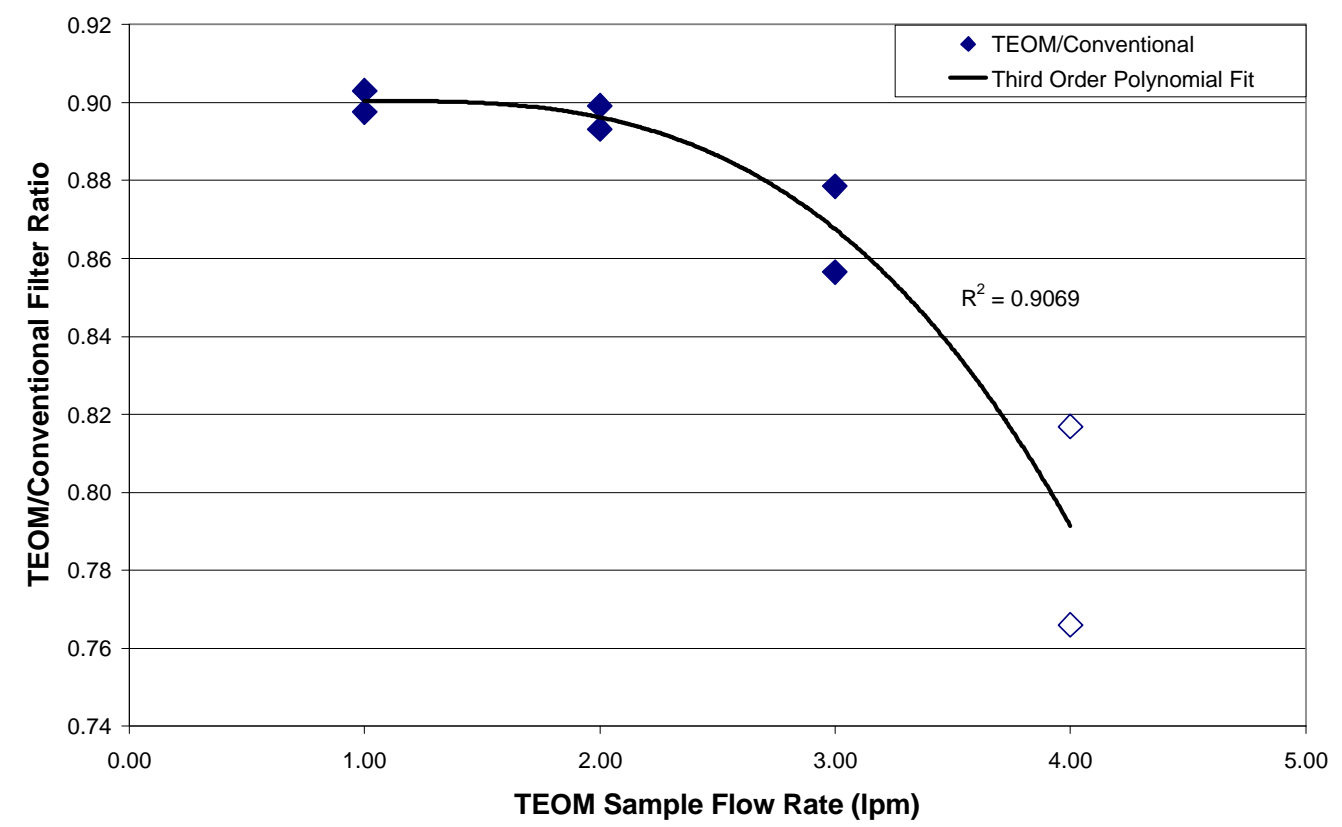

Figure 30: TEOM/ conventional PM ratio as TEOM sample flow rate was varied on the Cummins engine. The hollow data points represent tests that required a new TEOM filter, solid data points represent test taken with a used TEOM filter.

Note that tests five and six have the same TEOM settings as tests four, five, and six in the Cummins section of temperature effects, namely $40^{\circ} \mathrm{C}$ sample path temperature and three lpm sample rate. However, the tests in the temperature effects section resulted in a lower error value. This was due to a cooler conventional PM air temperature during the flow effect test series. The cooler conventional PM temperature was a result of cooler ambient conditions. As TEOM sample flow rate increased, TEOM values increasingly deviate from conventional PM results. Results from tests seven and eight would have been closer to conventional PM values if new filters were not required for each test.

As with temperature, flow also affected real-time data. Tests one, four, six, and seven were chosen to represent one, two, three, and four lpm set points on least error criteria. Figure 31 and table 14 display real time data results. 


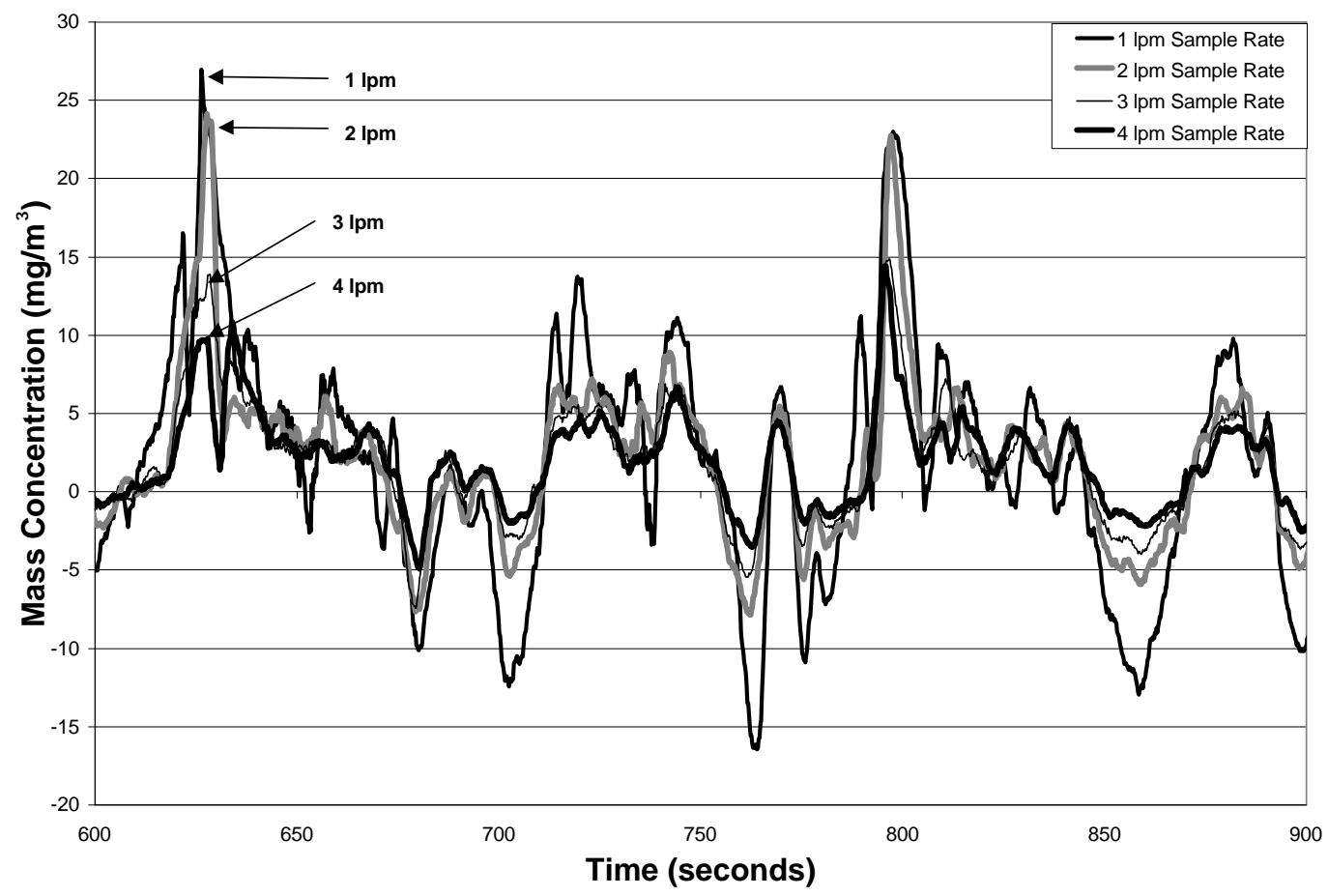

Figure 31: A section of the FTP illustrating increased flow decreased TEO M real-time data amplitude.

Table 14: Real-time positive/ negative collection evaluation for varying flow rate.

\begin{tabular}{|l|l|l|l|l|}
\hline TEO M Sample Flow Rate (lpm) & 1.00 & 2.00 & 3.00 & 4.00 \\
\hline Positive Collected Mass (micrograms) & 55.62 & 77.15 & 99.04 & 111.24 \\
\hline Negative Collected Mass (micrograms) & 33.10 & 31.49 & 32.05 & 25.57 \\
\hline Positive/ Negative Ratio & 1.68 & 2.45 & 3.09 & 4.35 \\
\hline
\end{tabular}

FTP data show that as TEOM sample rate increased, amplitude of the response, both positive and negative decreased. However, as TEOM sample rate increased, the ratio of the total positive mass collected to negative mass collected increased. The four lpm yielded the least collection of negative mass per positive mass collection. The 99\% confidence value of the conventional PM concentration for the 17 tests (temperature and flow tests) recorded on the Cummins engine was $\pm 1.7 \%$, or 1.24 $\pm 0.021 \mathrm{mg} / \mathrm{m}^{3}$. The $99 \%$ confidence of the TEOM measurements for the Cummins data set was $\pm 4.3 \%$, or $1.08 \pm 0.047 \mathrm{mg} / \mathrm{m}^{3}$. Note an improvement in confidence level between the Navistar and the Cummins. The data suggests that this improvement was caused by disregarding the tests with new filters. 


\subsection{Sample Location Effects}

The tests were conducted on the Cummins 10.8 liter DI diesel engine. The engine was operated through a FTP cycle to bring the engine and tunnel to operating temperature before data were taken. Three FTP cycles were run back to back with a nominal engine off time of 10 minutes between tests. The COV\% of the conventional PM flow normalized data was $1.9 \%$, demonstrating data viability. A new TX40 filter was installed in the TEOM before the test series began. The average relative humidity of the ambient air for the duration of the test series was $25 \%$. Results shown in table 15 are from sampling at the secondary tunnel.

The third test in the series yielded the lowest error value in the Cummins test battery. However, when compared to the Cummins, $40^{\circ} \mathrm{C}$, three lpm data taken during temperature tests, the improvement was less than a percent, as shown in table 15. This improvement was well within the $99 \%$ confidence range of $\pm 4.3 \%$, and thus qualifies this improvement as negligible. Moving the sampling location did affect the real-time data. The real-time data were smoother possibly due to pressure dampening from the secondary tunnel dead volume, as shown in figure 32.

Table 15: Results of sampling from the secondary dilution tunnel.

\begin{tabular}{|c|c|c|c|c|c|}
\hline $\begin{array}{c}\text { Test } \\
\text { Number }\end{array}$ & $\begin{array}{c}\text { TEOM Flow } \\
\text { Set Point (lpm) }\end{array}$ & $\begin{array}{c}\text { TEOM } \\
\text { Temperature Set } \\
\text { Point }\left({ }^{\circ} \mathrm{C}\right)\end{array}$ & $\begin{array}{c}\text { Conventional PM } \\
\text { Concentration } \\
\left(\mathrm{mg} / \mathrm{m}^{3}\right)\end{array}$ & $\begin{array}{c}\text { TEOM } \\
\text { Concentration } \\
\left(\mathrm{mg} / \mathrm{m}^{3}\right)\end{array}$ & $\begin{array}{c}\text { Percent } \\
\text { Difference } \\
\text { From } \\
\text { Conventional }\end{array}$ \\
\hline 1 & 3 & 40 & 1.59 & 1.31 & $17.9 \%$ \\
\hline 2 & 3 & 40 & 1.55 & 1.42 & $8.8 \%$ \\
\hline 3 & 3 & 40 & 1.56 & 1.44 & $7.7 \%$ \\
\hline
\end{tabular}




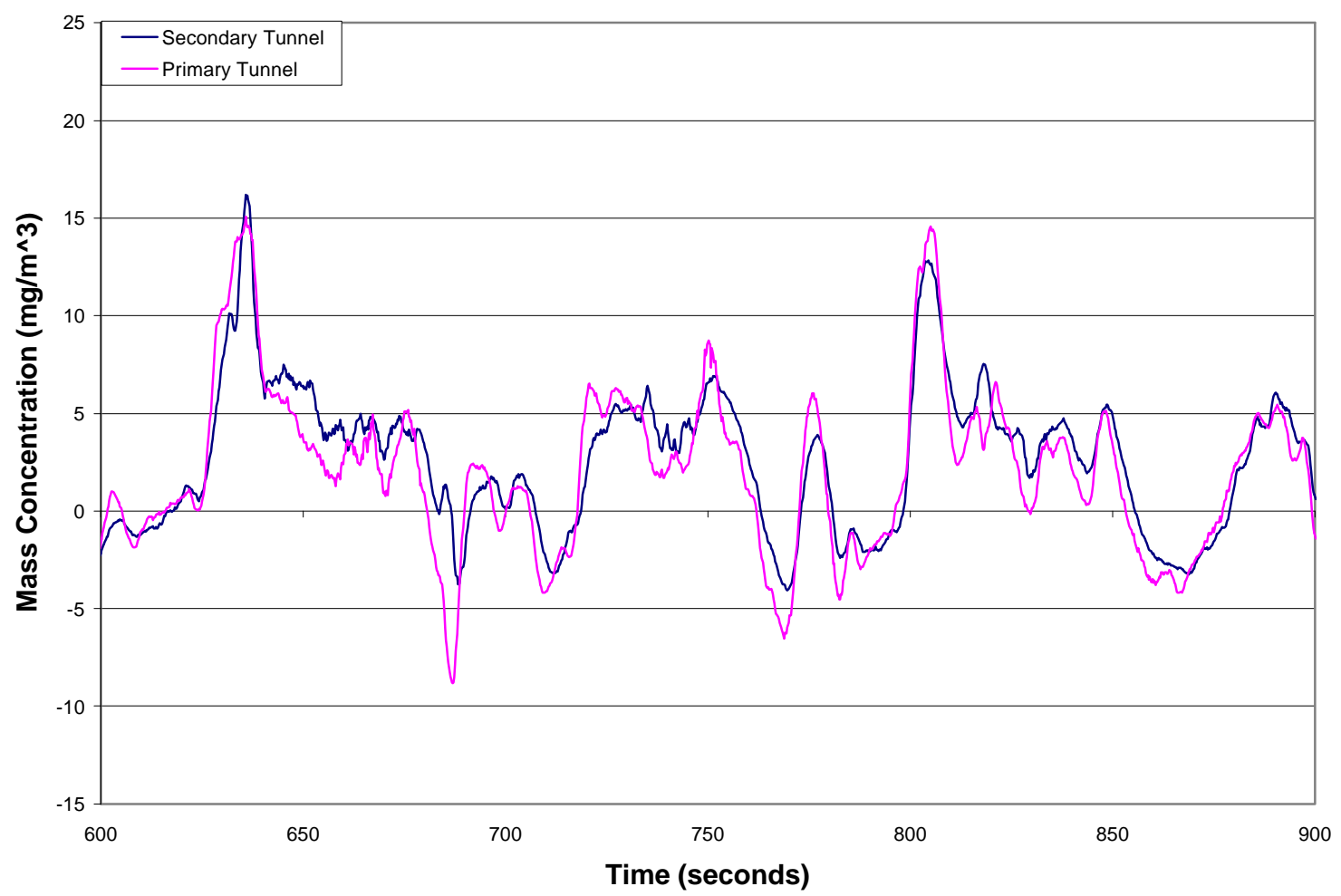

Figure 32: A section of the FTP illustrating sample location effects on real-time TEOM data.

Table 16: Positive/ negative collection evaluation for secondary tunnel sampling.

\begin{tabular}{|c|c|c|c|c|}
\hline Location & $\begin{array}{c}\text { Secondary Tunnel, } \\
\text { Test 2 }\end{array}$ & $\begin{array}{c}\text { Secondary Tunnel, } \\
\text { Test 3 }\end{array}$ & $\begin{array}{c}\text { Primary Tunnel, } \\
\text { Test 5 }\end{array}$ & $\begin{array}{c}\text { Primary Tunnel, } \\
\text { Test 6 }\end{array}$ \\
\hline $\begin{array}{c}\text { Positive Collected Mass } \\
\text { (micrograms) }\end{array}$ & 108.72 & 111.86 & 104.96 & 106.92 \\
\hline $\begin{array}{c}\text { Negative Collected Mass } \\
\text { (micrograms) }\end{array}$ & 21.06 & 23.50 & 36.85 & 36.66 \\
\hline Positive/ Negative Ratio & 5.16 & 4.76 & 2.85 & 2.92 \\
\hline
\end{tabular}

Moving the sample location also improved the positive mass collection, as well as decreasing the negative mass collection, as shown in table 16. Other cycles showed improvement due to sample location and temperature changes also.

When the WVU FTP 75 cycle was applied to the Navistar 7.3 liter, slight improvements were made to the conventional PM/ TEOM agreement, as catalogued in table 17. Three systems were tested with the WVU FTP 75 cycle. System 1 was a conventional exhaust routing with all exhaust routed to the dilution tunnel. In system 2, flow was split in approximately one-half to create a base line for investigating catalyst effects and routed into the dilution tunnel for a separate project. In system 3 , the 
split flow system was used to evaluate an oxidation catalyst. The data in table 17 illustrates the variability in TEOM collection when the test system was varied. The best agreement between TEOM and conventional PM for this cycle was 15.1\% difference when sampled from the secondary tunnel. In comparison, the best heavy-duty FTP cycle agreement for the secondary tunnel was $7.7 \%$ difference.

Table 17: WVU FTP 75 comparison of sampling modification results shows a $10.6 \%$ average improvement

\begin{tabular}{|c|c|c|c|}
\hline $\begin{array}{l}\text { Sampled from the } \\
\text { Secondary Tunnel at } \\
40^{\circ} \mathrm{C} \text { and } 3 \mathrm{lpm} \text {. }\end{array}$ & $\begin{array}{c}\text { Conventional PM } \\
\text { Concentration } \\
\left(\mathrm{mg} / \mathrm{m}^{3}\right)\end{array}$ & $\begin{array}{c}\text { TEOM } \\
\text { Concentration } \\
\left(\mathrm{mg} / \mathrm{m}^{3}\right)\end{array}$ & $\begin{array}{c}\text { Percent } \\
\text { Difference } \\
\text { From } \\
\text { Conventional }\end{array}$ \\
\hline System 1 & 1.25 & 0.99 & $21.0 \%$ \\
\hline System 2 & 1.14 & 0.46 & $59.5 \%$ \\
\hline System 3 & 0.51 & 0.41 & $19.1 \%$ \\
\hline System 1 & 1.10 & 0.93 & $15.1 \%$ \\
\hline System 2 & 0.79 & 0.57 & $28.0 \%$ \\
\hline $\begin{array}{l}\text { Sampled from the } \\
\text { Primary Tunnel at } 50^{\circ} \mathrm{C} \\
\text { and } 2 \mathrm{lpm} \text {. }\end{array}$ & $\begin{array}{c}\text { Conventional PM } \\
\text { Concentration } \\
\left(\mathrm{mg} / \mathrm{m}^{3}\right)\end{array}$ & $\begin{array}{c}\text { TEOM } \\
\text { Concentration } \\
\left(\mathrm{mg} / \mathrm{m}^{3}\right)\end{array}$ & $\begin{array}{c}\text { Percent } \\
\text { Difference } \\
\text { From } \\
\text { Conventional }\end{array}$ \\
\hline System 1 & 0.56 & 0.44 & $22.1 \%$ \\
\hline System 2 & 0.92 & 0.36 & $61.2 \%$ \\
\hline System 3 & 1.31 & 0.88 & $32.6 \%$ \\
\hline System 1 & 0.84 & 0.50 & $40.7 \%$ \\
\hline System 2 & 1.42 & 0.86 & $39.0 \%$ \\
\hline
\end{tabular}




\subsection{Filter Conditioning}

Five types of tests were performed to investigate the effect of filter pre-conditioning on start up after filter replacement. Multiple tests were performed for each type of conditioning, but only the worst case results are shown in figure 33. The objective was to find the maximum time need to bring a filter to a stable state.

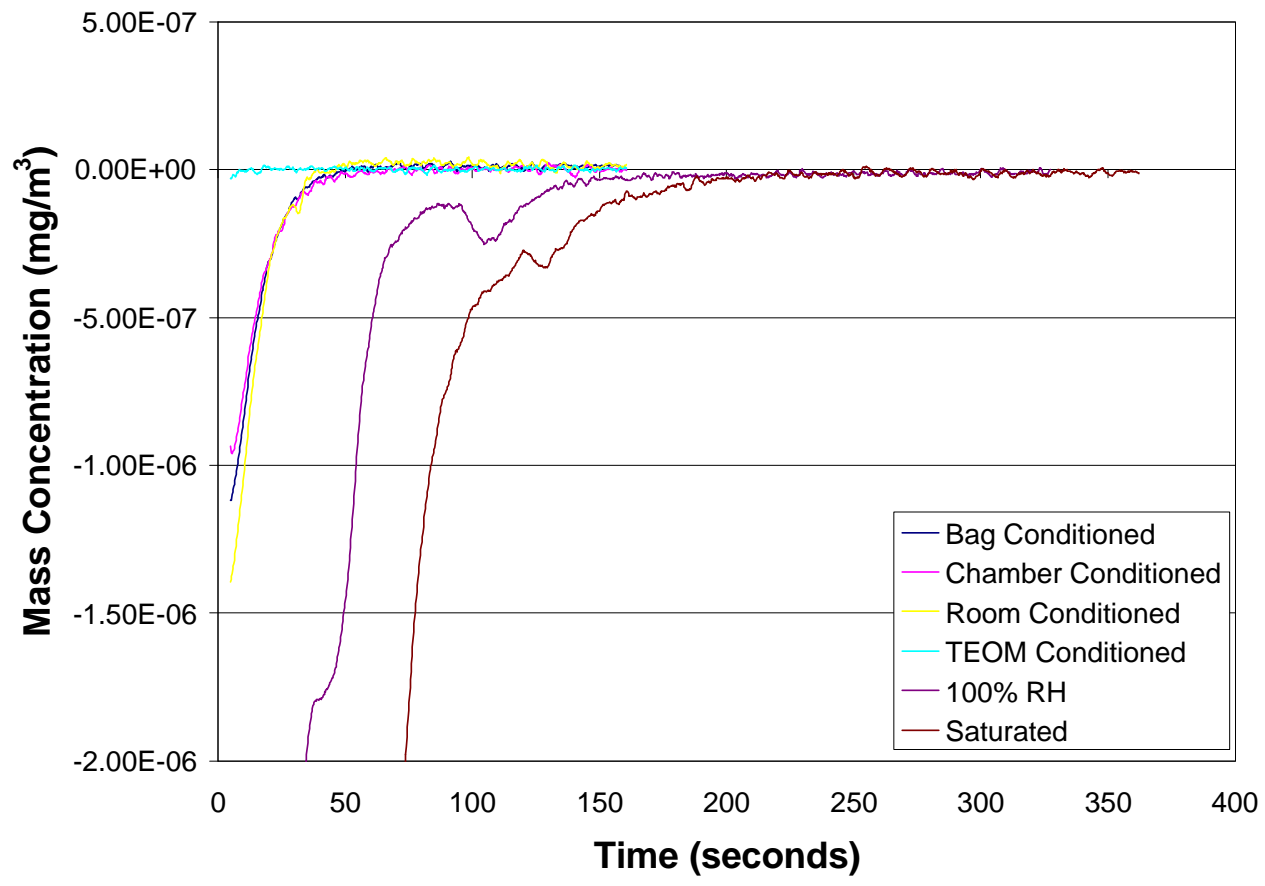

Figure 33: Mass concentration response due to different filter conditioning.

The TEOM was set to sample at $50^{\circ} \mathrm{C}$ and $2 \mathrm{lpm}$ during all tests except $100 \% \mathrm{RH}$ tests. In $100 \% \mathrm{RH}$ tests, results from $50^{\circ} \mathrm{C}, 2 \mathrm{lpm}$ settings were compared to $40^{\circ} \mathrm{C}, 3 \mathrm{lpm}$ settings, worst case is shown, a test from $40^{\circ} \mathrm{C}, 3 \mathrm{lpm}$. In the worst case, filter saturation, the TEO M was ready to sample by 350 seconds or approximately 6 minutes. Under normal conditioning criteria, such as storing the filters in the R\&P bag, the TEOM was ready to sample within 75 seconds. It is uncertain what caused dips in the data from the $100 \%$ RH and Saturated tests. 


\subsection{Effect of Filter Type}

The tests were conducted on the Cummins 10.8 liter DI diesel engine. The engine was run through an FTP cycle to bring the engine and tunnel to operating temperature before data were taken. Four FTP cycles were run back to back with a nominal heat soak time of 10 minutes between tests. The COV\% of the conventional PM flow normalized data was $1.2 \%$, proving data viability. The average relative humidity of the ambient air for the duration of the test series was $27 \%$. The TEOM temperatures were set to $40^{\circ} \mathrm{C}$ while flow rate was set to $3 \mathrm{lpm}$.

Table 18: Results from using T60A20 filters in the TEOM.

\begin{tabular}{|c|c|c|c|c|}
\hline $\begin{array}{c}\text { Conventional } \\
\text { PM Average } \\
\text { Temperature } \\
\left({ }^{\circ} \mathrm{C}\right)\end{array}$ & $\begin{array}{c}\text { Temperature Set } \\
\text { Point }\left({ }^{\circ} \mathrm{C}\right)\end{array}$ & $\begin{array}{c}\text { Conventional PM } \\
\text { Concentration } \\
\left(\mathrm{mg} / \mathrm{m}^{3}\right)\end{array}$ & $\begin{array}{c}\text { TEOM } \\
\text { Concentration } \\
\left(\mathrm{mg} / \mathrm{m}^{3}\right)\end{array}$ & $\begin{array}{c}\text { Percent } \\
\text { Difference } \\
\text { From } \\
\text { Conventional }\end{array}$ \\
\hline 30 & 40 & 1.21 & 0.78 & $35.97 \%$ \\
\hline 34 & 40 & 1.23 & 0.97 & $21.37 \%$ \\
\hline 35 & 40 & 1.20 & 1.00 & $16.33 \%$ \\
\hline 36 & 40 & 1.20 & 1.03 & $14.35 \%$ \\
\hline
\end{tabular}

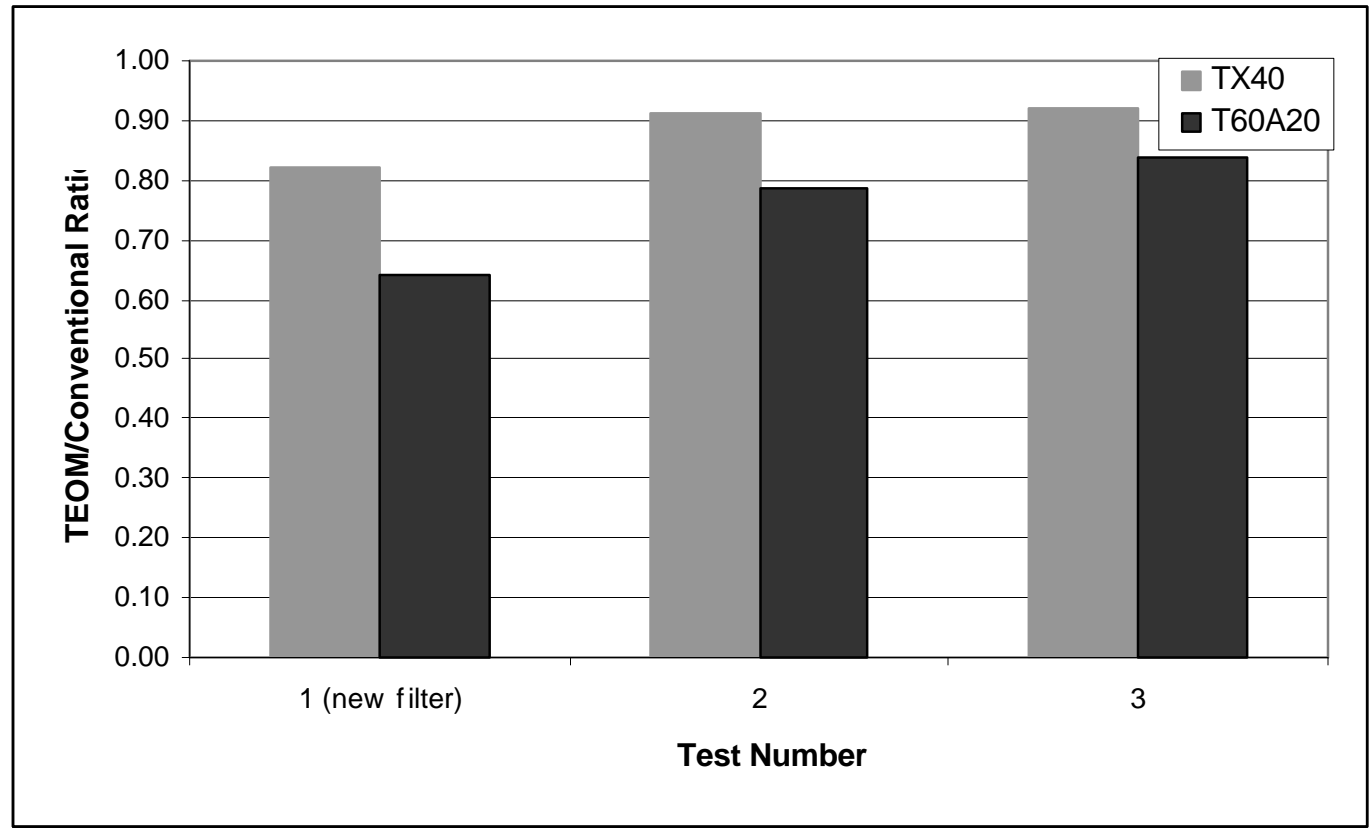

Figure 34: Error showing the initial collection efficiency of TX 40 and T60A20 filter media types. 
Collection efficiency was lower for the T60A20 than the TX 40, as communicated in table 18 and figure 34. The medium used for conventional PM capture was T60A20. From these filter media tests, the difference in previous comparisons between TEOM and conventional measurements could even be more exaggerated when filter media are equivalent. 


\section{Real-time Observations}

Real-time data were graphed with data from other real-time analyzers to search for relationships or characteristics of PM. Data were time shifted based on the results of the correlation program. Figure 35 shows the results of the program, were the peaks in the graph represent the best time shift (delay) each emission. The correlation coefficient equation is listed in section 4.6.

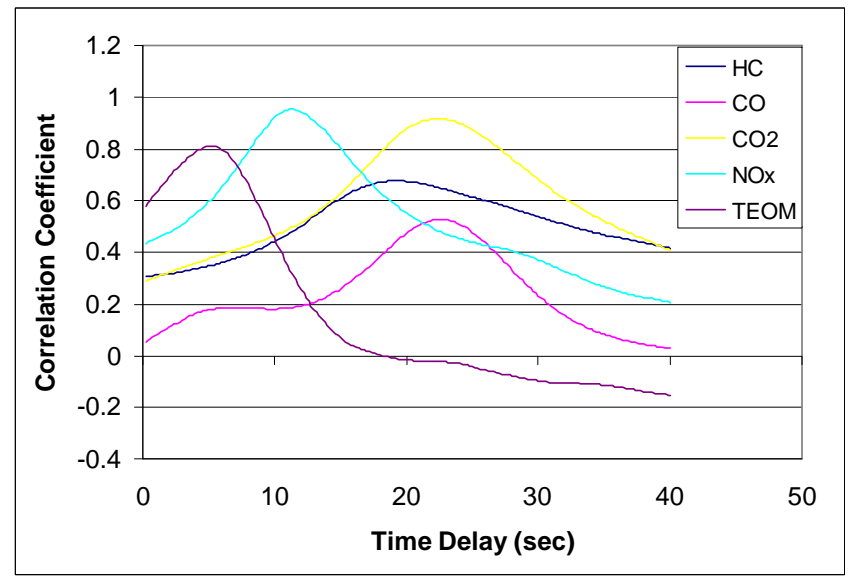

Figure 35: Results from the cross correlation program, where peaks in data represent best estimated time shift. TEOM data were the least delayed, possibly due to the fast response of the instrument and shorter sample length. Validation of the time shifting program can be found in Appendix C.

For ease of reading and comparison, chart data are normalized by dividing the real-time values by the average, creating average normalized data.

No strong correlations, determined by a coefficient of determination $\left(\mathrm{r}^{2}\right)$ close to one, were found between TEOM and $\mathrm{HC}, \mathrm{CO}_{2}$, and $\mathrm{NO}_{\mathrm{x}}$ for the FTP cycle. In figure 36, an increase in TEOM value seemingly corresponds to increased in HC. However, figure 37 shows no significant correlations are evident. The trend in figure 36 could be due to turbocharger lag or possibly an over fueling condition from transient maneuvers. Figure 38 shows average normalized CO and TEOM real-time data for the FTP cycle. The CO data tends to follow the TEOM data with exception to the zones of high speed in combination with varying or low load conditions. A slight $\left(r^{2}=0.49\right)$ linear relationship with CO was found. This supports work done by Jarret et al. [16]. The real-time TEO M data tended to correlate best with $\mathrm{CO}$ during regions of high torque in figure 39. Low torque, high-speed regions did not yield a linear relationship, but clock-wise forming loops. The larger loops relate to the zones of high speed in combination with low load conditions. An example of these loading conditions is from 600 to 900 seconds during the FTP cycle. In the author's experience with electronic engine controls, these larger loops could be formed from inconstancies in fuel control during low air mass conditions. The varying fuel mass could be due to the low duty cycle of injectors, where the injection error is a 
larger fraction of the total amount of fuel delivered. A trend between TEOM and CO as well as HC was expected. Relationships were $\mathrm{CO}$ might correlate with soot and $\mathrm{HC}$ with the SOF. However, soot would correlate better due its closer relationship with transient fueling, hence a better correlation with CO. In figure 40, normalized $\mathrm{CO}_{2}$ and TEOM real-time data for the FTP cycle are plotted. The amplitude and duration of the TEOM spikes do not correlate with the $\mathrm{CO}_{2}$ spikes thought the cycle. Average normalized $\mathrm{CO}_{2}$ versus TEOM real-time data is shown in figure 41. This figure shows that there is a slight upward trend between $\mathrm{CO}_{2}$ and real-time TEOM data with a coefficient of determination of 0.53 . As with $\mathrm{CO}, \mathrm{CO}_{2}$ had a clockwise forming loop relationship with TEOM data. Figure 42 illustrates average normalized time derivative of $\mathrm{CO}_{2}$ and TEOM real time data for the FTP cycle. Additional time shifting brought about a correlation, which could correspond to a turbocharger lag. Figure 43 illustrates the relationship of average normalized time derivative of $\mathrm{CO}_{2}$ verses TEOM real-time data. Figures 44 and 45 illustrate the relationship that was found between $\mathrm{NO}_{\mathrm{x}}$ and TEOM real-time data. The amplitude and duration of the TEOM spikes do not correlate with the $\mathrm{NO}_{\mathrm{x}}$ spikes thought the cycle. Note the similarities between figure 41 and 45 as $\mathrm{NO}_{\mathrm{x}}$ is closely related to $\mathrm{CO}_{2}$ on an energy specific basis. Torque and TEOM, shown in figures 46 and 47, seem to folow each other with exception to the zones of high speed in combination with low load conditions. A second order polynomial correlation between torque and real-time TEOM data was found. The areas of high speed in combination with varying or low load conditions tend to give a weaker relationship. For example, around the time of 230 seconds and from 600 to 900 seconds (see Figure 2 for the speed and load points during an FTP).

Inconsistent TEOM results were found when comparing FTP data to WVU FTP 75 data. Trends found in FTP tests were not always found in WVU FTP 75. The exception to this was CO, forming an upward trend in counterclockwise loops, as illustrated in figure 48. Figure 49 shows the linear relationship of $\mathrm{NO}_{\mathrm{x}}$ and TEO M with a coefficient of determination of $0.57 . \mathrm{NO}_{\mathrm{x}}$ data displayed a relationship with TEOM for the WVU FTP 75 that was not as apparent with the FTP. It appears that two modes of operation are shown. A weak second order polynomial correlation between torque and real-time TEOM data was found of the FTP cycle. The correlation did not prove to be apparent in the WVU FTP 75 cycle, as shown in figure 50.

Trends in the CBD seemed to be different yet again, however, it should be noted that the CBD cycle is a simple, repetitive test, where the same trend will repeat, giving a false "correlation". See figure 12 for the vehicle speed during a CBD. Figures 51, 52 and 53 display the relationship between TEOM and $\mathrm{CO}, \mathrm{NOx}$ and axle power respectively. A correlation between $\mathrm{CO}, \mathrm{NOx}$ and axle power and realtime TEOM data were evident. 


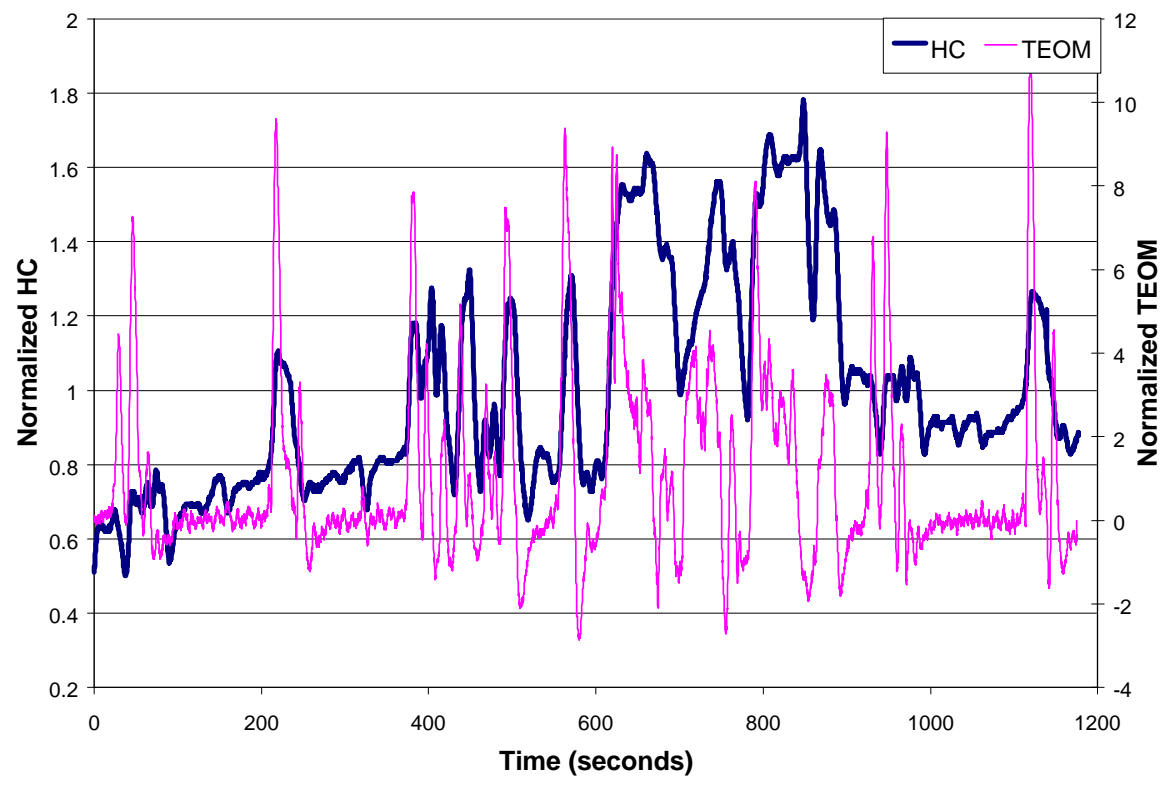

Figure 36: Average normalized HC and TEOM real-time data for the FTP cycle. The amplitude and duration of the TEOM spikes do not correlate with the HC spikes thought the cycle.

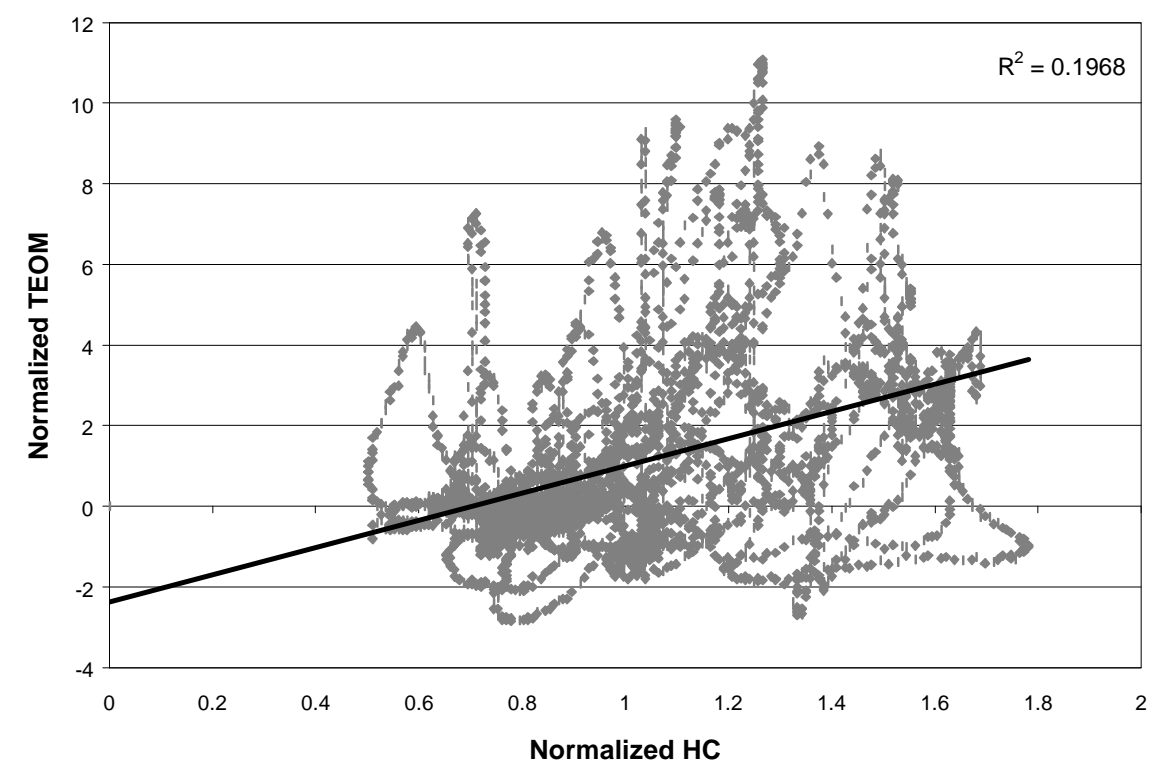

Figure 37: Average normalized HC versus TEOM real-time data for the FTP cycle. There was not a correlation between $\mathrm{HC}$ and real-time TEO M data. 


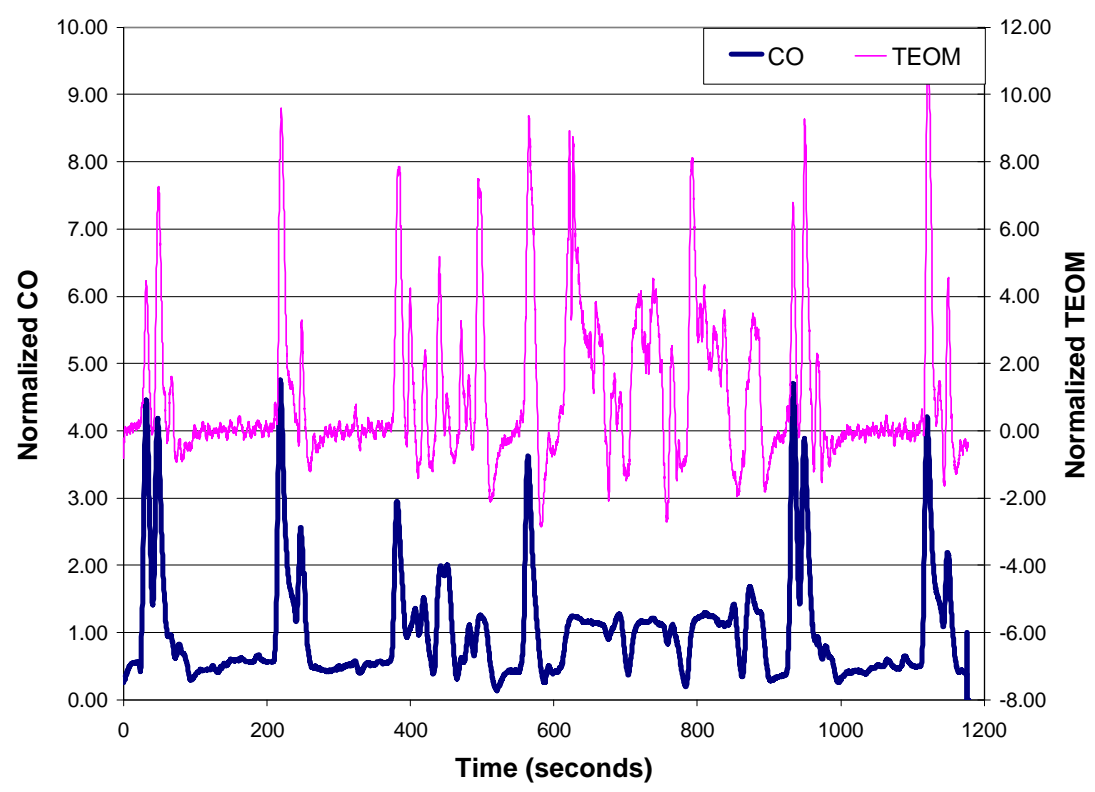

Figure 38: Average normalized CO and TEOM real-time data for the FTP cycle. The CO data tends to follow the TEOM data with exception to the zones of high speed in combination with varying or low load conditions.

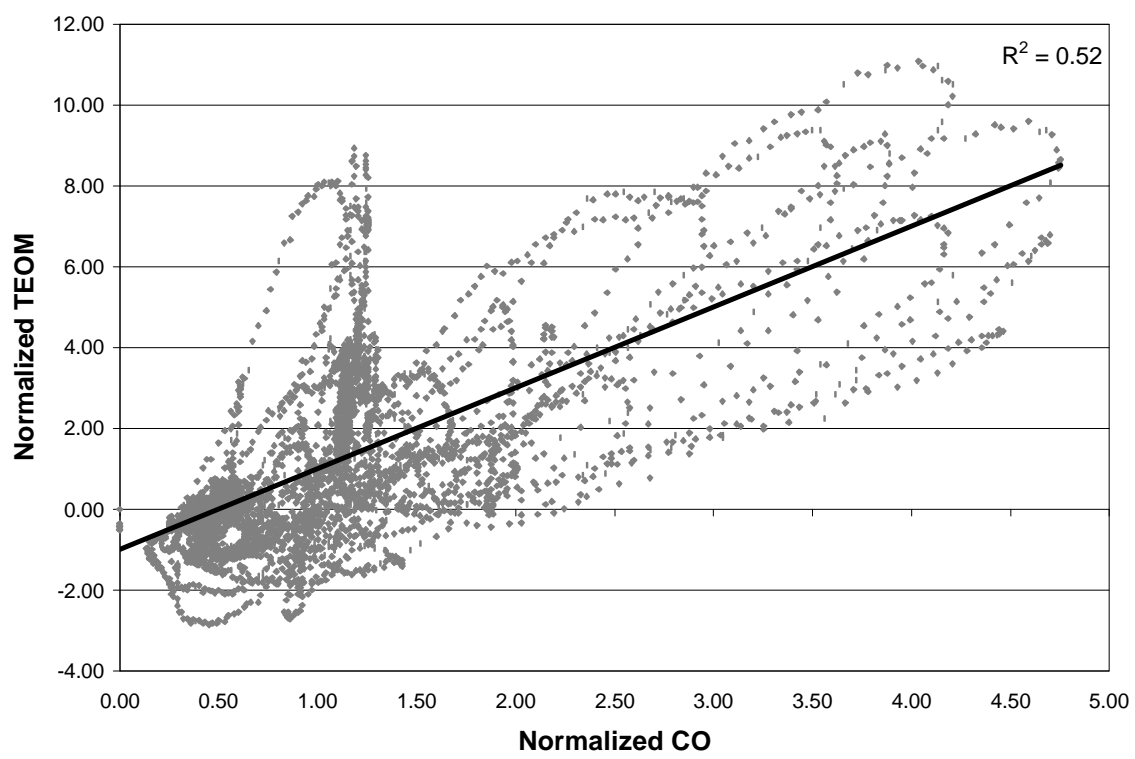

Figure 39: Average normalized CO versus TEOM real-time data for the FTP cycle. A weak linear correlation between CO and real-time TEOM data were shown. This does support the conclusions reached by Clark [16]. The larger loops relate to the zones of high speed in combination with low load conditions. For example, around the time of 230 seconds and from 600 to 900 seconds (see Figure 2 for the speed and load point during an FTP). 


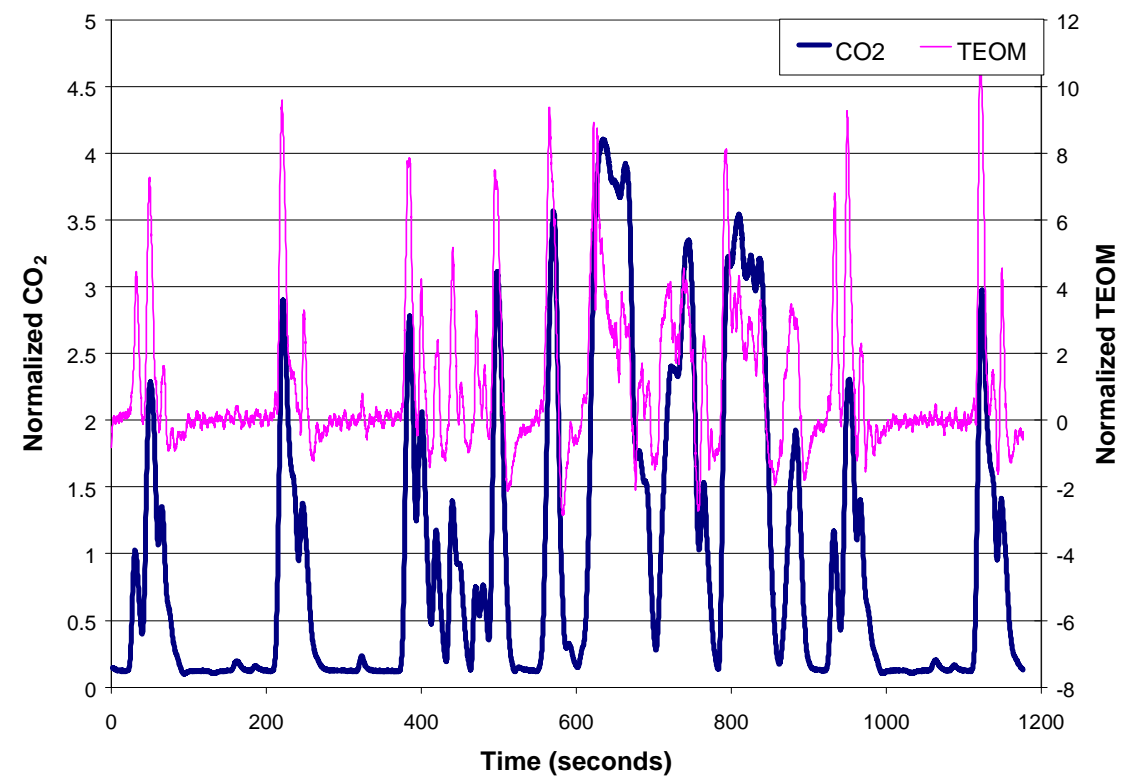

Figure 40: Average normalized $\mathrm{CO}_{2}$ and TEOM real-time data for the FTP cycle. The amplitude and duration of the TEOM spikes do not correlate with the $\mathrm{CO}_{2}$ spikes thought the cycle.

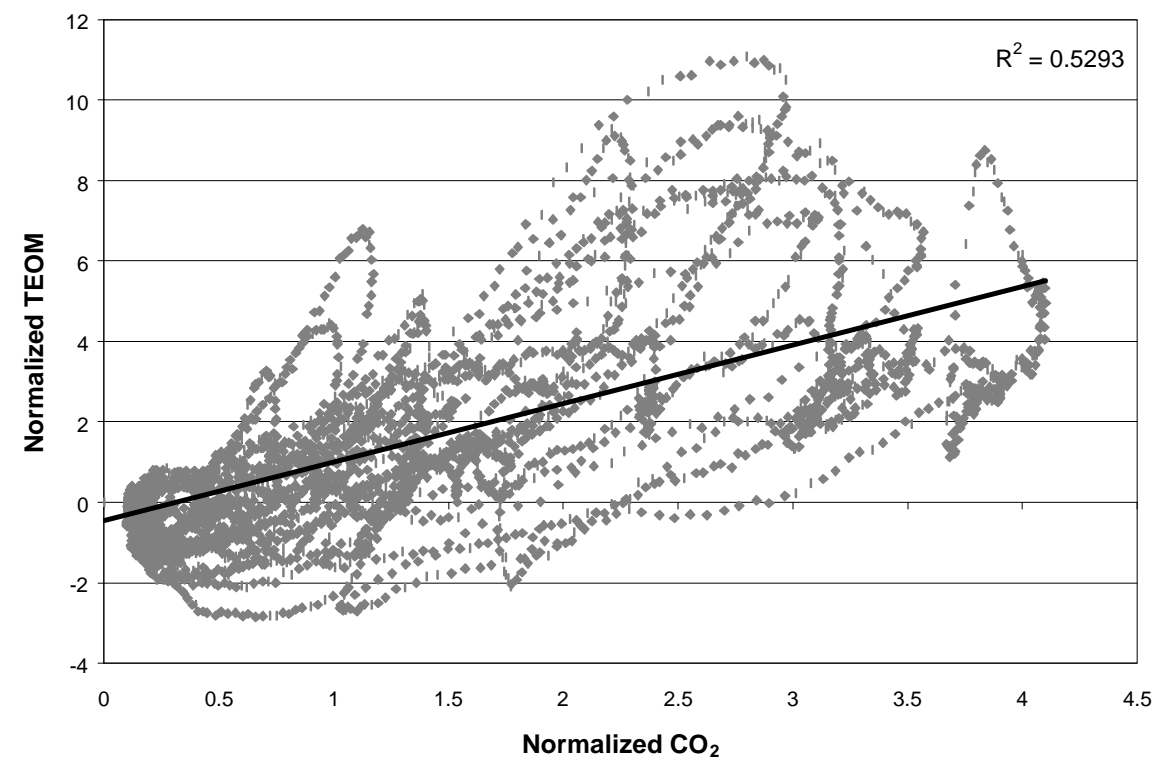

Figure 41: Average normalized $\mathrm{CO}_{2}$ versus TEOM real-time data for the FTP cycle. This figure shows that there was a slight upward trend between $\mathrm{CO}_{2}$ and real-time TEOM data. 


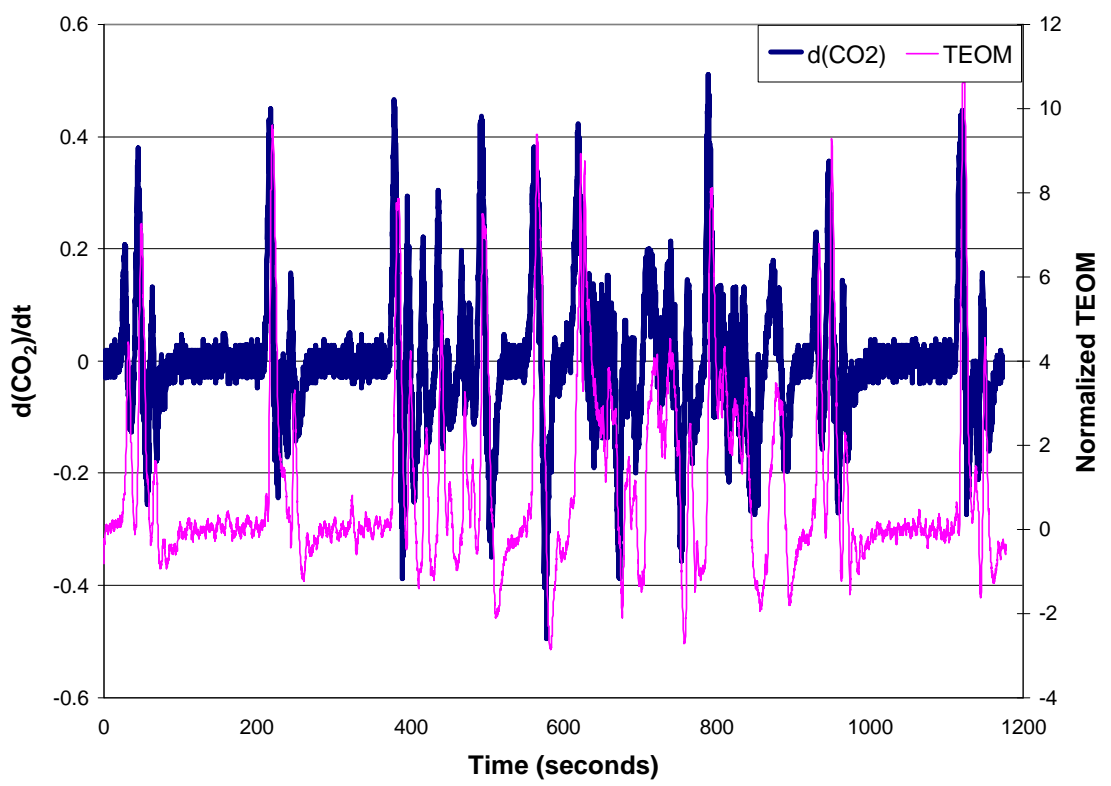

Figure 42: Average normalized time derivative of $\mathrm{CO}_{2}$ and TEOM real time data for the FTP cycle. Additional time shifting brought about a correlation, which could correspond to turbocharger lag.

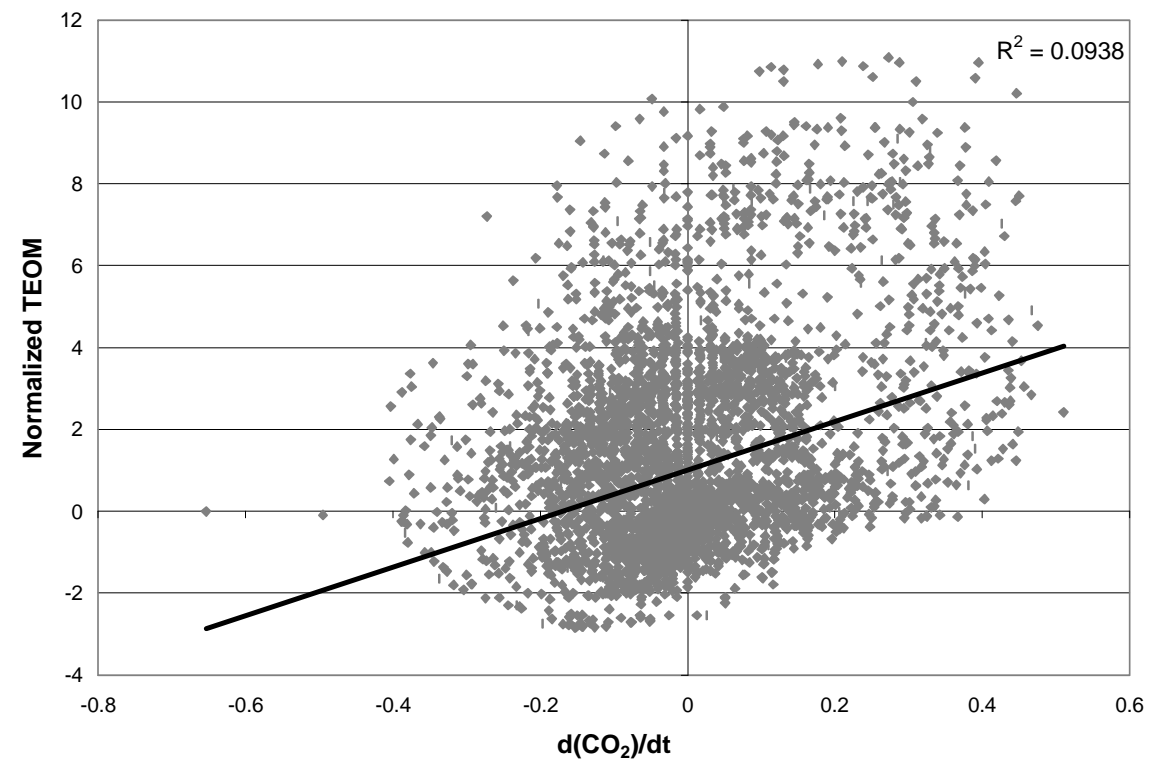

Figure 43: Average normalized time derivative of $\mathrm{CO}_{2}$ versus TEO M real-time data for the FTP cycle. 


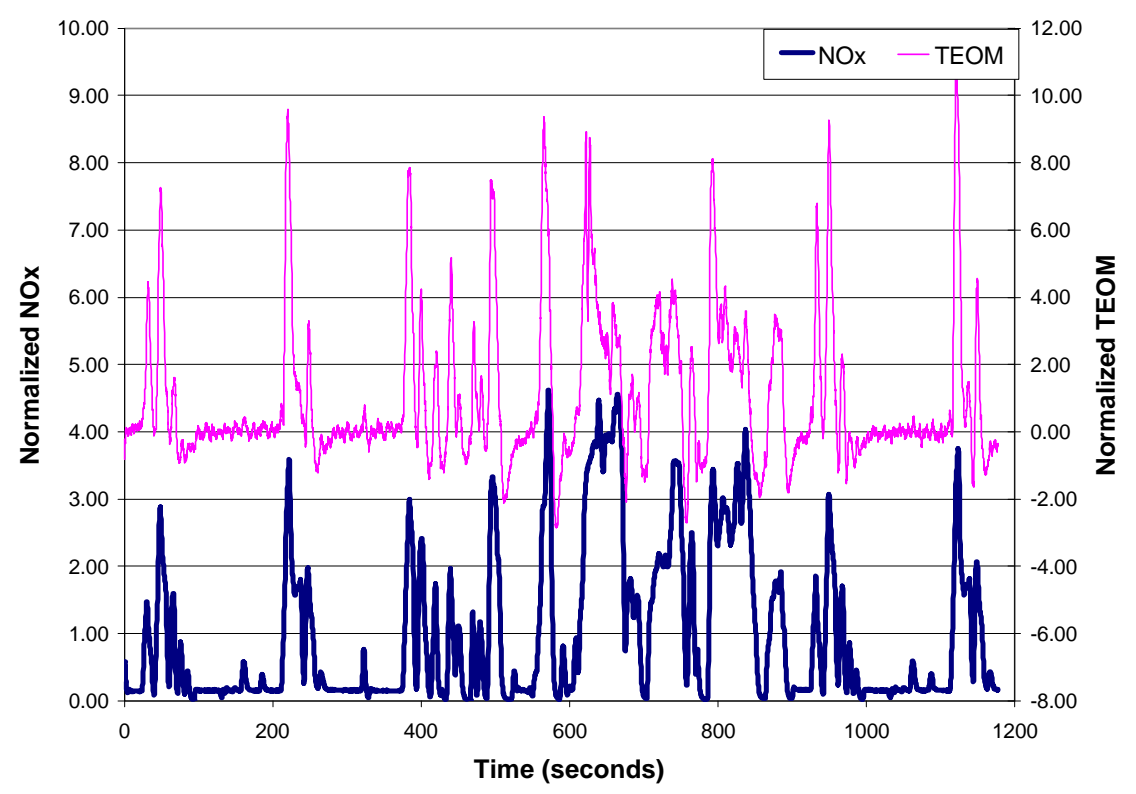

Figure 44: Average normalized $\mathrm{NO}_{\mathrm{x}}$ and TEOM real-time data for the FTP cycle. The amplitude and duration of the TEOM spikes do not correlate with the $\mathrm{NO}_{\mathrm{x}}$ spikes thought the cycle.

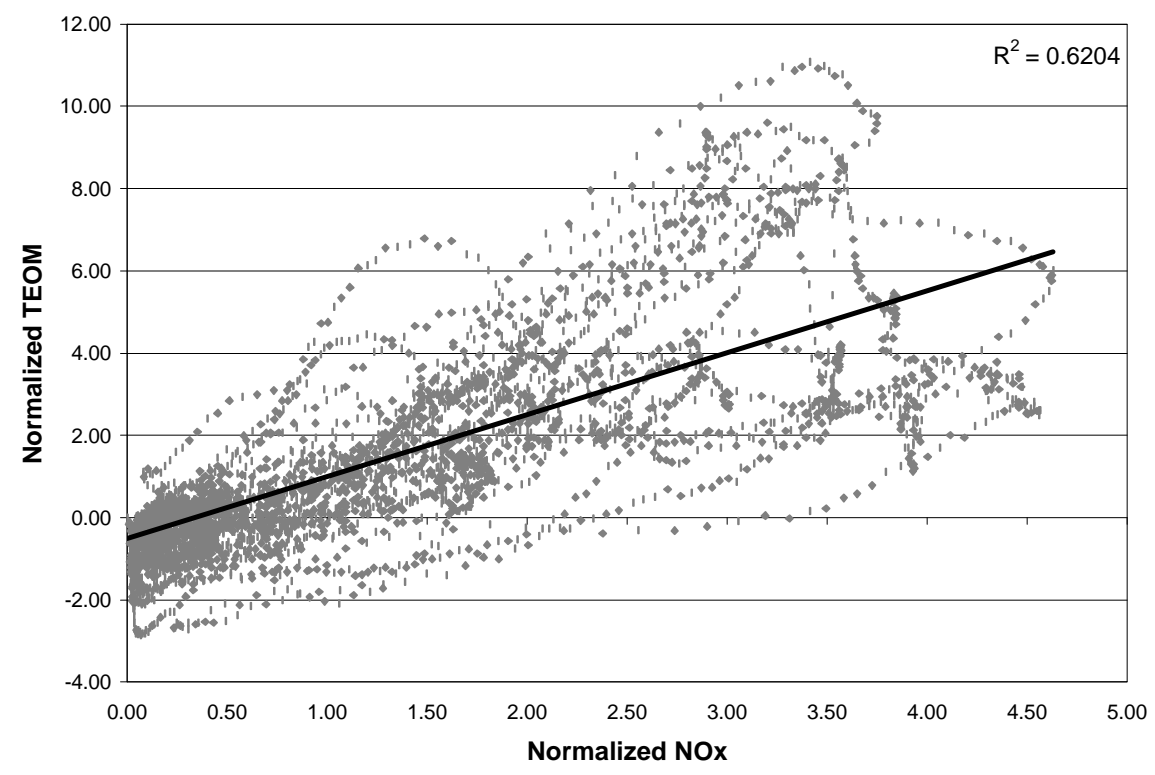

Figure 45: Average normalized $\mathrm{NO}_{\mathrm{x}}$ versus TEOM real-time data for the FTP cycle. There was a slight upward trend between $\mathrm{NO}_{\mathrm{x}}$ and real-time TEOM data. 


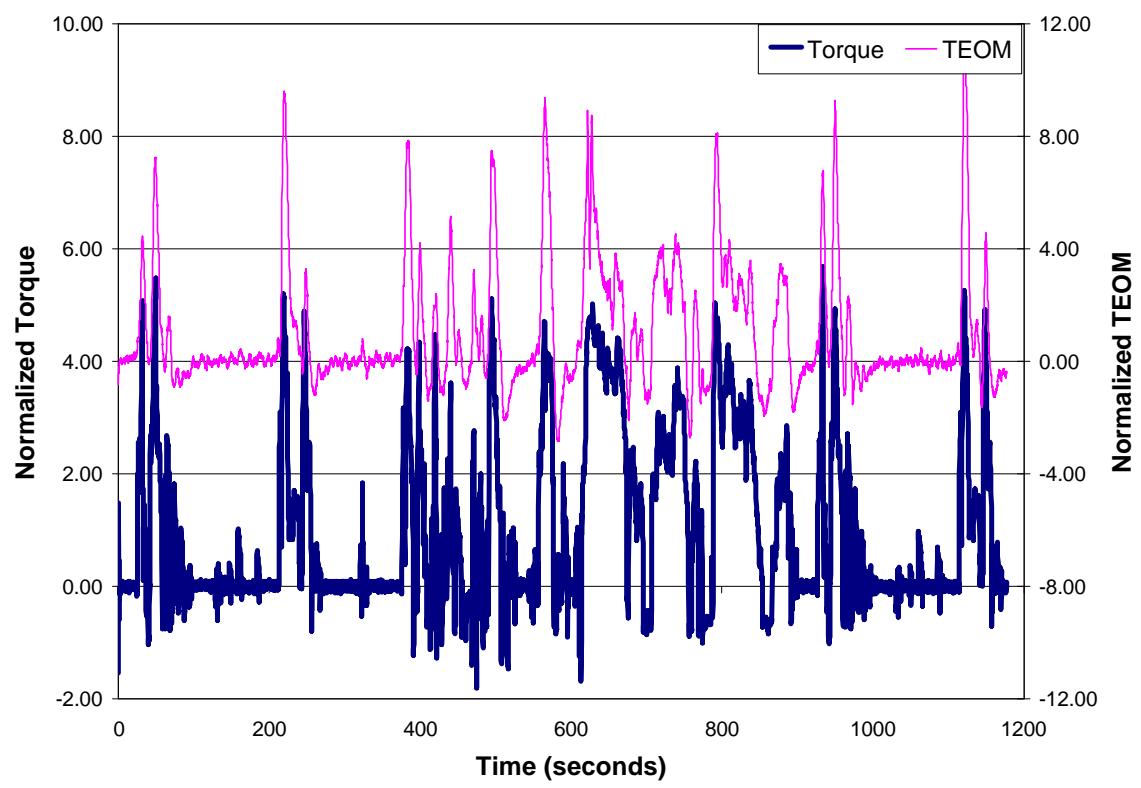

Figure 46: Average normalized torque and TEO M real-time data for the FTP cycle. The torque data tends to follow the TEOM data with exception to the zones of high speed in combination with low load conditions.

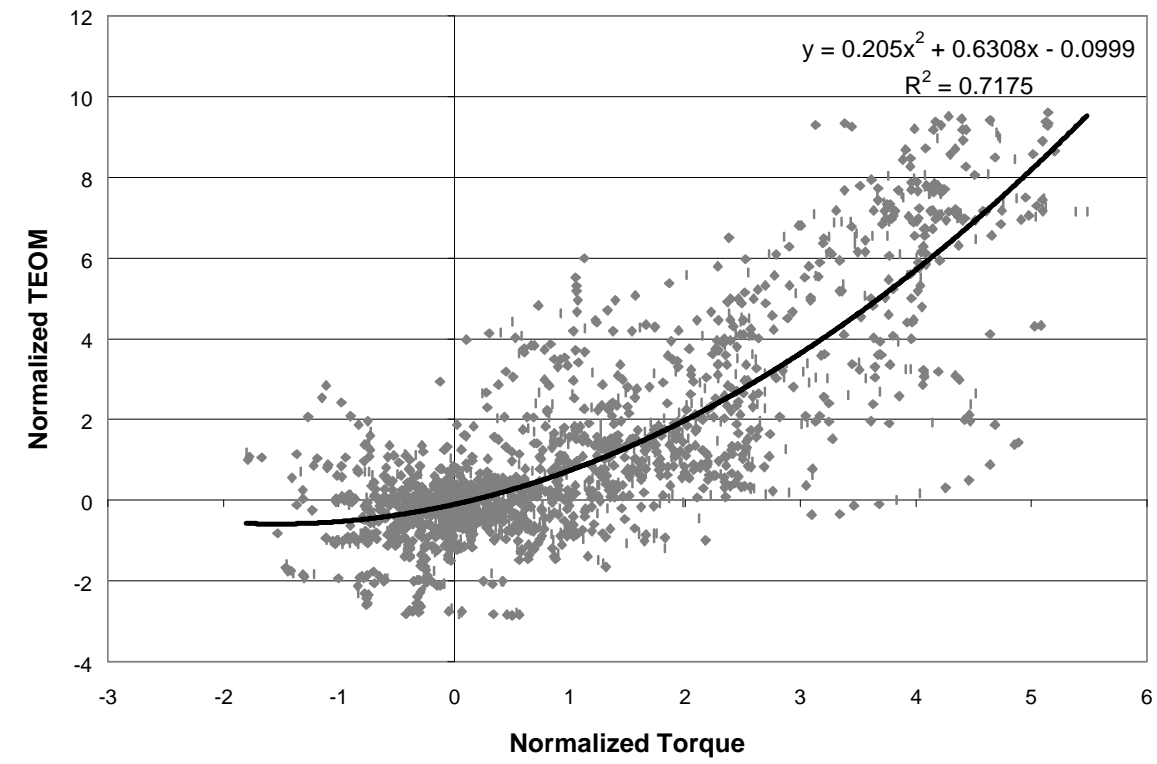

Figure 47: Average normalized torque versus TEO M real-time data for the FTP cycle. This figure shows that there was a weak second order polynomial correlation between torque and real-time TEOM data. The areas of high speed in combination with varying or low load conditions tend to give a weaker relationship. For example, around the time of 230 seconds and from 600 to 900 seconds (see Figure 2 for the speed and load points during an FTP). 


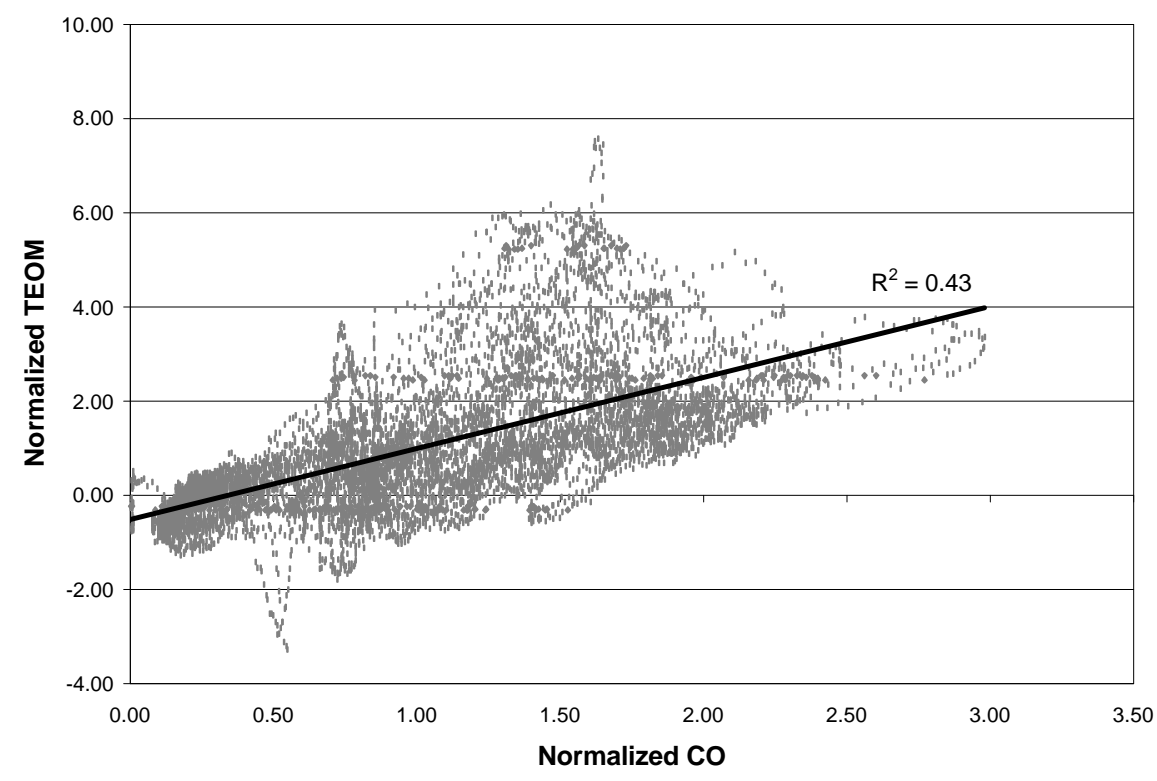

Figure 48: Average normalized CO versus TEO M real-time data for the WVU FTP 75 cycle. This figure shows that there was a weak linear correlation between $\mathrm{CO}$ and real-time TEOM data.

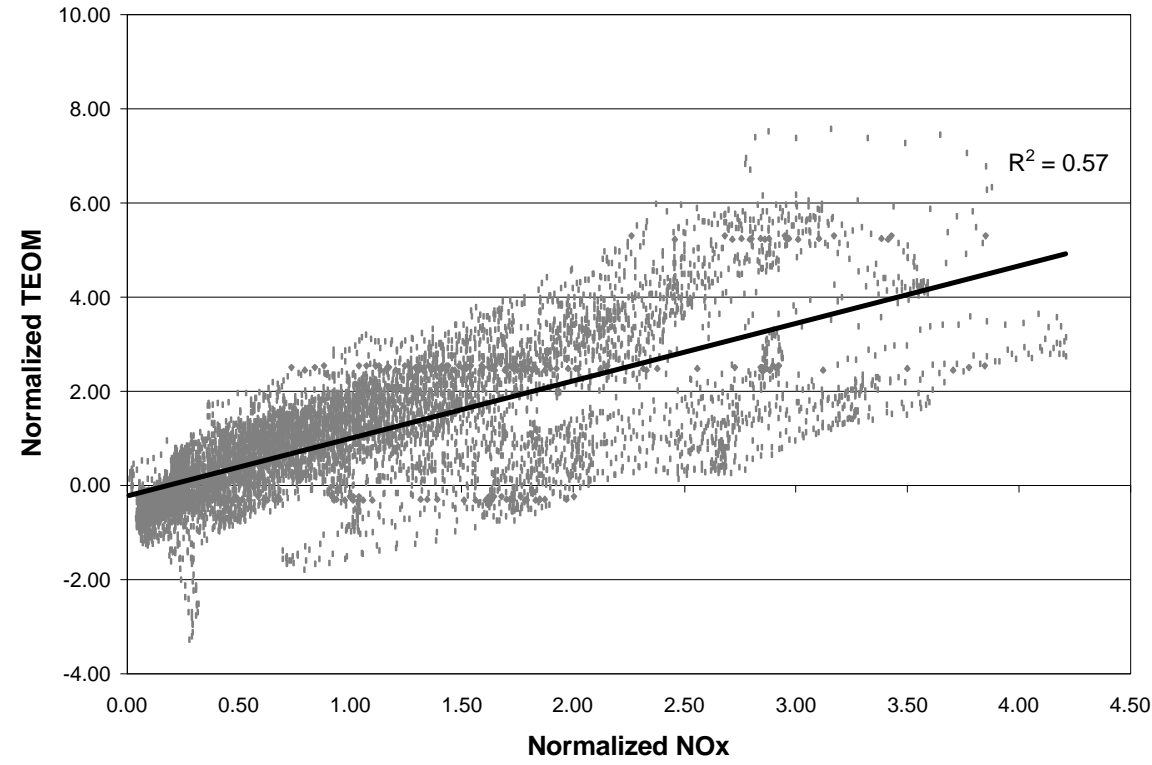

Figure 49: Average normalized NOx versus TEO M real-time data for the WVU FTP 75 cycle. A weak linear correlation between NOx and real-time TEO M data were shown. It appears that two modes of operation are shown here. 


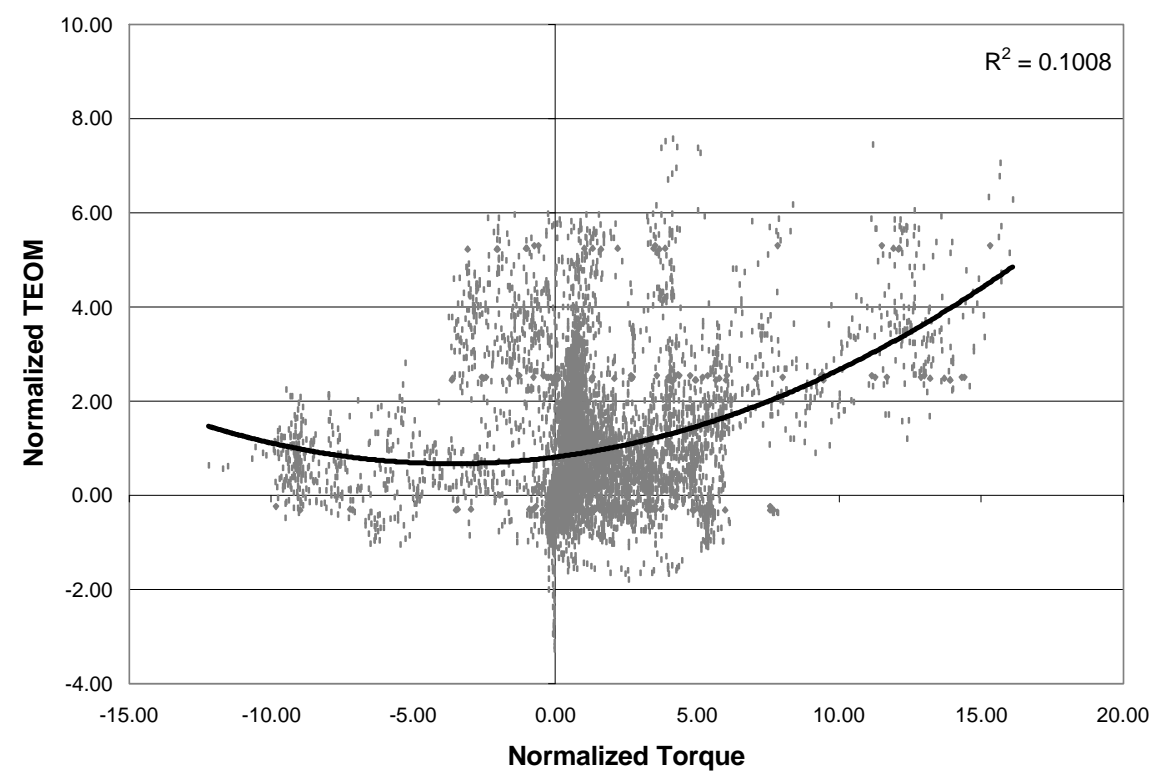

Figure 50: Average normalized torque versus TEO M real-time data for the WVU FTP 75 cycle. The second order polynomial correlation found with the FTP cycle did not prove to exist with the FTP75.

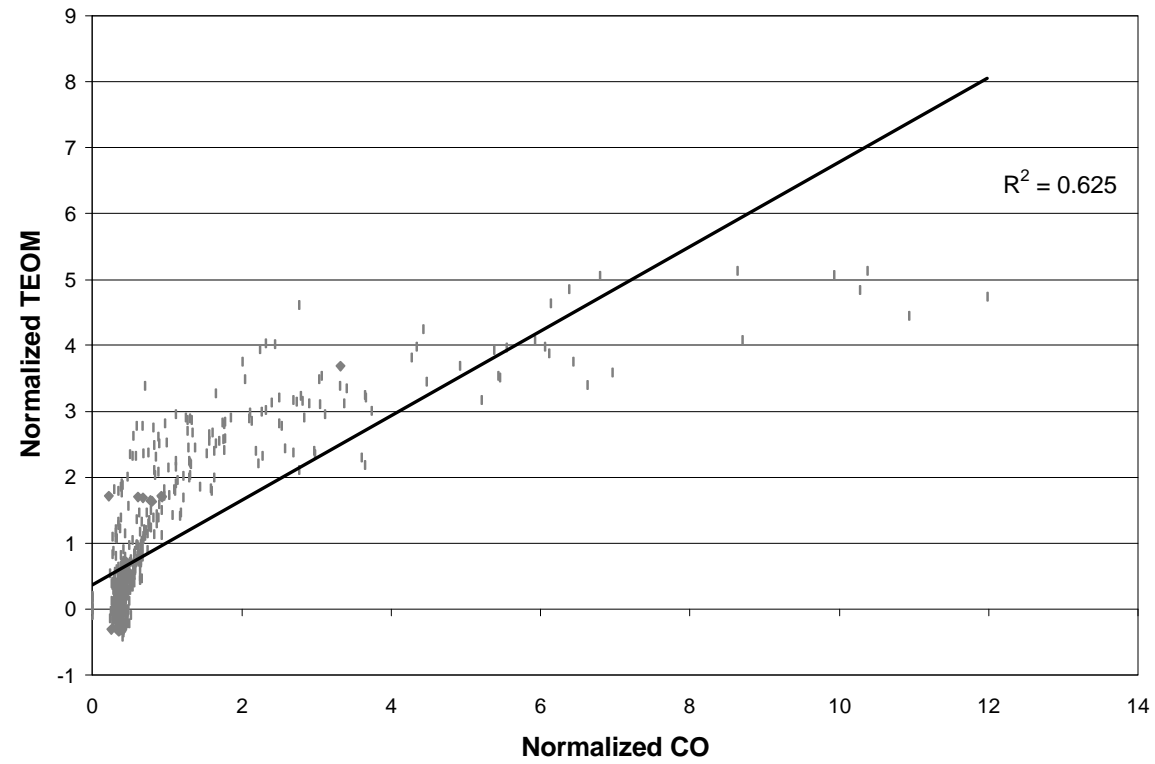

Figure 51: Average normalized CO versus TEOM real-time data for the CBD cycle. A correlation between $\mathrm{CO}$ and real-time TEOM data were evident. See figure 12 for the vehicle speed during a CBD. 


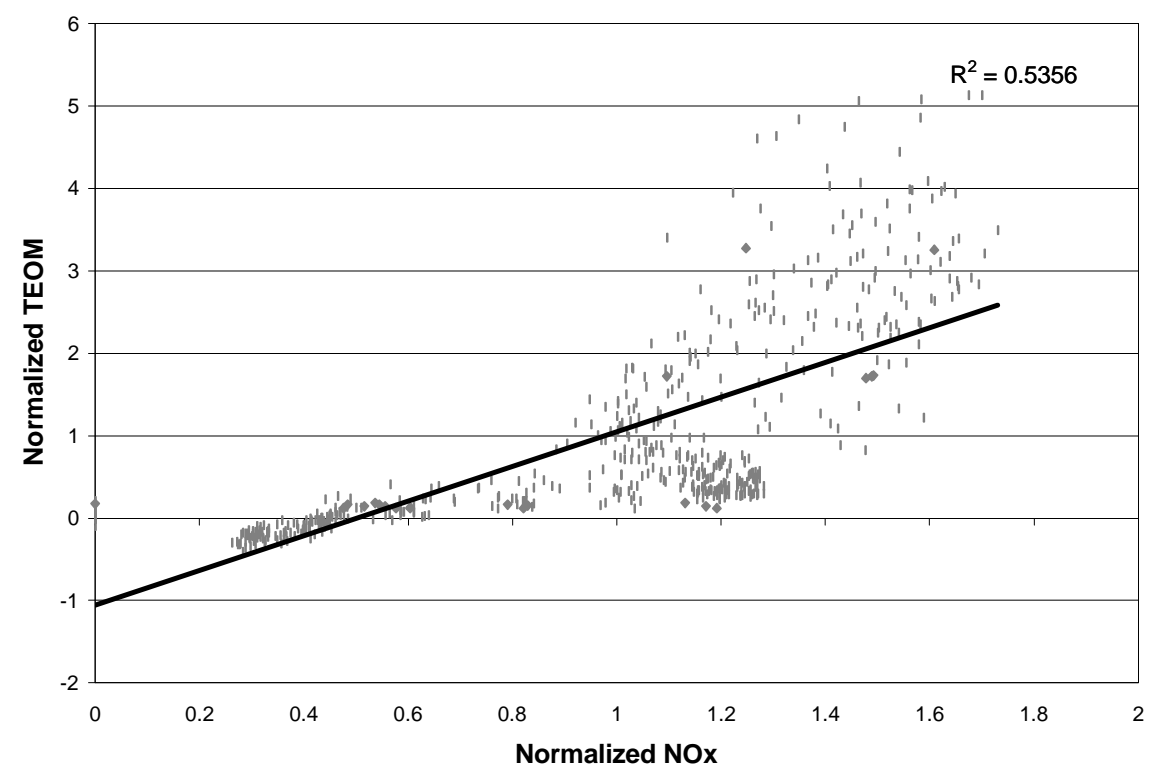

Figure 52: Average normalized $\mathrm{NO}_{\mathrm{x}}$ versus TEO M real-time data for the CBD cycle. A correlation seems to exist, however, the CBD cycle was a repetitive cycle. A trend is likely to repeat, looking as if there is a good correlation.

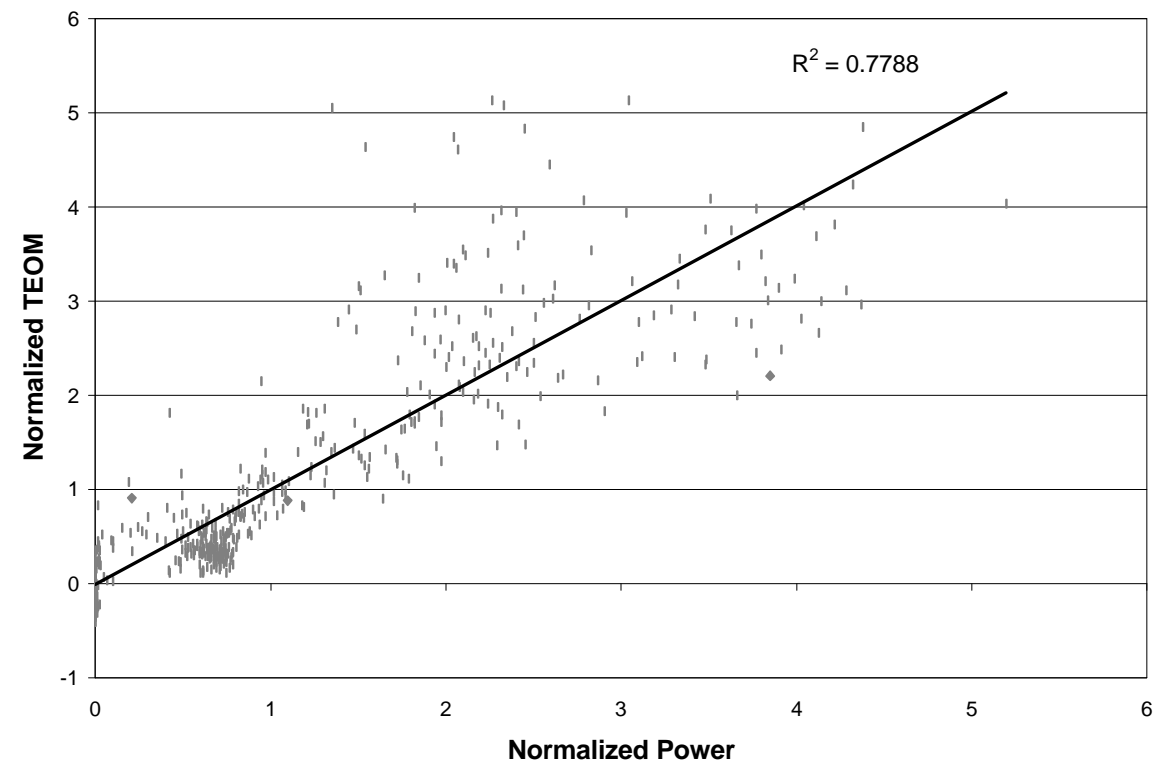

Figure 53: Average normalized axial power versus TEO M real-time data for the CBD cycle. Again, a trend will recur with this repetitive cycle. 


\section{Conclusions}

A TEOM series 1105 diesel particulate mass monitor was operated and compared to the EPA's accepted method for particulate measurement. TEOM temperature and flow settings were varied one at a time to evaluate their affect on collection and real-time data. It was found that TEOM temperatures in the $30^{\circ} \mathrm{C}$ range yielded the best agreement to conventional PM filtration because it is likely that a higher quantity of volatile organic compounds were trapped at this low temperature. However, as sample path temperatures increased, an increase in the positive-to-negative mass ratio was reported. A higher positive-to-negative ratio is useful in real-time PM measurement. A sample path of $50^{\circ} \mathrm{C}$ gave the highest ratio of positive-to-negative mass ratio. This phenomenon is theorized to be from an increased VOC and moisture rejection rate due to the increase in temperature. A compromise between conventional filter agreement and real-time data was made in selecting the temperature set point of $40^{\circ} \mathrm{C}$ as the optimum sampling temperature. Sample flow rate was varied from one to four lpm. The conventional filter agreement diverged as TEOM flow increased. The positive-to-negative mass ratio decreased as flow decreased. This trend was theorized to be a reduced resident time for ultrafine PM and volatiles to become attached in the crevices of the filter due to the increased filter face velocity. The flow rate of three lpm was chosen to be a compromise between conventional filtration agreement and real-time characteristics.

The filter collection efficiency of a new filter was found to be a significant source of variability. On average, the first test captured $40 \%$ less mass than the third. A two element system would improve this deficiency. The best conventional filtration agreement for an FTP test cycle was a TEOM/ conventional ratio of 0.97 . The best results for an FTP test set was a three point average TEOM/ conventional ratio of 0.92 with a COV percentage of $0.15 \%$. Seven FTP tests taken on two different days with $40^{\circ} \mathrm{C}$ sample path temperatures and three lpm sample flow rate yielded an average TEOM/ conventional ratio of 0.90 and a COV\% of $25.62 \%$. When the initial test with a new filter is disregarded, the $99 \%$ confidence in TEOM results was $\pm 4.3 \%$. In comparison, the $99 \%$ confidence in conventional PM results was $1.7 \%$.

An improvement of only one percent was measured when sample location was moved from the primary dilution tunnel to the secondary dilution tunnel. The real-time data were smoother when sampling from the secondary dilution tunnel when compared to primary dilution tunnel sampling.

The TEOM filter was found to be ready to be used in approximately one minute if it was kept inside the provided storage bag supplied by R\&P. If there is a doubt about the filter storage environment, a six minute delay time should be taken to allow the filter to stabilize before a test was started. The current TEOM filter available that yields the best collection efficiency utilizes the TX 40 
filter media. The TX40 media exhibited better initial collection efficiency and a faster time to asymptote that the T60A20 filter media.

No strong linear correlations were found with $\mathrm{HC}, \mathrm{CO}_{2}$, or $\mathrm{NO}_{\mathrm{x}}$ were found. Trends that were observed between TEOM and other emissions were not always constant between test cycles. 


\section{Recommendations}

The TEOM was very sensitive to cycle to cycle variations. The best agreement between TEOM to conventional PM filters for the WVU FTP 75 cycle was 15.1 percent difference (from conventional). This difference could be due to the differing amount of SOF collecting on the two filtering methods. Stabilizing the temperature of the PM sample could reduce deficiencies in the convention method. Currently, the sampling temperature varies with dilution ratio. A SOF content comparison between TEOM and conventional filtration was needed. To improve the TEOM as a realtime filter mass measuring devise, the filter efficiency should be stabilized. A two-stage filter module needs to be developed for use on the TEOM, shown in figure 52. The two-stage filter would be used once, just as the conventional PM filters. A detailed correlation attempt between transient $\mathrm{HC}, \mathrm{CO}$ and TEOM would be a valuable calibration tool. A method of calculating out the water mass measurement would aid in such a study [19].

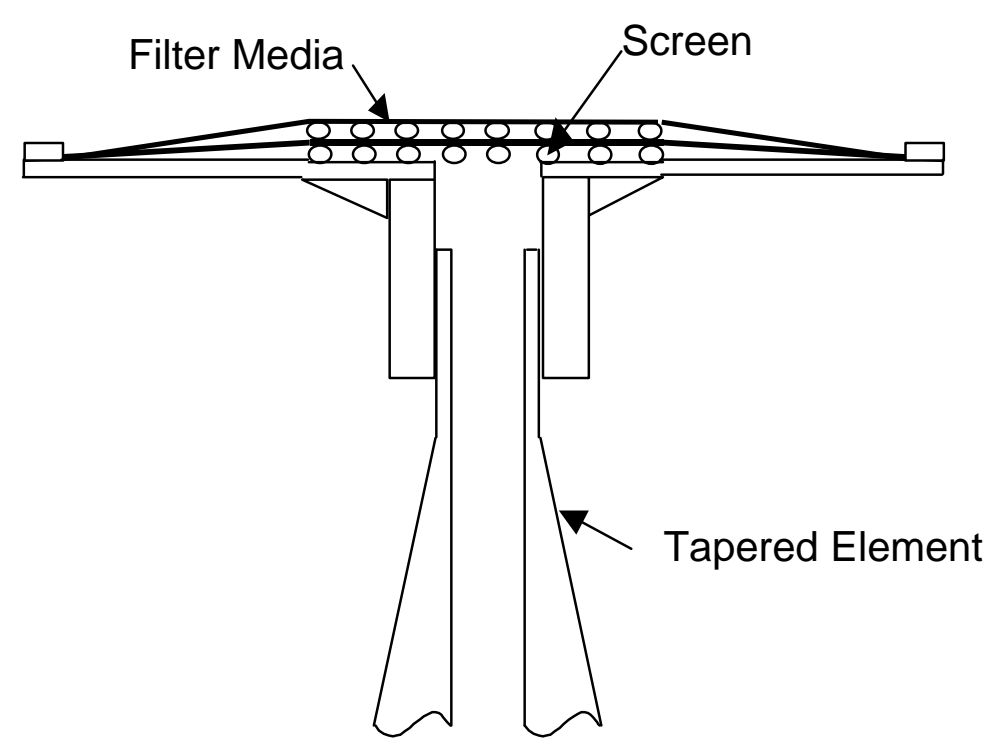

Figure 54: A proposed TEOM filter design. 


\section{References}

1. HEI Special Report, "Diesel Exhaust: A Critical Analysis of Emissions, Exposure, and Health Effects," Health Effects Institute, Cambridge, MA, 1995.

2. Environmental Protection Agency, Code of Federal Regulations, Title 40 Part 86 Subpart N, Office of the Federal Register National Archives and Records Administration, July 1, 1998.

3. Ogawa, T., Toshimi, A, Masanori, O., Y oshio, F., "Fuel Effects on Particulate Emissions from D.I. Engine - Chemical Analysis and Characterization of Diesel Fuel," SAE Paper 95351, 1995.

4. Heywood, J. B., Internal Combustion Engine Fundamentals, McG raw-Hill, New York, NY, 1988.

5. Challen, R., Baraneseu, B., Diesel Engine Reference Book, Second Edition, SAE 1999

6. Kato, S., Takayama, Y., Takeshi, S. G., "Investigation of Particulate Formation of D.I. D iesel Engine with Direct Sampling from Combustion Chamber," SAE Paper 972969, 1997.

7. Shore, P. R., Cuthberson, R. D., "Application of a Tapered Element O scillating Microbalance to Continuos Diesel Particulate Measurement," SAE Paper 850405, 1985.

8. Okrent, D. A., "Optimization of a Third Generation TEOM Monitor for Measuring Diesel Particulate in Real-Time," SAE Paper 980409, 1998.

9. Whitby, R., Gibbs, R., Johnson, R., Hill, B., Shimpi, S., Jorgeson, R., "Real-Time Diesel Particulate Measurement using a Tapered Element O scillating Microbalance," SAE Paper 820463, 1982.

10. Whitby, R., Johnson, R., Gibbs, R., "Second Generation TEOM Filters - Diesel Particulate Mass Comparisons Between TEOM and Conventional Filtration Techniques," SAE Paper 850403, 1985.

11. Saito, K., O samu, S., "The Measurement of Diesel Particulate Emissions with a Tapered Element O scillating Microbalance and an Opacimeter," SAE Paper 900644, 1990.

12. Sienicki, E., "Status of 1994 Heavy Duty Round Robin Engine Transient Emissions Measurement," Engine Manufacturing Association Committee Correspondence, Chicago, IL, February 23, 1995.

13. Jarett, R. P., Clark, N. N., "Evaluation of Methods for D etermining Continuous Particulate Matter from Transient Testing of Heavy-D uty D iesel Engines," SAE Paper 2001-01-3575, 2001.

14. Clark, N. N., Gautam, M., Bata, R. M., Wang, W. G., Loth J. L., Palmer, G. M., Lyons, D. W., "Design and Operation of a New Transportable Laboratory for Emissions Testing of Heavy Duty Trucks and Buses," Int. J. Vehicle D esign (Heavy Vehicle Sys.), 1995.

15. Pall-G elman Sciences Product data, Hydrocarbon, Chemical, Polymer Group, East Hills, NY, A pril 1998. 
16. Clark, N. N., Jarrett, J. P., Atkinson, C. M., "Field Measurements of Particulate Matter Emissions, Carbon Monoxide, and Exhaust O pacity from Heavy-Duty Diesel Vehicles," ISSN 1047-3289, J. Air and Waste Management Association, Volume 49, pp. 78 - 84, 1999.

17. Beckwith, T. G., Marangoni, R. D., Lienhard, J. H., Mechanical Measurements, Fifth Edition, Addison-Wesley Publishing Company, Inc., Reading, MA, 1993.

18. Messer, J. T., Clark, N.N., Lyons, D.L., "Measurement Delays and Modal Analysis for a Heavy Duty Transportable Emissions Testing Laboratory," SAE Paper 950218, 1995.

19. Jarrett, R. P., Clark, N. N., Gilbert, M., Ramamurthy, R., "Evaluation and Correction of Moisture Adsorption and Desorption from a Tapered Element Oscillating Microbalance," Powder Technology, Volume 119, pp. 215 - 228, 2001. 


\section{Appendix A: TEOM configuration files and I/ 0 port pin out}

Table 19: The TEOM user configuration, "1105P.CON", file mainly contains data logging information.

\begin{tabular}{|c|c|c|c|}
\hline Slot & & Description & Contents \\
\hline 0 & $\mathrm{X}$-Axis & X-Axis Span (min) & 30 \\
\hline 1 & & X-Axis Format (code) & 0 \\
\hline 2 & On-Line & $\begin{array}{l}\text { Printing Interval (sec) } \\
\end{array}$ & -300 \\
\hline 3 & Printing & Mode (0:No 1:Prt 2:Plt) & 0 \\
\hline 4 & On-Line & Disk D rive (A-Z) & $\mathrm{D}$ \\
\hline 5 & Storage & Subdirectory (name) & teomdata \\
\hline 6 & & Storage Interval (sec) & 0.2 \\
\hline 7 & & Store Data (0:No 1:Y es) & 1 \\
\hline 8 & Y-Axis & D efault Left (0-10) & 6 \\
\hline 9 & & D efault Right (0-10) & 7 \\
\hline 10 & Averaging & TM Calc (0:Ave 1:Exp) & 0 \\
\hline 11 & & TM Time Window (sec) & 3 \\
\hline 12 & & MR/ MC Time Window & 3 \\
\hline 13 & Settings & Sample Flow Rate & 2 \\
\hline 14 & & Housing Temperature & 40 \\
\hline 15 & & Air Tube Temperature & 40 \\
\hline 16 & & Horiba MDT & 0 \\
\hline 17 & & Horiba MDT & 0 \\
\hline 18 & & External Tube Temp & 40 \\
\hline 19 & Flow Cont & STP Temperature & 25 \\
\hline 20 & Transform & Clip Data (0:No 1:Y es) & $\overline{0}$ \\
\hline 21 & & MR Conversion Factor & 1 \\
\hline 22 & & MC Conversion Factor & 1 \\
\hline 23 & & TM Conversion Factor & 1 \\
\hline 24 & Printing & Contents of Column 01 & 83 \\
\hline 25 & & Contents of Column 02 & 84 \\
\hline 26 & & Contents of Column 03 & 85 \\
\hline 27 & & Contents of Column 04 & 88 \\
\hline 28 & & Contents of Column 05 & 89 \\
\hline 29 & & Contents of Column 06 & 118 \\
\hline 30 & & Contents of Column 07 & 122 \\
\hline 31 & & Contents of Column 08 & 177 \\
\hline 32 & Disk & Contents of Column 01 & 83 \\
\hline 33 & Storage & Contents of Column 02 & 84 \\
\hline 34 & & Contents of Column 03 & 85 \\
\hline 35 & & Contents of Column 04 & 123 \\
\hline 36 & & Contents of Column 05 & 117 \\
\hline 37 & & Contents of Column 06 & 120 \\
\hline Slot & & Description & Contents \\
\hline
\end{tabular}




\begin{tabular}{|c|c|c|c|}
\hline 38 & & Contents of Column 07 & 122 \\
\hline 39 & & Contents of Column 08 & 88 \\
\hline 40 & Analog & Contents & 83 \\
\hline 41 & Output & Chan 1 Minimum Point & $-5.00 \mathrm{E}-07$ \\
\hline 42 & & Maximum Point & $1.00 \mathrm{E}-06$ \\
\hline 43 & & Contents & 84 \\
\hline 44 & & Chan 2 Minimum Point & $-4.00 \mathrm{E}+01$ \\
\hline 45 & & Maximum Point & $6.00 \mathrm{E}+01$ \\
\hline 46 & & Contents & 85 \\
\hline 47 & & Chan 3 Minimum Points & $-1.00 \mathrm{E}-05$ \\
\hline 48 & & Maximum Point & $2.90 \mathrm{E}-04$ \\
\hline$\overline{49}$ & Serial Output: & Contents & 83 \\
\hline 50 & Key & \begin{tabular}{l|l} 
Contents & Units
\end{tabular} & $\begin{array}{l}-116 \mid C \\
\end{array}$ \\
\hline 51 & Assign & F1 Minimum Point & 49.8 \\
\hline$\overline{52}$ & & Step & 0.1 \\
\hline 53 & & \begin{tabular}{l|l} 
Contents & Units
\end{tabular} & \begin{tabular}{l|l}
$-117 \mid \varnothing C$ \\
$\varnothing C$
\end{tabular} \\
\hline 54 & & F2 Minimum Point & 49.8 \\
\hline 55 & & Step & 0.1 \\
\hline 56 & & \begin{tabular}{l|l} 
Contents & Units
\end{tabular} & $-118 \mid \varnothing \mathrm{C}$ \\
\hline 57 & & F3 Minimum Point & 49.8 \\
\hline 58 & & Step & 0.1 \\
\hline 59 & & \begin{tabular}{l|l} 
Contents | Units
\end{tabular} & $-119 \mid \varnothing C$ \\
\hline 60 & & F4 Minimum Point & 44.8 \\
\hline 61 & & Step & 0.1 \\
\hline 62 & & \begin{tabular}{l|l} 
Contents & Units
\end{tabular} & \begin{tabular}{l|l}
83 & $\mathrm{~g} / \mathrm{sec}$
\end{tabular} \\
\hline 63 & & F5 Minimum Point & $-2.50 \mathrm{E}-07$ \\
\hline 64 & & Step & $2.50 \mathrm{E}-07$ \\
\hline 65 & & \begin{tabular}{l|l} 
Contents & Units
\end{tabular} & \begin{tabular}{l|l|l}
$84 / \mathrm{m}^{\wedge} 3$ \\
\end{tabular} \\
\hline 66 & & F6 Minimum Point & $-4.00 \mathrm{E}+01$ \\
\hline 67 & & Step & $2.00 \mathrm{E}+01$ \\
\hline 68 & & Contents | Units & $85 \mid \mathrm{gms}$ \\
\hline 69 & & F7 Minimum Point & $-1.00 \mathrm{E}-05$ \\
\hline 70 & & Step & $6.00 \mathrm{E}-05$ \\
\hline 71 & & \begin{tabular}{l|l} 
Contents & Units
\end{tabular} & \begin{tabular}{l|l|}
88 & $\mathrm{~Hz}$ \\
\end{tabular} \\
\hline 72 & & F8 Minimum Point & 200 \\
\hline 73 & & Step & 20 \\
\hline 74 & & \begin{tabular}{l|l} 
Contents & Units
\end{tabular} & \begin{tabular}{l|l|}
89 & SD
\end{tabular} \\
\hline 75 & & F9 Minimum Point & $0.00 \mathrm{E}+00$ \\
\hline 76 & & Step & $1.00 \mathrm{E}+06$ \\
\hline 77 & & \begin{tabular}{l|l} 
Contents & Units
\end{tabular} & $-122 \mid$ in. $\mathrm{Hg}$ \\
\hline 78 & & F10 Minimum Point & 0 \\
\hline 79 & & Step & 5 \\
\hline
\end{tabular}


Table 20: The instrument configuration file, "1105.INS”, containing critical instrument settings.

\begin{tabular}{|c|c|c|c|}
\hline Slot & & Description & Contents \\
\hline 0 & Files & Conversion Files & 1105 \\
\hline 1 & & User Config File & $1105 p$ \\
\hline 2 & Screens & Instrument Title & Series 1105 TEO M Monitor \\
\hline 3 & & Screen Divisions & 5 \\
\hline 4 & Hardware & Calib Constant (K0) & 14166 \\
\hline 5 & & MR/ MC/ TM Cycle (sec) & 0.1048576 \\
\hline 6 & & An/ Di Cycle (sec) & 0.1048576 \\
\hline 7 & Country & Language & English \\
\hline 8 & & Print Code: Compress & 15 \\
\hline 9 & & Print Code: Next Page & 12 \\
\hline 10 & Clipping & Time Window (sec) & 5 \\
\hline 11 & & In-Clip (0.0-0.5) & 0.02 \\
\hline 12 & & Out-Clip (0.0-0.5) & 0.02 \\
\hline 13 & D efault & Resistance & 51100 \\
\hline 14 & Temp/ Flow & Low Reference & 0 \\
\hline 15 & Constants & High Reference & 6 \\
\hline 16 & & T-Constant 1 & $8.27 \mathrm{E}-04$ \\
\hline 17 & & T-Constant 2 & $2.09 \mathrm{E}-04$ \\
\hline 18 & & T-Constant 3 & $8.09 \mathrm{E}-08$ \\
\hline 19 & & Flow Rate Constant & 1 \\
\hline 20 & Counter Board & Board Type & 1 \\
\hline 21 & & Base Address & 768 \\
\hline 22 & & Board Type & 5 \\
\hline 23 & Analog-In Board & Channels & 15 \\
\hline 24 & & Base Address & 784 \\
\hline 25 & & Board Type & 5 \\
\hline 26 & Analog-O ut Board & Channels & 8 \\
\hline 27 & & Base Address & 784 \\
\hline 28 & & Board Type & 0 \\
\hline 29 & Digital-In Board & Channels & 0 \\
\hline 30 & & Base Address & 0 \\
\hline 31 & & Board Type & 5 \\
\hline 32 & Digital-Out Board & Channels & 8 \\
\hline 33 & & Base Address & 784 \\
\hline 34 & & Readings per Analog Input & 12 \\
\hline 35 & & Short Numerical D isplay & 120 \\
\hline 36 & Numerical Display & 01: Row 1L & 83 \\
\hline 37 & Window & 02: Row 1M & 84 \\
\hline 38 & & 03: Row 1R & 85 \\
\hline 39 & & 04: Row 2L & 116 \\
\hline 40 & & 05: Row 2M & 124 \\
\hline 41 & & 06: Row 2R & 119 \\
\hline Slot & & Description & Contents \\
\hline
\end{tabular}




\begin{tabular}{|c|c|c|c|}
\hline 42 & & 07: Row 3L & 90 \\
\hline 43 & & 08: Row 3M & 88 \\
\hline 44 & & 09: Row 3R & 89 \\
\hline 45 & & 10: Row 4L & 120 \\
\hline 46 & & 11: Row 4M & 122 \\
\hline 47 & & 12: Row 4R & 123 \\
\hline 48 & & 13: Row 5L & 173 \\
\hline 49 & & 14: Row 5M & 174 \\
\hline 50 & & 15: Row 5R & 177 \\
\hline 51 & & 16: Row 5L & 117 \\
\hline 52 & & 17: Row 6M & 118 \\
\hline 53 & & 18: Row 6R & 0 \\
\hline 54 & & 19: Row 6L & 0 \\
\hline 55 & & 20: Row 7M & 0 \\
\hline 56 & & 21: Row 7R & 0 \\
\hline 57 & & 22: Row 7L & 0 \\
\hline 58 & & 23: Row 8M & 0 \\
\hline 59 & & 24: Row 8R & 0 \\
\hline 60 & $\overline{\mathrm{AK}}$ & Station Number & 52 \\
\hline 61 & Protocol & Channel Number & 75048 \\
\hline 62 & & Append Codes & 13010 \\
\hline 63 & & Baud Rate & 9600 \\
\hline 64 & & Data Bits & 8 \\
\hline 65 & & Stop Bits & 1 \\
\hline 66 & & Parity & 0 \\
\hline 67 & & Handshaking & 0 \\
\hline 68 & & Serial Port & 2 \\
\hline 69 & \multicolumn{2}{|c|}{ Pres. Comp. $(\mathrm{Yes}=1 / \mathrm{No}=0)$ ? } & 0 \\
\hline 70 & \multicolumn{2}{|c|}{ Bypass(1)/ Purge(0) Status } & 0 \\
\hline 71 & \multicolumn{2}{|c|}{ Warm-Up: Filter Change (sec.) } & 0 \\
\hline 72 & \multicolumn{2}{|c|}{ Warm-Up: Initial D elay (sec.) } & 900 \\
\hline 73 & $\begin{array}{c}\text { Collection Data } \\
\text { Delay (sec.) }\end{array}$ & & 13 \\
\hline 74 & & & 0 \\
\hline 75 & & & 0 \\
\hline 76 & & & 0 \\
\hline 78 & & & 0 \\
\hline 79 & & & 0 \\
\hline 80 & & & 0 \\
\hline
\end{tabular}


Table 21: TEOM channel assignments for the configuration files.

\begin{tabular}{|c|c|}
\hline $\begin{array}{c}\text { Channel } \\
\text { Number }\end{array}$ & $\begin{array}{c}\text { Channel } \\
\text { Contents }\end{array}$ \\
\hline 83 & MR \\
\hline 84 & MC \\
\hline 85 & TM \\
\hline 88 & FR \\
\hline 89 & SD \\
\hline 90 & Xtime \\
\hline 110 & UIn1 \\
\hline 111 & UIn2 \\
\hline 112 & UIn3 \\
\hline 113 & UIn4 \\
\hline 116 & Head \\
\hline 117 & Air \\
\hline 118 & Cap \\
\hline 119 & EST \\
\hline 120 & Flow \\
\hline 121 & VAC \\
\hline 122 & TnlP \\
\hline 123 & FltP \\
\hline 124 & IST \\
\hline 125 & AGCV \\
\hline 137 & UO-1 \\
\hline 138 & UO-2 \\
\hline 139 & UO-3 \\
\hline 173 & PCLw \\
\hline 174 & PCHi \\
\hline 175 & Stat \\
\hline 176 & PWM \\
\hline 177 & B/ PV \\
\hline
\end{tabular}


Table 22: Pin designations for the user I/ O connection for external data collection and remote activation.

\begin{tabular}{|c|c|}
\hline $\begin{array}{c}\text { Pin/ Block } \\
\text { Designator }\end{array}$ & Label \\
\hline 1 & User Out 1 \\
\hline 2 & User Out 2 \\
\hline 3 & User Out 3 \\
\hline 4 & Remote Start + \\
\hline 5 & User D igital In 1 \\
\hline 6 & User Digital In 2 \\
\hline 7 & User D igital In 3 \\
\hline 8 & User D igital In 4 \\
\hline 9 & User Out 1 Gnd \\
\hline 10 & User O ut 2 Gnd \\
\hline 11 & User Out 3 Gnd \\
\hline 12 & Remote Start Gnd \\
\hline 13 & User Digital Gnd \\
\hline 14 & User Digital Gnd \\
\hline 15 & User Digital Gnd \\
\hline
\end{tabular}

Table 23: TTL control logic for remote collection.

\begin{tabular}{|c|c|c|}
\hline $\begin{array}{c}\text { User Digital } \\
\text { In 1 }\end{array}$ & $\begin{array}{c}\text { User Digital In } \\
\mathbf{2}\end{array}$ & $\begin{array}{c}\text { Operation Mode } \\
\text { Selected }\end{array}$ \\
\hline$<2.5$ volts & $<2.5$ volts & No Change \\
\hline$>=2.5$ volts & $<2.5$ volts & Collection \\
\hline$<2.5$ volts & $>=2.5$ volts & Stop \\
\hline$>=2.5$ volts & $>=2.5$ volts & Initialization \\
\hline
\end{tabular}




\title{
Appendix B: Time Shifting Program
}

\author{
Sub crosscorrmyway() \\ ' CrossCorro Macro \\ ' Cross Corrolation Macro \\ ' Keyboard Shortcut: Ctrl+Shift+C
}

'This program uses the excel function CORREL to determine the time shift of 'continuous emission data readings with that of the engine (or axial) torque to 'provide maximum correlation. The program was designed to read from an Excel 'spread sheet. The program uses the first column (Time)to calculate the number 'of data points and the sample rate. The next column should be power (engine or 'axial), hub speed, or engine speed. The nest column should be the first emission 'column. There should also be 2 rows at the top as header (first row being 'emission, second row being unit).

Dim Rmax(7), t(7), NewR(1000, 7), OldR As Single

Dim A As Range, B As Range

Dim label(7) As String

D im sps As Integer

$\mathrm{I}=0$

Sum $=0$

$\mathrm{x}=0$

'Time Range for evaluation in seconds

$\operatorname{tr}=40$

'Find the range of the data

Range("a3").Select

D o While ActiveCell.Offset(x, 0) > " "

$\mathrm{x}=\mathrm{x}+1$ 
Loop

'find samples per second (sps)

sps $=1 /$ (ActiveCell.Offset $(\mathrm{x}-19,0)$ - ActiveCell.Offset( $\mathrm{x}-20,0))$

$\operatorname{tr}=\operatorname{tr} *$ sps

'find number of labels

$\mathrm{y}=0$

Range("b1").Select

D o While ActiveCell.Offset $(0, y+1)>$ " "

label $(\mathrm{y}+1)=$ ActiveCell.Offset $(0, \mathrm{y}+1)$

$\mathrm{y}=\mathrm{y}+1$

Loop

'This cell was the start of the power or speed data

Range("b2").Select

For $\mathrm{z}=1$ To y ' $\mathrm{z}=$ the number of emission columns

timeshift $=1$

$\operatorname{NewR}($ timeshift, $\mathrm{z})=0$

$\operatorname{Rmax}(\mathrm{z})=0$

For timeshift $=1$ To tr

Set $\mathrm{A}=$ Range(ActiveCell.Offset(1, 0), ActiveCell.Offset((x - timeshift), 0))

Set B = Range(ActiveCell.Offset(1 + timeshift, $\mathrm{z})$, ActiveCell.O ffset(x, z))

NewR(timeshift, z) = Application.WorksheetFunction.Correl(A, B)

'finding max correlation

If NewR(timeshift, $\mathrm{z}$ ) > Rmax(z) Then

$\operatorname{Rmax}(\mathrm{z})=\operatorname{NewR}($ timeshift, $\mathrm{z})$

$\mathrm{t}(\mathrm{z})=$ timeshift

'OldR = NewR(timeshift, $\mathrm{z}$ ) 
'else if NewR(timeshift, z) < Rmax(z)then

End If

Next timeshift

Next z

'Print out

Sheets.Add.Name = "cross correlation"

Range("a1").Select

ActiveCell.O ffset $(0,1)=$ "Time Shift"

ActiveCell.O ffset $(0,2)=$ "Emission"

ActiveCell.O ffset $(1,1)=$ "(seconds)"

ActiveCell.Offset $(2,0)=$ "time @ best correl"

ActiveCell.O ffset $(3,0)=$ "best correl"

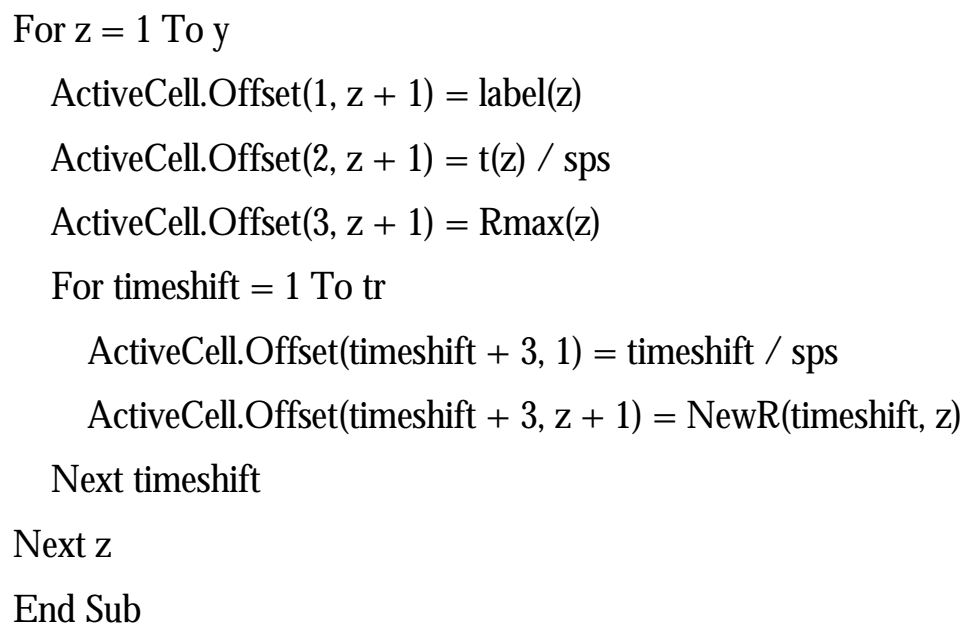




\section{Appendix C: Verification of the Time Shifting Program}

The output of the time shifting program was figure 35 and table 24 . The program indicated that the shifts necessary for $\mathrm{CO}$ and $\mathrm{CO}_{2}$ power correlation were greater than 20 seconds. It is stated in the CFR [2] that the maximum response time of the analyzers must be less than 20 seconds of the step change. To verify the programs suggested time shift: (1) the emission traces were plotted with power to verify correlation and (2) the data shift was verified by using the coefficient of determination $\left(\mathrm{r}^{2}\right)$ to find the best shift.

Table 24: The time shifts for $\mathrm{CO}$ and $\mathrm{CO}_{2}$ emissions suggested by the correlation program exceeded the EPA recommended 20 second maximum.

\begin{tabular}{|l|c|c|c|c|c|}
\hline Emission & $\mathrm{HC}$ & $\mathrm{CO}$ & $\mathrm{CO}_{2}$ & $\mathrm{NO}_{\mathrm{x}}$ & $\mathrm{TEOM}$ \\
\hline Suggested Shift (sec) & 19.2 & 22.6 & 22.4 & 11.2 & 5.2 \\
\hline
\end{tabular}

The gaseous emissions were plotted with power on the time scale to verify correlation between emissions and engine power. Correlation was considered present if a change in gaseous emissions followed a change in power. The strength of the correlation is not of concern here. A small excerpt of the FTP data that was discussed in chapter 6 is illustrated in figure 55. The gaseous emissions graphed are time shifted per the recommendations of the shifting program in Appendix B. In the figure, power increased after a long idle as did emissions and generally, emission subsided when power decreased. However, it can be seen that the emissions are shifted in advance of the first power rise. This is thought to be unrealistic because the ideal engine does not increase pollutants in anticipation of a transient. The recommended visual shift based on initialization is listed in table 25. Unfortunately, CO and $\mathrm{CO}_{2}$ emissions were still greater than 20 seconds. The cause of the long time shifts was unknown.

Table 25: The recommended emission shifts base on the alignment of emission and power increase after an idle. Unfortunately, these time shifts also exceed the 20 second EPA guidelines.

\begin{tabular}{|l|c|c|c|c|c|}
\hline Emission & $\mathrm{HC}$ & $\mathrm{CO}$ & $\mathrm{CO}_{2}$ & $\mathrm{NO}_{\mathrm{x}}$ & TEOM \\
\hline Suggested Shift (sec) & 14.4 & 21.4 & 20.2 & 10.0 & 3.2 \\
\hline
\end{tabular}




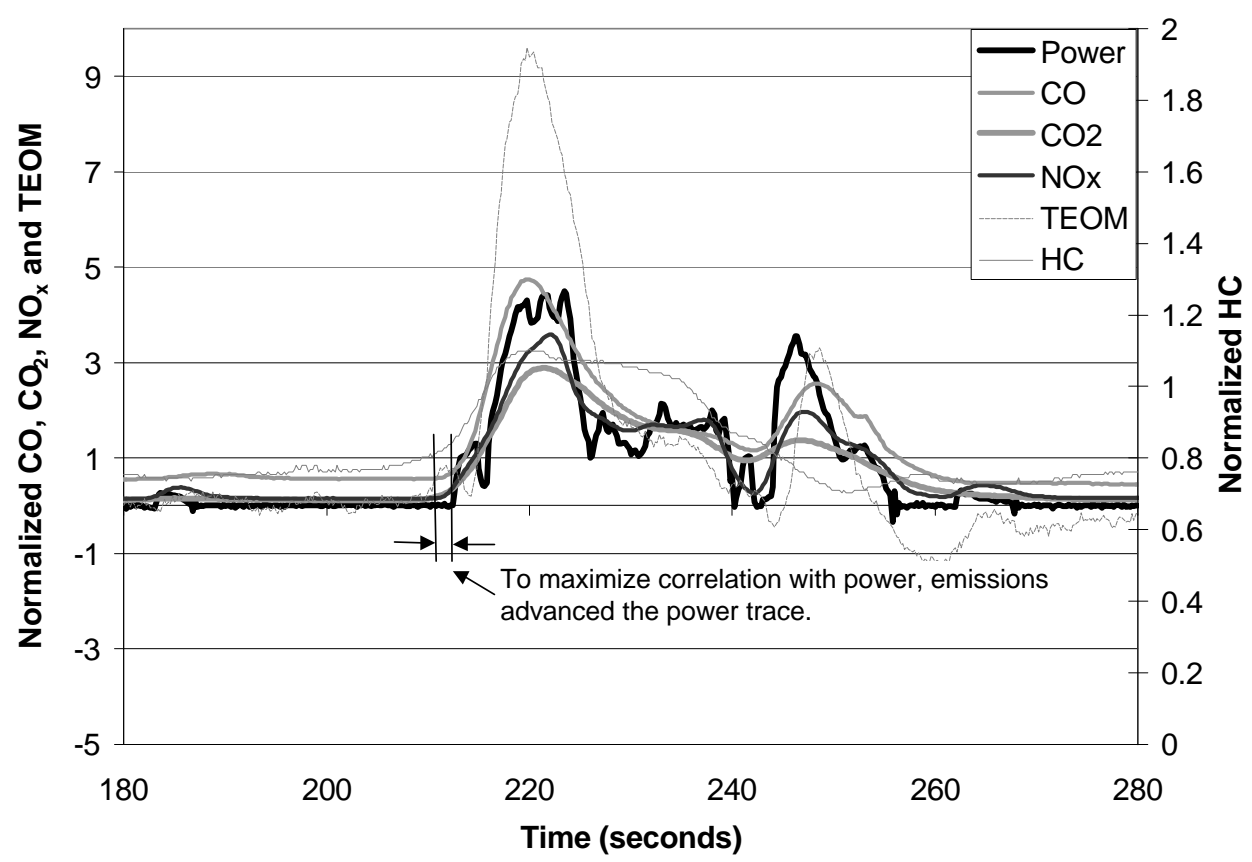

Figure 55: A section of real-time FTP data shifted per the program's recommended amount. It can be seen here that the compromise to best power correlation is an unrealistic advance of the emission data.

To verify the correlation of the time shift program, another method of correlation was applied to the $\mathrm{NO}_{\mathrm{x}}$ and $\mathrm{CO}_{2}$ data sets. The emissions data were shifted forward with respect to engine power, which remained stationary. As the data were shifted, the coefficient of determination $\left(\mathrm{r}^{2}\right)$ was recorded. The best time shift was declared when the $\mathrm{r}^{2}$ value reached a maximum. This is represented graphically in figure 56. The maximum correlation occurred at 11.2 seconds for the $\mathrm{NO}_{\mathrm{x}}$ data and 22.4 seconds for the $\mathrm{CO}_{2}$ data. This result matched the program's recommended shift. 


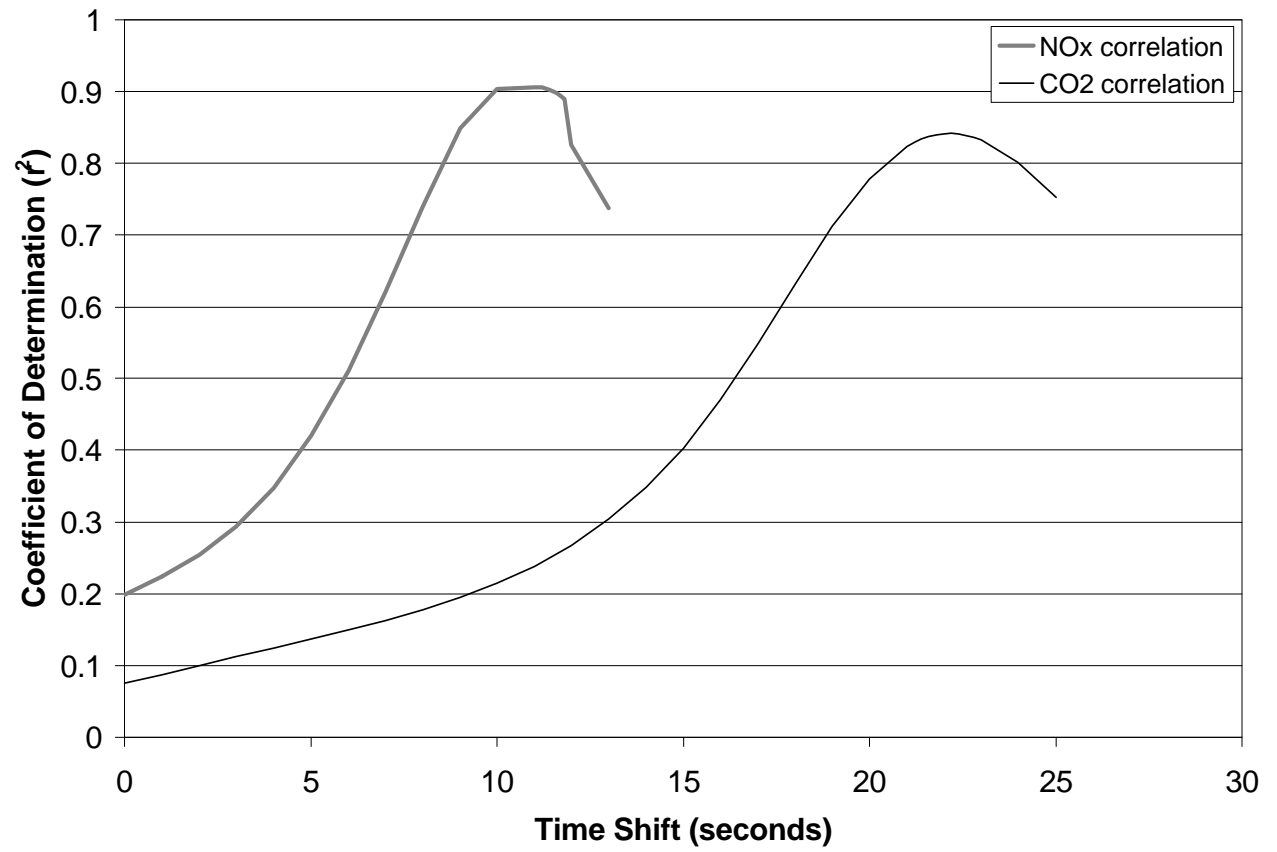

Figure 56: Results from cross correlating engine power with $\mathrm{NO}_{\mathrm{x}}$ and $\mathrm{CO}_{2}$ using the coefficient of determination. The time at peak correlation using this method is equal to the time shift of the program. 